Illinois State University

ISU ReD: Research and eData

Theses and Dissertations

3-18-2015

\title{
Listen. I have Something to Say! A Critical Inquiry into the Educational and Socio-cultural Context of African-American Male Student Achievement in an Urban School Setting
}

Patricia P. Watson

Illinois State University, wats1612@sbcglobal.net

Follow this and additional works at: https://ir.library.illinoisstate.edu/etd

Part of the African American Studies Commons, Education Commons, and the Feminist, Gender, and Sexuality Studies Commons

\section{Recommended Citation}

Watson, Patricia P., "Listen. I have Something to Say! A Critical Inquiry into the Educational and Sociocultural Context of African-American Male Student Achievement in an Urban School Setting" (2015).

Theses and Dissertations. 359.

https://ir.library.illinoisstate.edu/etd/359

This Dissertation is brought to you for free and open access by ISU ReD: Research and eData. It has been accepted for inclusion in Theses and Dissertations by an authorized administrator of ISU ReD: Research and eData. For more information, please contact ISUReD@ilstu.edu. 


\title{
LISTEN. I HAVE SOMETHING TO SAY！ A CRITICAL INQUIRY INTO THE EDUCATIONAL AND SOCIO-CULTURAL CONTEXT OF AFRICAN-AMERICAN MALE ACADEMIC ACHIEVEMENT \\ IN AN URBAN SCHOOL SETTING
}

\author{
Patricia Pullums Watson
}

154 Pages

May 2015

There is a general awareness that a substantial gap exists between the educational achievement of the White and African-American populations in our nation. Several prominent researchers have attempted to address this issue of the achievement gap. Kunjufu (1985), with his seminal work on the fourth-grade failure syndrome, Noguera (2003), Ferguson (2001), Tatum (1997), Payne (2005), and Gordon and Gordon (2006) all point to issues of race and income. Leary (2005) offers a theory of multigenerational trauma; Fordham and Ogbu (1986) present their theory of oppositional culture; while Sewell (1998), Gurian (2005), Kozol (1991), and Sax (2007) suggest that the gap may be at least partially attributable to a lack of "boy-friendly" content in curricula. While the negative impact of African-American male student achievement has already been outlined by many researchers, what needs to be further investigated are the factors and processes which affect African-American males and their values in relation to school and schooling. 
This qualitative study aims to provide an understanding of African-American student academic achievement from the perspective of critical race theory. It explores how connections between critical pedagogy, socially and culturally relevant curricula and impact agency and provide deeper insight into some of the causal factors of low achievement in African-American male students. Understanding the educational and socio-cultural factors that contribute to African-American male student failure is important and has been found to be consistent across the population. 


\title{
LISTEN. I HAVE SOMETHING TO SAY! A CRITICAL INQUIRY INTO THE EDUCATIONAL AND SOCIO-CULTURAL CONTEXT OF AFRICAN-AMERICAN MALE ACADEMIC ACHIEVEMENT
}

IN AN URBAN SCHOOL SETTING

PATRICIA PULLUMS WATSON

\author{
A Dissertation Submitted in Partial \\ Fulfillment of the Requirements \\ for the Degree of \\ DOCTOR OF EDUCATION
}

School of Teaching and Learning ILLINOIS STATE UNIVERSITY 
(C) 2015 Patricia Pullums Watson 


\section{LISTEN. I HAVE SOMETHING TO SAY! A CRITICAL INQUIRY INTO THE EDUCATIONAL AND SOCIO-CULTURAL CONTEXT OF AFRICAN-AMERICAN MALE ACADEMIC ACHIEVEMENT \\ IN AN URBAN SCHOOL SETTING}

PATRICIA PULLUMS WATSON

COMMITTEE MEMBERS:

Eurvine J. Williams, Chair

Pauline Williams

Brian Horn 


\section{ACKNOWLEDGMENTS}

My friends and supporters, I cannot find any other word(s) to express my gratitude, appreciation, and love for you that the words thank you do not cover, so please accept it my with deepest sincerity. Have you ever wondered why the words thank you are so powerful? They are two small words that express gratitude or appreciation for something; a grateful feeling or an acknowledgement (Dictionary.com). The word thank derives from Old English pancian, meaning to give thanks, which in turn derives from the Proto-German term thankojan, which also spawned the Middle German term danken, meaning to thank. The English term thank you was shortened from the phrase I thank you (Retrieved from answers.com)

I would like to thank God for his many blessings, my husband Charles who held my hand, even when I didn't know it. My son Kevyn and daughter Angela for their words of encouragement. I thank my parents, James and Aletha (now deceased), for seeing my potential; my sisters (Rose) Spanky, Vern (now deceased), Renea and Anise; my brothers Leroy, Garrick, Darryl and Reverend Reginald for believing in me. I'm sorry that I missed so many years with you.

Thank you my dear sister Reggee; don't ever change! Thank you or walking this journey with me. Thank you Breakfast Clubbers, Divas, and Ginny’s Girls for lifting me up. Thank you Mary, Tippi and Gerri for all of your help on my behalf. Thank you Estraleta for being a listening ear, helping me to see my strengths and finding my voice. 
Thank you Dr. Brian Horn for being on my committee and including me in your already packed schedule. I took your advice to heart and felt comfortable 'telling my story’. Thank you Dr. Pauline Williams for giving your time to be on my committeeyou were there when I started this journey and here again to see it to completion. Thank you Cynthia for leading me to Dr. Williams and thank you Dr. Eurvine Williams for seeing my potential, filling my cup with water and making me drink it. You have simply been-magnificent!

P. P. W. 


\section{CONTENTS}

Page

ACKNOWLEDGMENTS $\quad$ i

CONTENTS

TABLES vii

FIGURES viii

CHAPTER

I. THE PROBLEM AND ITS BACKGROUND 1

Research Question $\quad 1$

Purpose of the Study 1

$\begin{array}{ll}\text { Introduction } & 2 \\ & \end{array}$

Background and Personal Perspective 3

Johnny's Story $\quad 5$

$\begin{array}{ll}\text { Statement of the Problem } & 7\end{array}$

Theoretical Framework $\quad 8$

$\begin{array}{ll}\text { Conceptual Framework } & 11\end{array}$

$\begin{array}{ll}\text { Education } & 11\end{array}$

Critical Pedagogy 13

Socially and Culturally Relevant Curricula $\quad 14$

Agency 14

$\begin{array}{ll}\text { Significance of the Study } & 15\end{array}$

Rationale and Need for the Study 19

Assumptions and Limitations $\quad 20$

Operational Definitions $\quad 22$

Summary of the Theoretical and Methodological Direction for Study 23

$\begin{array}{ll}\text { Critical Race Theory } & 23\end{array}$

$\begin{array}{ll}\text { Conclusion } & 24\end{array}$

II. REVIEW OF THE LITERATURE 27 
$\begin{array}{lr}\text { Adolescent Males } & 29\end{array}$

African-American Males $\quad 30$

Critical Pedagogy $\quad 44$

Culturally and Socially Relevant Curricula $\quad 47$

Agency 49

Analysis of Research Studies and Scholarly Works

Related to the Research 51

Socioeconomic Status (SES)

III. METHODOLOGY 59

Literature Supporting the Design 62

Critical Reflexivity $\quad 64$

Interpretation $\quad 65$

Transformation $\quad 66$

Assumptions of Critical inquiry 66

Research Design Procedures 69

Methods of Data Collection and/or Field Procedures 69

$\begin{array}{ll}\text { Interviews } & 70\end{array}$

$\begin{array}{ll}\text { Participants } & 72\end{array}$

$\begin{array}{ll}\text { Setting } & 73\end{array}$

$\begin{array}{ll}\text { Follow-up } & 73\end{array}$

Member Checks $\quad 73$

$\begin{array}{ll}\text { Data Analysis } & 74\end{array}$

$\begin{array}{ll}\text { Coding } & 74\end{array}$

$\begin{array}{ll}\text { Researcher Bias } & 76\end{array}$

$\begin{array}{ll}\text { IV. ANALYSIS OF THE DATA } & 78\end{array}$

Statement of the Problem $\quad 78$

$\begin{array}{ll}\text { Data } & 81\end{array}$

Overall Summary of Interview One Responses $\quad 87$

Overall Summary of Interview Two Responses $\quad 88$

Overall Summary of Interview Three Responses 89

$\begin{array}{lr}\text { Analysis } & 91\end{array}$

$\begin{array}{ll}\text { Perception of Schooling and Success } & 91\end{array}$ 
Perception of schooling $\quad 92$

Grades/curriculum 93

Teacher disposition/perception $\quad 94$

Provides opportunities for learning $\quad 94$

$\begin{array}{ll}\text { Disposition } & 95\end{array}$

Student disposition $\quad 95$

Discipline/boredom $\quad 95$

$\begin{array}{ll}\text { Motivation } & 96\end{array}$

Rewards 96

Interests 96

$\begin{array}{ll}\text { Support } & 97\end{array}$

Parent/family $\quad 97$

Teachers/administrators $\quad 98$

Others (coaches, mentors, peers) 99

$\begin{array}{ll}\text { Social Capital } & 100\end{array}$

Prejudice $\quad 101$

Stereotypes 101

Identity 102

$\begin{array}{ll}\text { Summary } & 103\end{array}$

$\begin{array}{ll}\text { Conclusions } & 104\end{array}$

V. SUMMARY, CONCLUSIONS, AND RECOMMENDATIONS 105

Summary of the Study 105

Findings in Relationship to the Research Question 106

$\begin{array}{ll}\text { Research Question } & 106\end{array}$

$\begin{array}{ll}\text { Agency } & 106\end{array}$

Teaching and learning environments 108

Motivation and engagement 109

$\begin{array}{ll}\text { Support systems } & 110\end{array}$

Interpretation of Findings $\quad 111$

Implications of Findings $\quad 119$

Limitations of Study 121

Future Directions for Research 122 
APPENDIX A: Series 1 Interview Questions

APPENDIX C: Series 3 Interview Questions 


\section{TABLES}

Table Page

1. Characteristics of the Program Participants 80

2. Data Analysis by Research Questions 84

3. Themes Extracted from Interview Data 87 


\section{FIGURES}

$\begin{array}{lll}\text { Figure } & \text { Page }\end{array}$

1. Conceptual Framework 12

2. Reading Scores Gap Between Whites and Blacks, 1971-2012 17

3. Dropout Rates Among Youth Ages 16 to 24 by Race 20

4. Average ACT Composite Test Scores for White and Black Students, 2009-2013

5. Trend in Eighth-grade NAEP Reading Average Scores and Score Gaps for White and Black Students

6. The Process Used to Identify the Study's Emerging Themes 


\section{CHAPTER I}

\section{THE PROBLEM AND ITS BACKGROUND}

I am an African-American female examining African-American male student achievement. My entire career has been dedicated to the education of children. I have always been concerned with the underperformance of African-American males and troubled by data which reveal that only $52 \%$ of ninth-grade students in 2006 graduated in 2010 (Schott Report 2012, 2015). This study is important to me because I believe (Jackson, 2012) that we have already lost a generation of African-American males. What we do now will determine if another generation is fated to the same end.

\section{Research Question}

This study addressed the following research question: What are the perceptions of agency, teaching and learning environments, motivation, engagement and support systems on the academic achievement of six African-American males ages 13-17?

\section{Purpose of the Study}

The purpose of this research is to provide critical insight into African-American male student achievement to determine the impact of racism, classism, or other forms of oppression by questioning fundamental assumptions that have, over the years, been taken for granted using critical inquiry (CI) as a research methodology. This methodology allows for an examination of factors and processes that impact student achievement from the perspective of adolescent males ages 13-17. This range is important because research suggests that African-American males begin experiencing academic failure at 
approximately the fourth grade (Kunjufu, 1985; Noguera, 2003; Jackson, Gordon, \& Gordon, 2006; Leary, 2005; Ogbu, 2008). At this grade, the curriculum strategies become more focused on high-stakes standardized tests, while teachers, in their attempts to encourage independent learning, become more distant. Unfortunately, many AfricanAmerican male students are not ready for this shift in learning. Some may not have had the opportunity to attend a pre-school, Head Start or other early learning program to prepare for the rigors of structured learning. As a result, many did not have the reading skills needed to understand and internalize text independently or develop critical problem solving skills (Kunjufu, 1985; Stallings, 2011; Office of Head Start, 2014).

\section{Introduction}

Close your eyes and imagine that you live in a land where certain people have blue hair. Imagine that many people who did not have blue hair felt uncomfortable about blue-haired people; especially males. What if these feelings were so widespread that they were openly discussed throughout schools, media, and community? What if energetic, little blue-haired males in kindergarten regularly heard messages about not being as smart or, even more damaging, having a bevy of problems needing to be fixed? What if most of the crime reported was about blue-haired males? What if TV criminals were mostly blue-haired males? What if there were special classrooms for students with blue hair? What if most of the school suspensions and truancies were blue-haired males? (Adapted from Fremon \& Hamilton, 1997). Now fast-forward four years. These same blue-haired boys are now in the fourth grade. They appear to be apathetic, unmotivated, have increased tardies, unexcused absences, are angry, and always involved in fights (Kunjufu, 1985). Now, open your eyes. Do you have a blue-haired boy? Do you teach blue-haired 
boys? Do your children play with blue-haired boys? Do you know blue haired boys?

What do you think the future hold for blue-haired boys?

Although this may sound like a plot for a science fiction movie, it gives a real life view of many African-American males enrolled in our nation's schools. These males are bombarded with characterizations that portray them as slow learners with behavior problems, and at-risk for certain failure. As a result, the academic achievement of African- American males is, has, and continues to be a considerable problem in the United States. The failure to effectively educate this group has consequences that result in increased high school dropout rates, high unemployment, lower socioeconomic conditions, predisposition for violence, and certain incarceration. An oft-spoken urban legend reveals that private prison development corporations use third grade data to predict the number of beds that will be needed in the next 6 to 9 years (Sanders, 2013). For these reasons, it is imperative that we continue to discuss and research this issue.

\section{Background and Personal Perspective}

As a former teacher and elementary school principal, one of my responsibilities was maintaining a safe learning climate for all students. My role as a classroom teacher was to develop independent learners. In 1995, I was assigned to a seventh- and eighthgrade split classroom with no teacher assistant or other supports. While able to work on a whole group basis for some course content, several sub-skills in reading and math required instruction by grade level, which demanded that I separate the groups. The first 2 weeks of school were spent teaching classroom routines and helping students to learn independently. As a principal, my teachers utilized a similar model—Guided Readingwhich also called for students to be self-directed while the teacher worked with other 
students in either groups or pairs at different learning levels and styles. Teachers utilizing this model must have a high level of classroom discipline and spend a good deal of time preparing students to utilize this model, but there were always a few who needed extra attention.

Not all students work effectively with this model. Students who are disruptive or otherwise unable to work independently impact classroom learning. The time that it takes to discipline one or two students individually takes precious minutes from classroom instruction. As an African-American female teacher, White (and sometimes AfricanAmerican) teachers would ask me if their disruptive students could serve a time-out in my class to allow for more unfettered time on classroom instruction.

When I became a principal, the counselor was the point person to field disciplinary complaints, but students with repetitive disruptive behaviors always made it to my office. Most times, I was already on a first name basis with the student and, 9 times out of 10, the disruptor was African-American and male. They were most always in grades 4-6, usually had other siblings, and a history of school disciplinary actions that included detentions as well as in- and out-of-school suspensions.

This study examined the educational and socioeconomic factors that contributed to the academic performance of urban African-American (AA) males like the disruptors previously described. These factors may signal the beginning of a disengagement process that starts in elementary schools with African-American male children as young as 6 and 7 years old. Their disengagement begins gradually through a series of events that can be seen in the following vignette. 


\section{Johnny's Story}

Johnny, one of my fourth-grade students, was in my office more than he was in class. His behavior demonstrated little respect for authority; he was disrespectful to his teachers and had a short fuse with his classmates. On many mornings he was sent to the office by 9:30 a.m. either for fighting or smart-mouthing the teacher. After being in the office for 40 minutes or so, he swore that he would behave and was returned to class. I attempted to get Johnny's teacher to understand that he uses this behavior to get out of her class, but she has only been teaching for 2 years and feels that his behavior unduly influences other students. She believes that he has issues with her because she is White. His father and mother are divorced but share a liberal visitation arrangement that allows his father to spend time with him every other week or as often as possible. With an income of approximately $\$ 20,000$ per year, the family qualifies for free lunch but cannot pay the registration fee needed to enroll in the tuition-based after-school program. When I asked Johnny about disrespecting his teacher, he says that she doesn't 'like' him, never calls on him to do anything in the class, and accuses him of acting out even when he is innocent. He says that she thinks that he is dumb and sometimes gives him 'baby' work, which makes the other kids laugh at him. He adamantly states that 'he's smart' and that when he was in Miss Brown's first-grade class, he was a " $B$ " student. He believes that Ms. Brown was the only teacher who really cared about him and wishes that he was back in her class. He was retained in the third grade.

Johnny never completes his classroom assignments, lies to his mother about having homework, and says that he hates school. During class Johnny tries to do the work, but bores easily. His teacher often places him in small learning groups with higher 
achieving peers, hoping that he will open up to them, but Johnny puts his head down, starts rough housing and/or starts a fight with his classmates. He is then isolated, sent to the disciplinarian's office, and scheduled for detention or suspension depending on the nature of the misconduct violation.

Because Johnny has been retained once, has reading and math deficits, and has a documented pattern of misbehavior, he is being referred for staffing by the school's Response to Intervention (RtI) unit. His mother reluctantly agreed to the process after an exhaustive session with Johnny's teacher, counselor, and principal; not because she felt that Johnny had a learning disability, but because there was no reasonable rationale as to why Johnny can't read. Johnny's current teacher, feels that he is capable of learning at his grade level, but is concerned that unless he buckles down and "gets it", he may be retained again.

This vignette is a true, but fictionalized, composite of boys that I worked with throughout my career both as teacher and principal. Students like Johnny typically post the lowest test scores, have the highest number of school suspensions, disciplinary referrals, absences, and tardies. They are often angry, depressed, defiant with their teachers, and problematic for school administrators. They resist any attempts at remediation or interventions that may be available and seem determined to fail. Often, as in Johnny's case, family circumstances may impact a child's development and put them into situations that force them to assume the role of a guardian while their parents work. As a result, they become resentful and develop a "get paid attitude"; that suggests that they are willing to do whatever it takes to make or to get money. School attendance is often seen as a hindrance. 
The issues of African-American male academic achievement in education are complex and varied. It is hoped that, with this study, the academic community will engage in dialogue about ways in which these issues can be addressed.

\section{Statement of the Problem}

Research suggests that no issue in American education is talked about more or with more agony and frustration than the academic achievement gap between Whites and non-Whites (Kozol 1991, 2005); Ferguson (2001); Hunsader (2002); Fisher (2005); Gurian (2005); Holtzman (2006); Allen (2008); Tyre (2008); Sax (2009); Gordon, Iwamoto, Ward, Potts \& Boyd (2009); Gao (2009); Fuller (2011); Yazdani (2011); Coy (2012); Earp (2012); Handrickson (2012); Harper (2012); Jackson (2012); Noguera (2008); Pople (2012); Toldson (2013); Nakkula (2013); Keilman (2013); Maitre (2014); Jacobson (2014); and Lynch (2014). African-American male achievement scores are lower than White males and females, Asian males and females, Hispanic males and females and African-American females.

When African-American males fail to succeed in school, they are least likely to be hired and most likely to be unemployed. They become prey for gangs, drug addiction, unemployment, poverty, and eventually end up in the criminal justice system fueling the school to prison pipeline. In fact, there are more African-American males in jail in the United States than there are African- American males incarcerated in the rest of the world. This is a serious commentary on the issue of African-American student achievement in the U.S. (Rocque \& Patemoster, 2011; Alexander, 2012).

As surmised in the report, Education on Lockdown by the Advancement Project (2005), incarceration data like that referenced above may signal the beginning of a 
criminalization process that starts in elementary school with African-American male children as young as 6 and 7 years old being arrested in staggering numbers. The problem is so pervasive that President Barack Obama, recognizing the severity of the problem, announced the creation of a new initiative to address America's challenge with AfricanAmerican males. The initiative, 'My Brother's Keeper,' is composed of a number of organizations committed to fund organizations that provide programs specifically for young men of color. Although this attempt is welcomed, this issue is an institutional one. Improvements must be systemic and examined at institutional and policy levels to have widespread impact (Obama, 2014).

\section{Theoretical Framework}

This study used critical race theory (CRT) to investigate the achievement of African- American male youth in an urban school setting. Critical race theory initially began as a component of critical legal studies (CLS). It argued that there is an acceptable standard in this country that perpetuates the power of the dominant culture by supporting an unequal and unjust distribution of power and resources along political, economic, racial, and gendered lines made legitimate by the legal system (Taylor, 2009; Arai \& Kivel, 2009; Oforlea \& Mullen, 2012). While several proponents of CLS have and continue to work diligently to identify these forms of oppression that exist in courts and schools, others (i.e., Bell, Crenshaw, Delgado, \& Lawrence et al.) became openly critical of its role in perpetuating the status quo in education, along with the stagnated civil rights litigation that followed Brown v. Board of Education in 1954.

Critical race theory, a growing field of study, is a cross-disciplinary form of critical analysis, race-equity methodology that originated in legal studies grounded in 
social justice. Critical race theory's tools for conducting research and practice are intended to examine contemporary racial phenomena, expand the vocabulary with which to discuss complex racial concepts, and challenge racial hierarchies. It means not taking things for granted, examining the complexity of the issue, challenging reductionism, looking at alternatives, ideologies and power structures. This involves reconsidering the relevancy and accuracy of claims by government or school officials, policy makers, theorists, what they are based on, and how they apply to a given situation (University of Sussex, 1998).

There are five recognized tenets of Critical race theory: the permanence of racism; Whiteness as property; interest convergence; counter-storytelling; and the critique of liberalism (Ladson-Billings, 1998). A primary tenet of CRT maintains that racism is normal. It suggests that racism controls the social, political, and economic pillars of U.S society and provides privileges to Whites, especially in areas such as employment, housing, and education. In fact, racism and inequality in matters regarding housing, employment, and education is so widespread that non-Whites regard it as a commonality. It acknowledges that White superiority is so ingrained in U.S. society that it is part of the fabric of our lives. Its global effects have so permeated worldwide structures that it has become a political system within itself that it is almost unrecognizable (Delgado, 1995). Consequently, Whites have a difficult time understanding that the advantages they enjoy are a result of a structure that was constructed by and is being fueled by racism. CRT is grounded in a sense of reality that reflects the distinctive experiences of people of color. It recognizes that the simple matter of the color of one's skin so profoundly affects the way one is treated and so radically shapes what one is allowed to think and feel about this 
society, that the decision to generalize from this decision is valid (Williams, 1991). In the second tenet, Whiteness as a property exists because it is an asset that only Whites can own and derive benefits from (Ladson-Billings \& Tate in Hiraldo, 2010). Harris' (1993) article "Whiteness as Property" argues that although our legal system formally ended racial discrimination, our laws still favor and legitimatize benefits to Whites simply because they're White. Beeman, Glasburg, and Casey (2010) contend that, as a result of institutionalized racism, those identified as Whites were allowed to accumulate a level of economic advantages that non-Whites were denied. This created a connection between White's accumulation and Black poverty. In other words, White American lives have been unjustly enriched, while Blacks continue to suffer as a result of a system forged under centuries of slavery, legalized and de facto segregation, and institutionalized racism. Interest convergence maintains that the interest of African-Americans in gaining racial equality has been accommodated only when they 'converge' with the interests of Whites. This tenet suggests that since racism advances the interests of both 'white' collar Whites and 'blue' collar and working class Whites, there is little incentive to eradicate it (Bell, 1980; Milner, 2008). Counter-story-telling provides an opportunity for marginalized groups to tell their stories in their own words regarding their own experiences. The fifth and final tenet, the critique of liberalism, finds its roots in the idea of colorblindness. It argues that although law is colorblind, its interpretation through the strands of racism is not. Racism is "not the act of individuals, but the larger systemic, structural conventions and customs that uphold and sustain oppressive group relationships, status, income and educational attainment” (Taylor, 2009). Moreover, 
upon accepting this terminology, the terms Black or White no longer identify a racial classification, but a political ideology rooted in White European supremacy.

American society continues to be deeply afflicted by racism because non-White students are constantly bombarded with racist messages (Delgado, 1995; Hooks, 2004). Minority children hearing these messages begin to question their competence, intelligence, and worth. Delgado also argues that racist-laced speech is a severe social problem and that such speech, along with other tools of racism, serves to keep minorities in an inferior position.

\section{Conceptual Framework}

In the examination of African-American male student achievement, key areas were identified from existing research and incorporated into this design. These areas are critical in understanding the foundations and general direction of this research design and serve as the framework for data collection and analysis. This framework will support an inquiry which can provide information for a discussion of the academic achievement of African-American males (Smyth, 2004; Goetz \& LeCompte, 1984). These points of reference will focus on an examination of African-American male student achievement through the framework of critical race theory by investigating how critical pedagogy and socially and culturally relevant curricula impacts agency as it relates to the importance of education.

\section{Education}

Freire (1970) believes that the system of education is deceptive. He compares it to a bank where customers come in to withdraw the knowledge that they will need to be successful. However, customer withdrawals are not equal, because knowledge is not a 
commodity that is passed from school to customer (student). Consequently, if some neighborhood banks (schools) are inferior in comparison to other neighborhood banks, the withdrawals will be limited. The Conceptual Framework, Figure 1, demonstrates the basis for thinking about student achievement, what it means and how it is influenced by research and by the ideas and influences of others. It outlines how CRT is being used to examine education and how it is impacted by critical pedagogy, socially and culturally relevant curriculum and agency leading to the need to study the academic achievement of African-American males.

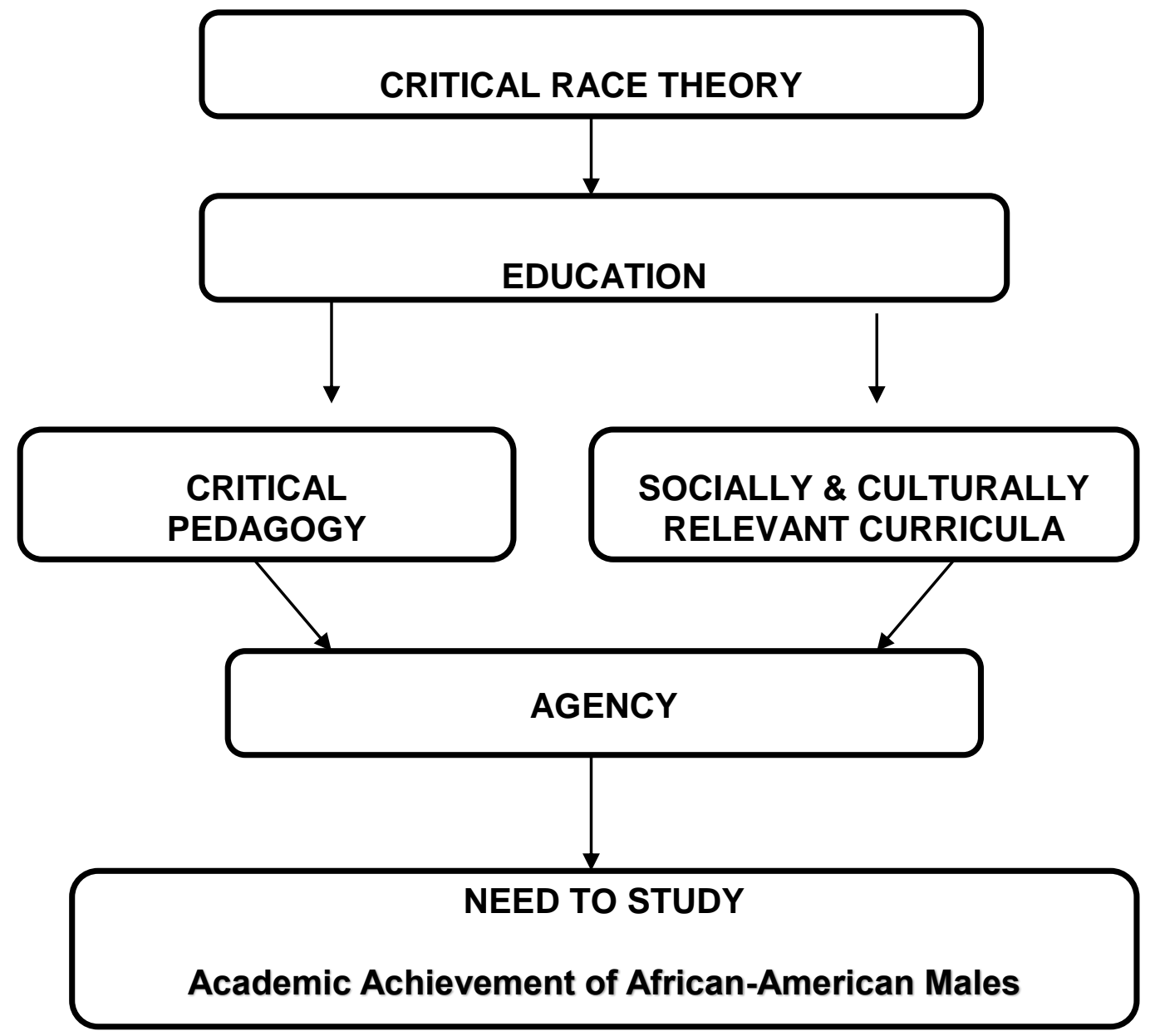

Figure 1. Conceptual Framework 
Freire contends that the first goal of education should be to raise the awareness of students so that they become subjects, rather than objects, of the world. He argues that this can only be done by teaching them to think democratically, continually question and make meaning from everything they learn.

In 1994, critical race theory (CRT) was first used as an analytical framework to assess inequity in education (Decuir \& Dixson, 2004; Ladson-Billings \& Tate, 1995 in Hiraldo, 2010). For the purpose of this investigation, education is regarded as a process where knowledge is presented, then shaped through understanding, discussion and reflection (Lyons, 2001). While the negative impacts of African-American male student achievement has been outlined by many researchers, what needs to be further investigated are the factors and processes which affect African-American males and their values in relation to school and schooling. CRT can be used to deepen an understanding of the educational barriers for non-Whites by focusing on values, perceptions, covert acts of racism, teacher attitudes etc. and by examining the relationship of power as it relates to the role and purpose of schooling, economics and history.

\section{Critical Pedagogy}

Critical pedagogy is concerned with helping us interpret what we see. It includes relationships between teaching and learning in a continuous process of "unlearning", "learning", and "relearning", "reflection", "evaluation", and their impact on students, particularly those that have been historically marginalized and continue to be disenfranchised by what may be deemed "traditional schooling" (Giroux, 2011; Apple, 2012; Hooks 1994; Freire, 1974; McLaren \& Kincheloe, 2007). Critical pedagogy enables one to make inquiries regarding inequality and justice, areas that can be subtle 
and covert and require a re-examination of familiar practices, beliefs, and behaviors of educational institutions.

\section{Socially and Culturally Relevant Curricula}

For years, researchers argued for the inclusion of diversity and multiculturalism as a critical component in the educational achievement of children (Oran, 2009). Using curricula that is socially and culturally relevant recognizes diverse groups and their experiences and provides opportunities for intercultural and cross cultural interactions. A curriculum that is culturally relevant is designed to use a student's cultural characteristics, beliefs, experiences, and perspectives in daily planning while maintaining the integrity of the lesson throughout the year (Ladson-Billings 1994).

Critics of the inclusion of socially and relevant curriculum argue that it is a time consuming divisive deviation from the structured curriculum. Proponents assert that it provides for increased student achievement, builds better understanding and values of other cultures, decreases intercultural tensions and conflicts, and exposes the historical contributions of our diverse population (Kincheloe \& McLaren, 2007; Steinberg, 2009; Giroux, 2011; Murrell, 2007; Nieto, 2007).

\section{Agency}

Agency refers to the capacity of individuals to act independently and to make their own free choices, on their own volition. It allows an individual to resist undesirable attempts at repositioning or subjugating them based on someone else's views and helps them to successfully navigate their own environment.

Agency is important in a student's developmental context because it indicates an ability to exert influence and power in a given situation. It suggests a sense of confidence, 
self-worth, empowerment and sense of self that allows them to make decisions on their own behalf without fear of reprisal (TC Record, 2004).

Agency is a process for understanding power relationships and how to utilize them. It is not an isolated issue. Teachers and other school staff also play a pivotal role. The teacher's agency is crucial to the student's development or decline. Agency maintains that different parties, involved in different situations with the same goal, may have a variety of motivations that can manifest in a variety of ways. An example of this can be seen through the development of curricula in schools and its course content (Emirbayer \& Mische, 1998; Murrell, 2007).

\section{Significance of the Study}

Issues regarding the academic achievement of African-American adolescent male youth have been a subject of public debate for decades. The origins of an achievement gap can be traced to 1863 when recently freed slaves were legally allowed to get an education. Unfortunately, the schools that they attended lacked resources, were overcrowded and understaffed. It is interesting to note that current media reports use the same descriptors to describe our nation's public schools. The "achievement gap" is a term used to describe the disparity in academic performance between groups of students on a standardized, often multiple-choice test. It is used to compare the achievement levels of racial groups in measures such as attendance rates, dropout rates, grades and standardized test scores where it is frequently used to describe the performance levels between Whites and non-Whites (Education Week, 2011)

Many experts have since asserted that achievement gaps are the result of more subtle environmental factors and "opportunity gaps" in the resources available to poor 
versus wealthy children (NCFOT, 2011). With the passage of No Child Left Behind (NCLB) in 2001, closing achievement gaps, especially among African-American and Hispanic students, became a major focus of federal education accountability. As a result, schools and districts were required to disaggregate student test scores and other performance data by characteristics such as race, ethnicity, and attendance to enable better comparisons between groups (Figure 2). This action led to an increase in performance testing and an acute awareness of racial disparities. The increased attention also gave rise to more targeted interventions for different groups of students.

Yet, critical researchers (Morrell, 2009; Hilliard, 2003) Reveal that achievement tests are limited in what they tell us about literacy and education. They do not reveal the effects of institutionalized racism, culturally alienating curricula, test anxiety or inexperienced teachers. They provide only one perspective of student performance often problematic for marginalized groups both in how it positions students and limit the discussion of problem solving alternatives (Pressley 2001 in Morrell 2009).

Students are impacted by this required focus on testing. Research on Stereotype Threat (an assumption that low performing students are judged by stereotype) reveals that the increased importance of diagnostic testing lowers the performance of students from what NCLB calls low-performing subgroups (McKown \& Weinstein, 2003; Steele \& Aronson, 1995 in Wasserman 2009). These facts suggest that we focus on a cycle, in which standardized achievement testing and state mandated curriculum may be serving to perpetuate educational inequities, and maintain an unbalanced status quo. Some of these inconsistencies can be seen in Figure 2. 


\section{UPS AND DOWNS}

The NAEP reading scores for both black and white 13-year-olds have risen in the past four decades. The data also show ebbs and flows in the achievement gap between the two races.

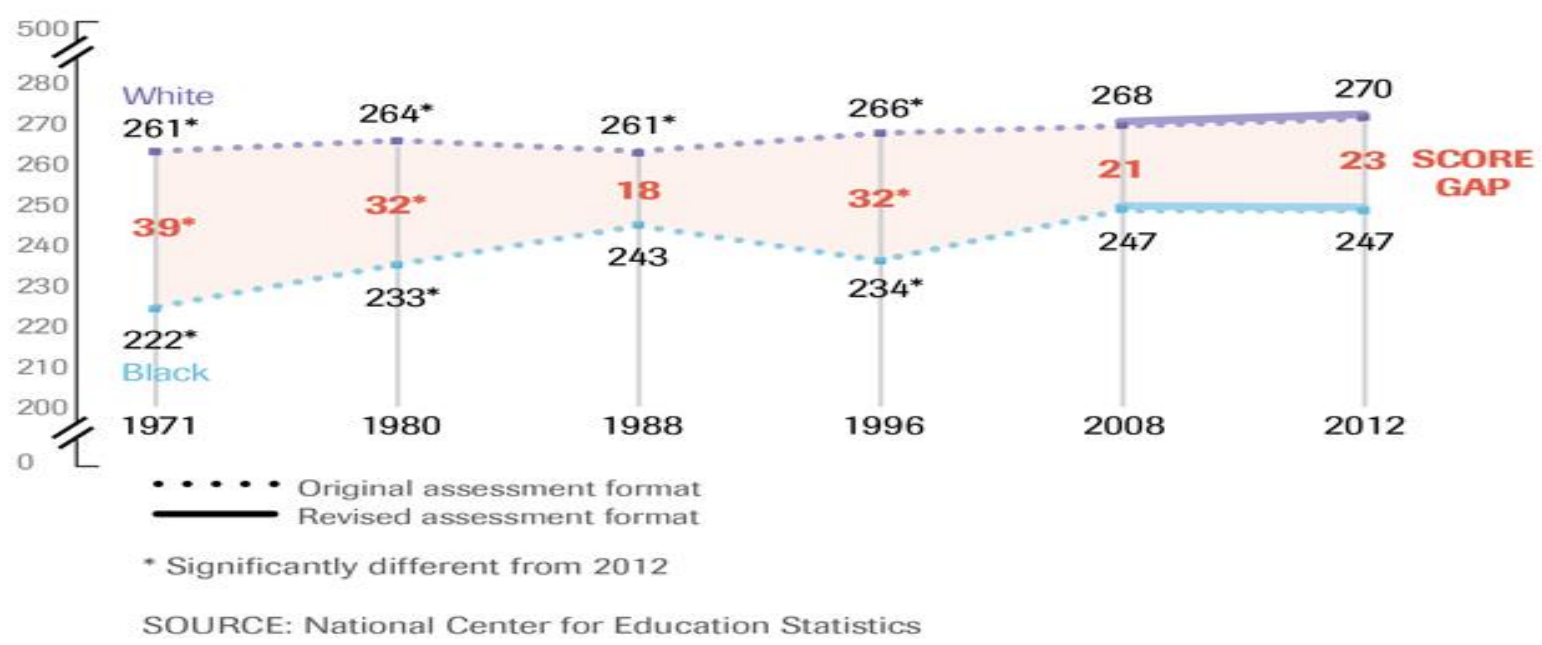

Figure 2. Reading Scores Gap Between Whites and Blacks, 1971-2012. Reproduced with permission from NCES.

According to Figure 2, reading scores for White students appear to have remained fairly constant from the reporting years with little significant change. While scores appear to have their ups and downs' for African-American students, there is an average of 28 points over the 41-year period referenced on this chart. The 2013 data reveals that reading scores for White students declined from 270 to 250 and African-American students from 247 to 224 . It's interesting to note that though the scores changed for each group, the gap in achievement remained statistically the same at $26 \%$. There are two significant years where the narrowing of the gap appears significant. A review of the literature indicates that the Department of Education allowed schools to 'opt' out of testing, which some school districts did. Therefore any 'narrowing' was not due to an increase in reading achievement, but rather a decrease in state reporting. 
This study gives voice to those directly impacted and affords them an opportunity to reflect on their academic achievement. When remediating, Best Practice maintains (a) that we ask the student whether he thinks that he has a problem, and (b) ask if he can identify it.

Prior research studies (Monk, 1998; Stinson, 2004; Harper, 2012) record the experiences and perceptions of African-American adolescent males, but not specifically from adolescents aged 13-17. This range is pivotal because, at this age:

- Adolescent teens make more of their own choices about school and how to perceive the world around them.

- Adolescent teens have a stronger sense of right and wrong and are better able to express feelings by talking.

- Adolescent teens are able to express their concerns and discuss issues that affect them.

- Adolescent teens 13-17 represent a category with the highest underachievers.

This investigation employed a qualitative critical inquiry methodology, using standardized open-ended interviews. Participants were asked to reflect on, and respond to questions regarding their schooling experiences and how it impacted their lives. The results of this research may be used by contemporary educational leaders in the context of current educational policy, state boards of education, universities and colleges of education by identifying key themes derived from student interviews. It will hopefully initiate discussions regarding African-American students' achievement and address some the social and emotional challenges that they often encounter in the school that may hinder their progress. 


\section{Rationale and Need for the Study}

A disproportionate percentage of African-American males are underperforming in school that can be seen in the form of low test scores, increased dropout rates, suspensions, delinquency, and special education staffings. This oppositional behavior appears in the form of sustained challenges to authority and is often used as a rationale for failure. Educational efforts have and are being made by the federal government's No Child Left Behind (NCLB) (2001) mandate, state and city policymakers, and local school districts to curtail this trend but with limited success.

I completed a qualitative critical inquiry using critical race theory to examine some of the prevailing factors that contributed to the academic achievement of AfricanAmerican males ages 13-17. The ages 13 through 17 are pivotal in child development as this is the point in time that adolescents begin thinking about themselves, their place in the world and envisioning himself on a more adult level (Firchow, 2004). This age is also pivotal because it represents a time when decisions regarding a child's academic future is impacted. Although the age to legally dropout of school varies from state to state, data reveals that these decisions are made between the ages of 15 and 16 (U.S. Census Bureau, 2011). See Figure 3. This figure is included here to further illustrate the importance of using this population for analysis.

The dropout rate for African-American youth reached an historic low of $8 \%$ in 2011, as did rates among Hispanic youth, at 14\%. However, preliminary research finds that this decline is at least in part related to increased incarceration rates among AfricanAmerican and Hispanic males (Holzman, 2006; Education Trust, 2007). In a Black Star Project article Phillip Jackson (2012) indicated that African-American male students have 
the worst grades, the lowest test scores, and the highest dropout rates of all students in the country. When young Black men do not succeed in school, they are much more likely to succeed in the nation's criminal justice and penitentiary system.

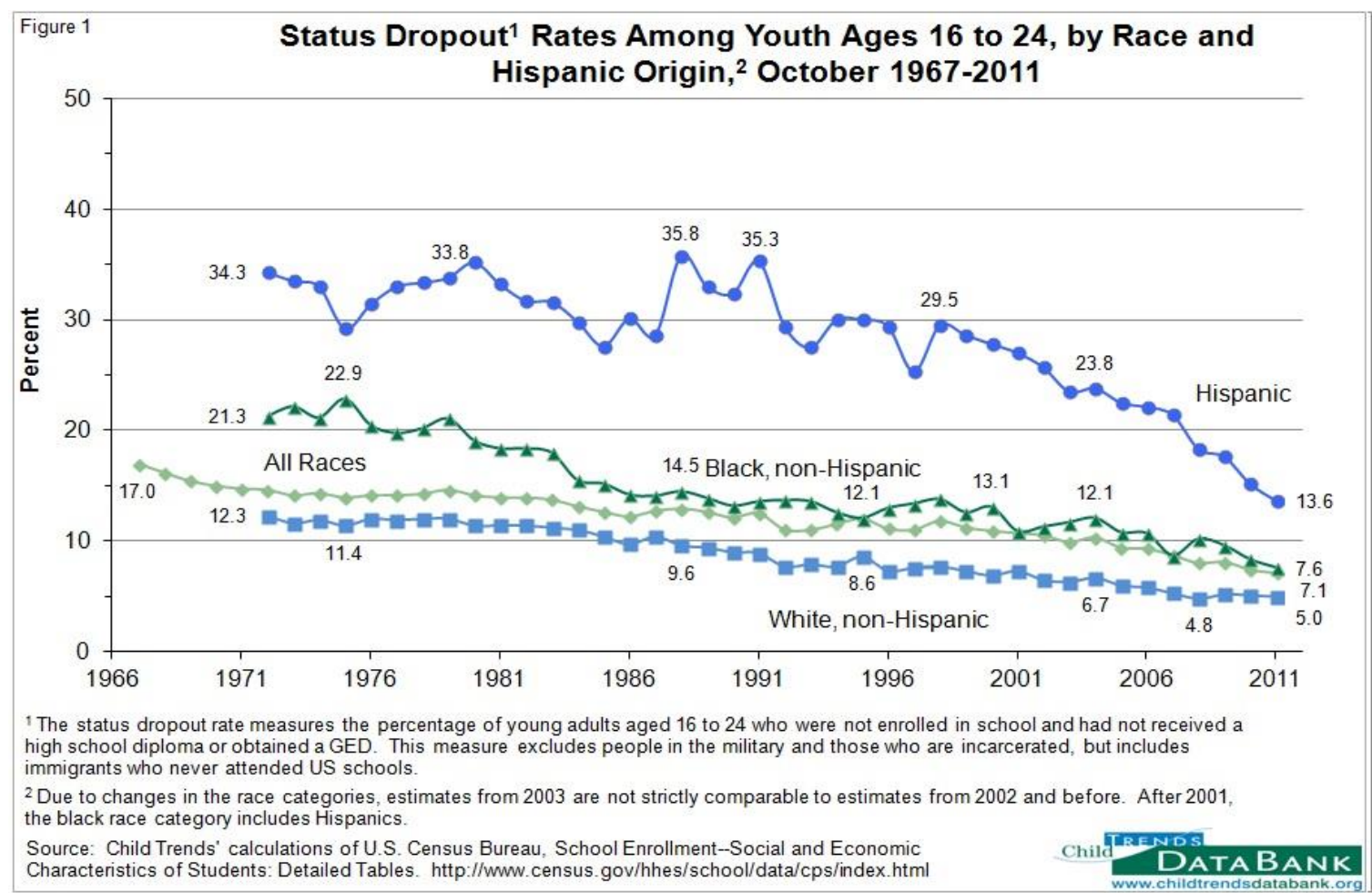

Figure 3. Dropout Rates Among Youth Ages 16 to 24 by Race

\section{Assumptions and Limitations}

This study was designed to investigate some of the sociocultural and educational factors that impact the achievement of African-American males. The main objective of this research was to determine if the low achievement of African-American males had been impacted by critical pedagogy, and/or socially and culturally relevant curriculum. These societal experiences are internalized by students and serve to fabricate adolescent males' interpretation of the world in which they live. This interpretation permeates every 
aspect of their lives; especially in regards to education and its value. With this understanding, it is virtually impossible for a researcher to examine and interpret interview data without an understanding of the participant's culture, experiences and values. As a result, I have attempted to gain as much knowledge as was possible regarding the participant's values and life experiences and have included an outline of the participant's age, grade, number of parents in the home, type of school and designation. McCracken (1988) describes the researcher as an instrument and, in this sense, is secondary to the participant because it is the researcher's responsibility to categorize code and analyze interview data. Research bias, also called experimenter bias, is a process where the investigator, performing the research, unknowingly influences the results, in order to portray a perceived outcome.

In qualitative data, the researcher may influence interview data by consciously or unconsciously influencing the participant, body language, types of questioning, interview schedule, existing relationship with the participant, or pre-existing ideas about the findings. To uncover materials and generative themes based on their emerging knowledge of students and their sociocultural backgrounds, researchers must understand the ways students perceive themselves, their interrelationships with other people and their social reality. This information is essential to the interviewer because it helps to understand how participants make sense of schooling and their lived world. It is with these understandings in mind, that the researcher understands what and how students make meaning. This information enables the researcher to construct interviews that ask students to discuss their experiences (Freire \& Faundez, 1989; Kincheloe \& Steinberg, 1998). It is because of these issues that the research design includes two reviews; by 
Research and Study questions and four levels of coding; Descriptive/In Vivo, Values, Axial, and Causation. It is also important that the researcher considers her influence on the participants, their data, and her role as an unintentional filter. I am passionate about this subject and must confront my own opinions, prejudices and biases for the sake of research. Credible research requires a neutral approach.

Also, in an effort to present the most accurate and realistic account of the participant's position, a fourth meeting was scheduled with each participant to review the interview data and their intended interpretation. This meeting served as a member check and additional source of data.

\section{Operational Definitions}

- Racism redefined is "not the act of individuals, but the larger systemic, structural conventions and customs that uphold and sustain oppressive group relationships, status, income and educational attainment”

- Prejudice is the act of holding preconceived ideas or beliefs about a person or group.

- Discrimination means to treat someone differently as a result of their race, gender, culture or class

- The terms African-American and Black are often used synonymously.

- The term "special education" is given to educational programs that serve children with mental, physical, emotional, and/or behavioral disabilities. 


\section{Summary of the Theoretical and Methodological Direction for Study}

Despite the vast amount of interventions that have been designed to transform their perennial disenfranchisement, African-American males continue to underachieve on most academic indices. This, conversely, results in poor quality of life options, a cycle of poverty, social isolation and incarceration.

\section{Critical Race Theory}

This study used critical race theory as a theoretical framework to examine the influence of pedagogy and curricula on agency for six males ages 13-17 in an urban school setting. Critical race theory (CRT) is a form of critical theory, a tradition developed by the Frankfurt School in Germany, based on the German tradition of the philosophical and political thoughts of Marx, Kant, Hegel, and Max Weber. Critical researchers assume that social reality is historically constituted, then produced and reproduced by people (Myers, 2008). Although people can consciously act to change their social and economic circumstances, critical researchers recognize that their ability to do so is strained by various forms of social, cultural and political domination. Critical research seeks to challenge taken-for-granted beliefs, values and social structures by making these structures and the problems they produce visible, by encouraging selfconscious criticism, and by developing an emancipatory consciousness in scholars and social members in general (Kincheloe \& McLaren, 1994). Critical theory's intent is to critique the status quo, focus on the conflicts and taken-for-granted beliefs to bring about cultural, political and social change to eliminate the causes of alienation and domination that may be at the root of student achievement. It provides a frame for understanding 
how the discourse of race and racism operates within our social structure because (a) it maintains that racial power is maintained by the education system and supported by the law, and (b) explains how people of color experience life and how it impacts their thinking and experiences.

The methodological direction for this study is Critical inquiry using standardized open-ended interviews. Interviewing is the most appropriate strategy to address the research because it can be structured to focus on student achievement and education. Critical inquiry is an effective tool because, within the teaching and learning relationship, the question of power and authority is paramount. Participants were asked to reflect on, and respond to questions regarding their schooling experiences and how it impacts their lives. This design compelled the researcher to ask questions and, upon coming up with an answer, question those answers in an effort to get more clarity (Trochim 2006; Hooks 2003; Lathner, 2004; Seidman, 2013).

\section{Conclusion}

Without question, the education of African-American males is in crisis. Large disparities in education exist for them at essentially all socioeconomic levels. Inequities in achievement can be seen as early as the third grade continuing through high school. In the 60 years after Brown v Board of Education we still find schools that are separated by race and economics (Elliott, 2014). In many school districts, up to $70 \%$ of AfricanAmerican males who enter ninth grade do not graduate 4 years later with their peers. In many districts, African-American males are disproportionately assigned to special education and nearly absent from advanced placement classes (Schott Foundation 2004). Education critic Jonathan Kozol (1991) revealed that a gulf of inequities can be found 
between the schooling experiences of African-Americans school children and their Whites, middle class counterparts that he refers to as 'Savage Inequalities.' These inequalities are the result of a society where schools, communities, employment, or other situations are impacted by race.

African-American males remain deeply afflicted by racism because they constantly hear racist messages in our society. Minority children hearing these messages begin to question their competence, intelligence, and worth. Racist-laced speech is a severe social problem and, along with other tools of racism, keeps minorities in an inferior position. When examining student achievement, these instances necessitate a critical analysis (Delgado, 1995).

Critical race theory (CRT) is an analytical approach that provides race-based epistemological and pedagogical approaches shown to be effective in the study of inequality in education (Crenshaw, Gotanda, Peller, \& Thomas, 2002). CRT was used as the Theoretical Framework to investigate the impact of critical pedagogy, socially and culturally relevant instruction and their impact on agency. CRT was selected to conduct this research because (a) it maintains that racial power is maintained and supported by the law, and (b) explains how people of color experience life and how it impacts their thinking and experiences.

Critical inquiry provided the study's research methodology. It examined subjective data using standardized, open-ended interviews derived from six AfricanAmerican males ages 13-17 focusing on socially and culturally relevant curricula, critical pedagogy, and its effect on student agency. Critical inquiry is an effective tool because, within the teaching and learning relationship, the question of power and authority is 
paramount. Critical inquiry looks to critical and social theory for its rationale and takes into account how our lives are mediated by systems of inequity such as classism, racism, sexism, and heterosexism. Interviewing is most appropriate to address the research because it can be structured to focus on student achievement and education.

This study and its results are intended to provide an opportunity for open dialogue regarding the academic achievement of African-American males. It discusses the impact of critical pedagogy, socially and culturally relevant instruction as it pertains to agency and its influence on education. Moreover, this study articulates how six AfricanAmerican male youth interpret their role and place in society and what it holds for their future(s). 


\section{CHAPTER II}

\section{REVIEW OF THE LITERATURE}

Student achievement has and continues to be one of the most troubling educational issues in our country. The United States, once the most educated country in the world, now ranks eleventh in proportion of young adults with a college degree (Walters 2010). National Assessment of Educational Progress (NAEP) (2011) data confirms what many people believe: that despite a plethora of efforts, this country has yet to solve its challenges to student achievement. There is even less of an agreement on the reasons for this challenge, which may change depending on who is labelling them, whether they are students, parents, educators, or lawmakers. Some fault the economy, socioeconomic conditions, under resourced schools, and even poor training in math and science (Walters, 2010; Thompson, Lewis, 2005). America's education issues gained worldwide attention when Russia successfully launched Sputnik, the first artificial earth satellite, in 1957. This event marked a huge technological threat to the United States because it was determined that the same technology could be used in an attack anywhere in the world. After the Sputnik launch, Congress approved millions of dollars to be allocated to improve our Department of Education (Powell, 2007).

Since then, many projects, programs and theories have been suggested to make the U.S competitive again. Some include: better trained and motivated teachers, more and better early childhood programs, better prepared school leaders, improved curriculums, 
higher standards, financial incentives, better data systems, and more rigorous and frequent assessments. Still, Microsoft founder Bill Gates believes that eradicating tuberculosis, malaria, and polio is easier than fixing education. He maintains that developing a plan to take schools in the right direction is easier said than done, because the issues are much more than mere economics (Walters, 2010; Chen, 2014; Gratz, 2011; Clausing, 2014; Noguera, 2003, 2012; Goodman, 2012; Hooks, 1994; Jackson, 2012; Ladson-Billings, 2007; United Church Press, 2012). The causes of our achievement challenges are multiple and complex. When investigating causation, it is imperative that we include gender, race, class and ethnicity to the discussion (National Education Association, 2014).

Educational psychologists have consistently found that girls tend to have higher standards in the classroom and evaluate their own performance more critically. Girls mature earlier than boys and perform better on a consistent basis in reading and writing related skills from high school through college. In comparison, boys perform better on a consistent basis than girls on math and science standardized tests. However, achievement has been often shown to have less to do with innate abilities and more to do with cultural expectations (Great Schools, 2008). Similarly, Cvencek, Meltzoff, and Greenwald (2011) add that a math-gendered stereotype is acquired early for males and influences emerging math self-concepts prior to ages where actual differences in math achievement can be expected. In our current education culture, classrooms rely heavily on talk, conversation, and the sharing of ideas. Variances in learning style account for a huge difference in how adolescent males and girls learn; however, none of these findings reveal any plausible basis for the consistent gaps in 
reading, writing, and science test scores reported in student achievement data. This study examined factors that impact the academic achievement of African-American males.

\section{Adolescent Males}

Gurian and Stevens (2006) reveal that adolescent males make up: (a) $80 \%$ to $90 \%$ of discipline referrals, (b) $70 \%$ of learning disabled children, (c) earn at least two-thirds of the D's and F's on classroom assignments, but less than one half the A's. Most boys simply do not enjoy reading and lag behind girls in reading (Jacobson, 2014; Keilman, 2013; Moyer, 2010; Chudowsky \& Chudowsky, 2010; Tyre, 2008).

Why this phenomenon? Tim Ross (2012) argues that traditional instructional strategies favor girls. He reports that schools believe that the same lessons, delivered the same way, will suffice for males and females. Other researchers like Leonard Sax, a proponent of single sex schools, posits that boy brains are 'hardwired' to learn, process data in a certain way and should be educated in single gendered environments (Whitmire \& Bailey 2010; Harris, 2008; Sax, 2009).

Sax (2009) and Patterson (2012) believe that males suffer from a 'toxic' mix of a curriculum that fails to engage them, an over-prescription of drugs that purport to curtail hyperactivity, and a lack of appropriate role models. Ross (2012) adds that the lack of competitive sports and opportunities to engage in physical activities in many of our schools also cause a disconnection between the school and schooling which leads to academic disengagement. Similarly, a study by Reichert, and Hawley (2013) examined the impact of teacher relationships and how it serves to improve student learning. Their study revealed that most of the participants accepted and valued their school and its programs and that resistance and opposition generally occurs when teachers fail to 
establish a positive relationship with students. Should this change the traditional approach to teaching and learning? How much of an emphasis should be placed on reading and writing?

Tyre (2008) asserts that in the 1970s employment opportunities were plentiful for males, even those who did not read or write well. However, today's job market, requires a high level of reading and writing skills and specific job competencies, as unskilled labor has been outsourced to other countries. Whitmire and Bailey (2010) maintain that we must be more innovative in our approach to this issue. They suggest that students need to complete 2 years of college or, at minimum, one year of post-high school study to survive today's job market.

Sparks (2011) adds that, although the needs of global labor have changed and college readiness standards have increased, American adolescent males have been slower to adapt to these changing needs than girls. Tobia (2012) maintains that not only are our adolescent males struggling with reading, but with critical thinking and reflection. While Mortenson (2011), whose research indicates that women have been gaining ground since the 1990s, believes schools are primarily responsible because they are formatted to have a broad focus on writing and test preparation with few to no opportunities for active

learning that has been proven effective in the teaching of males (Johnson \& Gooliaff 2013; Noguera, 2012; Rosler, 2010).

\section{African-American Males}

Achievement data are devastatingly profound for African-American males. They are unique in that they are members of two groups-African-American and males - both of which have historically underachieved in reading (Husband, 2012). While NAEP 
(2009) reports that White students score higher on all assessments than AfricanAmerican students, National Center for Education Statistics (NCES) (2009) data reports that there is a significant reading gap between African-American students that is visible as early as fourth grade. What is and how important is this achievement gap? ASCD (2006) describes the achievement gap as categories of students defined by race or economic status who, according to test data, fail to achieve academically at the same levels and rates as White students at the same age and grade level. Lavin-Loucks (2006) in Allen (2008) describe it as a kinder way to discuss the pervasive racial and socioeconomic disparities in student achievement. She believes that the sheer presence of an achievement gap based on race, ethnicity, and socioeconomic status is evidence of an unequal educational system. Ergo, it reveals that African-Americans and other people of color are more disadvantaged than their White peers.

Yazdani (2011) also alleges that the achievement gap and the economic gap are both socially constructed. He bases this allegation on data from Portland State University which reveals that while the average Whites household earns over $\$ 53,000.00$ per year, people of color earn approximately $\$ 37,500$, a difference of $\$ 15,500$ ! The difference being —one makes minimum wage, while the other makes a livable wage. The achievement gap in education correlates with this economic data. In fact, if we do the math, the income of people of color is almost $30 \%$ less than their White counterparts. That means that the resources that White families are able to provide for their families is difficult to non-existent for people of color. How does it impact the economy? Yazdani (2011) concludes that the diminished earning power of African-Americans and other people of color causes them to cut daycare and either stay at home or live on welfare in 
impoverished neighborhoods with few resources. Economically, if one is not earning money, one cannot spend money; without a fair and equal education, the opportunity to make a livable wage diminishes.

According to the McGee (2008), between 2004 and 2009, the percentage of large city fourth-grade African-American males performing at or above proficiency in reading improved from 8 to 11 percentage points, a small improvement, but still at least 27 percentage points lower than the percentage of White males in National Public schools scoring at or above proficient levels. Though there has been progress in the national graduation rate for male students across the board, the national graduation rate for African-American males increased by 10 percentage points, from $42 \%$ in $2001-02$ to $52 \%$ in 2009-10. Twelve percent of African-American male students in fourth grade meet or exceed national guidelines, compared to $38 \%$ of White males. In math, twelve per cent of African-American eighth-grade students meet proficiency compared to $44 \%$ of Whites. At this pace, it would take nearly 50 years for African-American males to progress to the same high school graduation rates as their White male peers.

Although boundless theories have been offered to address this issue, any discussion involving African-American males and the educational system must start with Brown v. Board of Education (1954). This ruling established that separate public schools for African-American and White students were unconstitutional because it denied African-American children equal educational opportunities. The Brown v. Board of Education (1954) ruling is representative of the effects of negative educational psychology on African-American boys. In his opinion, Justice Warren argued that to separate children in grade and high schools from others of similar age and qualifications 
solely because of their race generates a feeling of inferiority as to their status in the community that may affect their hearts and minds in a way unlikely ever to be undone. This rationale is significant in that it adds to the discussion regarding the disparities in achievement with African-American males. Justice Warren's belief that separating children of similar age and qualifications, thereby generating a feeling of inferiority, can be seen in present-day instructional strategies with classroom learning groups established according to ability. This seemingly effective strategy, when used in racially diverse classrooms, may cause African-American male students to begin to feel inferior to White and African-American female students, who educators sometimes view as smarter and better behaved than them in a way that may be irrevocable (Walton, 2010; Meadows, 2011; Pople, 2012; McDougal, 2013).

Education reforms, such as the reauthorization of Elementary and Secondary Education Act (ESEA, 1965) that focused on the inequality of school resources and No Child Left Behind (NCLB, 2001) that held states accountable to the federal government through annual testing, annual yearly progress, state report cards and stricter teacher qualifications, have failed to make any significant impact on decreasing the gap in academic achievement that exists between African-American and White students. Although ESEA is reauthorized every 5 years, the current mandate, NCLB, is still in place. This mandate requires that states decrease achievement gaps by providing each child with fair and equal opportunities to education; however it is left to the state to determine how it will be done. For many states, this has led to an over-reliance on achievement data that targets diverse groups of students. Achievement can be positive or negative as data can be used to further marginalize groups of students namely, African- 
Americans, Hispanic or Latinos, and students with special needs (Common Core Standards Initiative, 2014; Goodman, 2012; Zyngier, 2014; Schanzenbach, 2014; Achilles, C. M. et al., 2012; Jensen, 2010; Toch, 2003; Latarola, Schwartz, Stiefel, \& Chellman, 2008, in Abdulkadiroğlu, Weiwei Hu, \& Parag, 2013; Walker, 2011; White, 2009; Ralabate \& Foley, 2003).

Other issues impacting African-American student achievement and graduation rates can be seen in the number and percentages of student performance on the ACT, an acronym for American College Testing. This is a standardized test typically administered during a student's junior year of high school. The ACT has four parts: English, Math, Reading, Science, and Writing (optional). All 4-year colleges and universities recognize the ACT, but some institutions also require that students take the SAT, an acronym for Scholastic Aptitude Test. It differs from the ACT in that the ACT measures achievement, while the SAT measures aptitude, reasoning, and verbal abilities. Colleges and universities may also take into account student grades, grade point average (GPA), and class rank in admittance policies. According to Fair Test, the National Center for Fair and Open Testing (NCFOT) (2007), in 2013 the ACT was administered to approximately one million students predominately in the Midwest and South. About $58 \%$ of students taking the test were White and $13 \%$ African-American.

NCFOT argued that the ACT test includes race, class, and gender biases that give White males an unfair advantage. It revealed a strong correlation between ACT scores and family income, education of the parents, coursework and grades, but acknowledged that even when all factors are equal, Whites still outscore all other groups. The propensity to marginalize student populations is possible by using ACT data to limit 
student enrollment and acceptance by manipulating the cut scores. This can be seen in Louisiana, where students with an ACT score of 20 or more can apply to have their tuition and fees waived for up to 4 years at state colleges and universities. This minimum score is within the range for White students but more than five points above the average score of African-American students. (See Figure 4.)

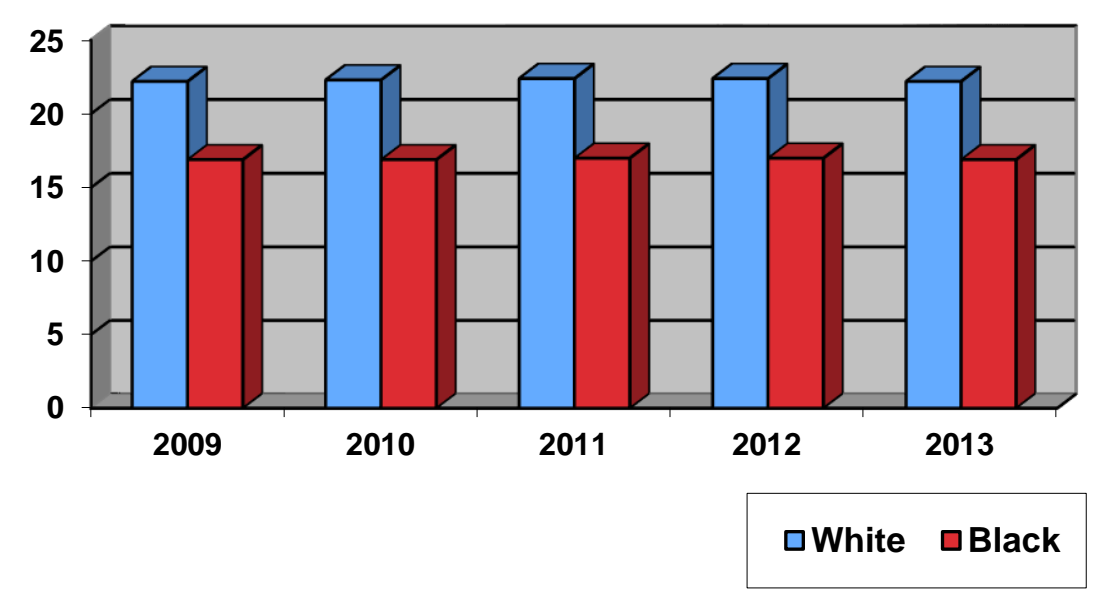

Figure 4. Average ACT Composite Test Scores for White and Black Students, 20092013

ACT trend data suggests that from 2009 to 2013, both White and AfricanAmerican student achievement percentages remained statistically the same. A majority of private and public Midwestern colleges and universities (DePaul University, Illinois State University, University of Iowa, Iowa State University, and University of Cincinnati etc.) require ACT scores of 22-26. This data also suggests that with ACT scores for African-American students topping out at 17.0, there is a substantially lower probability of being accepted at these colleges and no probability of acceptance at Ivy League and/or 
private institutions (Harvard, Cornell, Princeton, Syracuse, et al.) that require scores of $32-35$.

This has been an on-going concern for researchers investigating AfricanAmerican male academic achievement who ascertain that, by the fourth grade, $86 \%$ of these males are not reading at grade level. Due to the importance of reading in relation to educational competency, the likelihood of failure in almost every other subject area is high, an unfortunate statistic for African-American boys who already have many factors working against their success. Whether it is from impoverished backgrounds, broken homes, or parents with low educational attainments, the odds of failure are likely (Kunjufu, 1985; Vasquez, Forbush, Mason, Lockwood, \& Gleed, 2011; Harper \& Davis, 2012). Researchers (Gordon \& Gordon, 2006; Fincham, 2009; Nakkula, 2013) reveal that many children who live under these conditions develop a pattern of failure and simply stop trying. They believe that repeated failures cause children to develop cognitive, motivational, and emotional deficits that cause them to disengage from the learning process because it is the safest way to avoid another failure. In many school districts throughout the United States, African-American males are likely, more than any other racial group, to be suspended and/or expelled from school. This alone makes students susceptible to dropping out. Since 1977, more African-American males have been classified as mentally retarded and diagnosed with a learning disability (i.e., ADD, ADHD, BD) than any other cultural and/or ethnic group (Noguera, 2003; 2012; Ruffins, 2013 ). This data correlates with research that identifies some of the key indicators of students who are likely to drop out of school. These indicators include: poor grades especially in reading and math, low attendance, retention, and disengagement in the 
classrooms that include behavioral problems. This research concurs with Kunjufu's theory of a fourth-grade syndrome, and adds that $50 \%$ of sixth graders, who were truant less than $80 \%$ of the time, received low grades and failed either reading and/or math would eventually drop out of school. In addition, eighth graders who miss 5 weeks of school and fail reading and/or math are projected to have a $75 \%$ chance of dropping out of school (Balfanz \& Herzog, 2007; Ruffins, 2013; Bloomfield, Foster, Hodes, Konopniki, Pritz, 2013).

These high percentages result from disparities in education impacted by race and class (Ntiri, 2009). (Kozol, 1989) ascertained that there is no equality when it comes to education. In his review of school budgets, he learned that the lowest annual education allocations were located in areas with large urban populations of minorities (Kozol, 1991). An example of this can be seen in the school budget for New York City whose per pupil expenditure was $\$ 11,627$ while the smaller bordering town of Manhasset spent $\$ 22,311$ per student. He indicated that there are comparable disparities in many areas often separated only by a 10-15 minute drive, but offered different educational opportunities. These disparities can be seen as one school offering Advanced Placement and drama classes, while the other school requires hairstyling as a required elective (Kozol, 1991). African-American males have learned to respond to unequal disparities such as these in a variety of ways. Some have been successful and have managed to work through the malaise of programs and projects, while others fall prey to low expectations. Many seek an identity, playing the role of the cool, disinterested student in some circles and the goal-oriented student who works toward planning his future in others. 
The issue of identity is paramount in the African-American culture and is often a topic of debate regarding student achievement. Although we identify ourselves racially, culturally, or ethnically, there are a number of similarities among the groupings. Skin color and culture, once used as indicators of racial identity, are no longer valid due to recent immigrations from Asia and Latin America. As a result, ethnic identity appears to be the framework in which individuals consciously or unconsciously identify with based on the values and traditions they have become accustomed to.

Researchers (Ogbu 1992; Lacey \& Ono, 2011; Wright, 2009) claim that to understand how students identify themselves, one must understand the student's cultural model, degree of trust toward schooling, and frames of reference. These three categories are important in understanding a student's performance. Ogbu refers to a student's cultural model as their understanding of the world and how their interpretation of it guides their actions. He characterizes the degree of trust as the frequency of episodes that minorities' experience that cause them to believe that Whites and the institutions that they control, i.e., schools, cannot be trusted. Frames of references can be oppositional or non-oppositional. Oppositional cultural frames of references are adverse reactions to situations that involve the subordination of one group by another, as in the case of African slaves. Non-oppositional frames of reference can be due to primary differences that existed before a group became a minority, such as before immigrants from China, India, or Latin American arrived in the United States. Initially the two groups were characterized by their individual group's cultural difference; however, as minority groups begin to develop new cultural features, they reinterpreted the old ones in an effort to cope with the subordination or oppression. 
Ogbu (2008) contends that African-Americans developed an oppositional cultural identity after slaves were emancipated. He cites that this opposition can be seen in music, clothes, and speech, but is most visible in education where it gave birth to the concept of "Acting White." The concept of "Acting White" originally came out of a qualitative study by McArdle and Young, two researchers who described meetings in which both African-American and White students discussed transitioning to high school. Interestingly enough, African-American students who rejected commonly held AfricanAmerican behaviors were purported to "Act White" (McArdle \& Young 1970; Fordham \& Ogbu, 1986; Austen-Smith \& Fryer, 2006; Toldson \& Owens, 2010; Getz \& Roy, 2013; Chizhik, \& Chizhik, 2009). They maintain that "Acting White” began as a coping strategy at the end of the Civil War. They reported that African-Americans reject certain activities or signs of a perceived proximity to 'Whiteness' and define behaviors not associated with Whites as more legitimate. At that time African-Americans were not expected to incorporate White behavior and speech patterns but, after the Emancipation, were expected to assimilate into the dominate culture and adopt the same value system and beliefs as those who had previously enslaved them. Researchers maintain that an oppositional stance to school developed because students believed that education would not lead to social mobility and because successful school engagements required behaviors that are not considered compatible with their race, ethnicity, or class identity (Fordham \& Ogbu, 1986; Wright, 2009; Schweiger, 2012; Boyd-Zaharias, 2008; Reichert \& Hawley 2013).

Historically, African-American and low-income students have been subjected to discriminatory practices that only allowed limited opportunities for social mobility 
through education. This is the understanding that shaped student attitudes and responses toward to school and what may also be a cause of African-American students' disengagement from school. Moreover, Ogbu (2008), Hawkins (2008), Fordham (1996), Fordham and Ogbu (1986), Ogbu (1991), and Ogbu (2003) view student disengagement as an adaptation to barriers and limitations resulting from historical discrimination through what he called the Oppositional Culture Theory. Ogbu (2008) explains that each minority group has a different set of experiences that frame their relationships to school and the role that it plays in their lives. Historically, African-Americans were denied access to education. However, with the legislative end of slavery, educational opportunities began to emerge and larger numbers of former slaves began attending public schools. These schools were substandard and lacked books, materials, and certificated teachers. Regardless of these conditions, Ogbu noted that the motivation for getting an education was based on the premise that the more education one has, the better the job opportunities, the higher the wages, social status, and self-esteem. However, when African-American students became aware of how race, class, and ethnicity impacted job opportunities and social mobility, the effort and motivation needed to successfully complete their course of study began to erode.

Ogbu (2008) also explains that African-American male youth reflect an "oppositional" identity in his classification of non-voluntary minorities. Non-voluntary minorities are people who were brought to this country against their will, as in the case of the slave trade. Gonzales (2002) further adds that students develop identities in opposition to school cultures when they determine that getting a high school diploma is no guarantee of a job and refuse to put in the time needed for academic improvement. 
These students reject the promise that a diploma will lead to a job when they realize that gender, class, race, and ethnicity limit their opportunities.

Although Ogbu's Oppositional Theory research is well known, and respected, his ideas have been challenged by a number of critics. (Spencer, Cross, Harpalani, \& Goss, 2003; Horvat \& Lewis, 2003; Hassinger \& Plourde, 2005; Fisher, 2005; Chizhik \& Chizhik, 2009) allege that his theories over-generalize the academic performance of students with the argument that the concept of "Acting White" is overstated. They believe that the concept ignores structural barriers to academics, focusing instead on cultural deficiency. Racial identity can be a barrier as well as response that impact behaviors and attitudes; which in turn may impact school success or failure. The adage 'children learn what they live' is applicable here as African-American families bear an additional responsibility: that of preparing children to cope with experiences with prejudice and discrimination. Solórzano and Delgado-Bernal 2001 in Chizhik \& Chizhik (2009) have also been critical of this theory. They suggest that Ogbu's theory focuses on a 'self-defeating" resistance without recognizing that resistance can be transformative. They outline four types of student resistance. The first is opposition with no orientation or awareness of social justice or the dominant culture. They deem that, in this resistance, students misbehave for the sake of disrupting classroom instruction. The second form of student resistance is self-defeating. In this type, students may disengage from school due to an understanding that race, gender, and social status will limit their opportunities for upward mobility and, as a result, may engage in oppositional behaviors as a form of anger and/or frustration. This form of resistance is the most analogous to Ogbu's theory. The third type, conformist resistance, finds students aware of social injustices but 
adopting dominant behaviors anyway. Finally, transformative resistance describes students who see the inequalities of the world and work for social justice.

Issues regarding the disengagement of African-American males can also be seen in the impact — or lack of impact — of the classroom teacher (Spaulding, Cari, Klecka, Lin, Wang, \& Odell, 2011). Successful teaching should be hands-on, interesting, and stimulating, especially when working with diverse students (Dockett, Perry, \& Whitton, 2010; Killion \& Hirsch, 2011; Lee, 2011). Students need teachers who are familiar with their cultural values, traditions, mode(s) of communications and learning styles, understand how different ethnic groups view education, and how their views affect motivation, aspiration, and performance to implement an effective instructional program (Gay, 2000; Delpit, 1996; Ladson-Billings, 1994; Lai, 2012; Kanes, 2013; Naiditch, 2013). Typically, instruction from kindergarten through second grade is very much hands-on. However, there is often a change in instruction in the third and fourth grades where lessons are more abstract (Torgesen, Houston, Rissman, \& Kosanovich; 2007). Kozol (2006) explains this situation by suggesting that most schools take their inspiration from B.F Skinner, using a scripted and drill curriculum. This approach, which promotes positive reinforcement through some intrinsic reward, can alienate struggling students who have difficulties keeping up in the regular classroom. Students who do well in class are often the students who are called upon as classroom leaders and stars; however, those who struggle never seen to catch up, never see their papers posted on the bulletin board, never get the gold star, and are never selected as classroom leaders.

In urban classrooms, teachers are challenged to provide instruction whose effectiveness is measurable on the state achievement assessments. However, in a 
classroom of students, there may be a variety of learning styles, culturally diverse students, and different achievement levels with the teacher often using a one-size-fits-all instructional strategy. Because of this country's Eurocentric approach to education, it cultivates a system of inequality that caters to a certain segment of the population at the expense of others. Unfortunately, not all students perceive or integrate information in the same manner. This teaching strategy, especially for at-risk students, is yet another step towards disengagement.

Balfanz et al. (2007) surmises that school disengagement is composed of correlated sub factors measuring different aspects of the process of detaching from school, disconnecting from its norms and expectations, reducing effort and involvement at school, and withdrawing from a commitment to school and to school completion. Similarly, Margolis and McCabe (2006) suggest that student disengagement is the result of low self-efficacy in academics. For any number of reasons, many African-American students simply do not believe they are capable of success and are doomed to fail, adopt behaviors that make them complicit in their own failure, and act out in the classroom to avoid challenging themselves academically. Conversely, creating new programs and opportunities may not be effective if they do not involve strategies to counter and transform cultural patterns and what some have called the "oppositional identities" adopted by African-American males that undermine the importance that is attached to education (Noguera, 2002; Ogbu, 1992). Toldson, in Fuller (2011) also believes that schools should focus on how personal, emotional, school, and social factors impact African-American male student achievement. He maintains that school districts are addressing low student achievement as an academic problem, when, in reality, it should 
be viewed as a crisis situation with emphasis placed on monitoring, correcting, and clarifying social realities that cause African-American males to lack motivation.

Toldson's research is important because it reveals the importance of personal, emotional, social and school factors and how those factors impact academic success for African-American males. Toldson believes that educators, advocates, and policymakers need to do a better job of monitoring, correcting, and clarifying social realities that contribute to academic disengagement. He proposes that we develop strategies to reduce chronic absenteeism and suspensions, provide social services with community support, advocate for creating teacher teams, and increase staff development opportunities. James (2010) suggests that we need to explore the student achievement of African-American males within a framework that is responsive to their historical, political, economic, and social realities. These areas will be addressed in relation to critical pedagogy, socially and culturally relevant curricula, and their impact on agency as they relate to student achievement.

\section{Critical Pedagogy}

The most basic tenet of critical pedagogy supposes that the status system in our society is based on race, class and gender. In $21^{\text {st }}$ Century Schools (2010), McLaren believes that Critical Pedagogy is a lens that can be used to provide historical, cultural, and ethical direction for educators. U.S. Education Secretary Duncan (2009) cites that education is the civil rights issue of our generation and, if you care about promoting opportunity and reducing inequality, the classroom is the place to start. McLaren (2010) adds that those in power remain in power and control the rest of society, thereby maintaining the status quo. In order to retain this level, they consciously or unconsciously 
fight to keep it by controlling others. Control is wielded through the tool of hegemony, a subtle almost invisible form of control in which whatever is presented as the status quo is believed to be representative of 'the right way'. Apple (2012) explains that hegemony acts to penetrate our consciousness so that the educational, economic, and social world that we see and interact with and their interpretations become the real world. Schools perpetuate society's existing culture, beliefs, and practices, which is the hegemony. The pedagogy, subject matter, policies, and organization of schools all contribute to the hegemony of our society. For these reasons, any investigation that questions or challenges the status quo must begin in our schools.

Critical pedagogy is an educational philosophy that examines the contents, processes, and purposes of education. It is the rationale for how, what, and why one teaches. It challenges traditionalist, essentialist and teacher-centered perspectives in education and that education should enable students to become active, democratically oriented citizens sensitive to the plight of humans (McLaren, 1995; Widdensheim, 2013).

Critical pedagogy utilizes a framework in which social injustices or forms of oppression (race, gender, discriminatory practices based on class, or privilege) may be examined. One's life experience as well as previously uncovered knowledge is examined to generate individual and/or societal transformations. This approach asks the investigator to pinpoint and address dominant themes and practices within society through reflective and action-oriented instruction to determine if they are unfair or unjust. It encourages the learner to critique instances or episodes that may have been impacted by societal issues (education), and encourages critical action, through the engagement of the student's 
experiential knowledge and social agency. A critical pedagogical approach demands that people question their roles in society either as agents of change or transformation (Freire, 1970; Giroux, 2011; McLaren, 2007; Shor, 2006).

Objections have been raised regarding critical pedagogy and its use in classrooms. Widdensheim (2013) believes that schools are too regimented; teachers have no control over the content; and school boards, administrators, and policy makers still believe in traditional instructional strategies to use as an instructional strategy. However, Flynn's (2012) study examined what happens when a class of culturally and economically diverse students use critical pedagogy to study cultural conflict and resolution that includes a unit on racism and White privilege. The 8-month long project involved a series of conversations regarding their experiences with racism at school and community. As the conversations continued, patterns across racial groups emerged and revealed some of the differences in African-American, Latino, Asian, and White students and their perceptions of other races and cultures. One of the patterns involved the use of culturally and socially relevant curricula in today's classrooms.

\section{Culturally and Socially Relevant Curricula}

For the past 15 years, there has been a wide array of research regarding culturally and socially relevant curricula with special emphasis on students of color (Flynn, 2012; Pirofski, 2012; Steinberg \& Kincheloe, 2009; Dixon, 2008; Gomez, 2003). Current research indicates that academic achievement is closely related to curricula (Caraballo, 2012; Demir, Kilinc, \& Dogan, 2012; deHaan, Elbers, \& Leseman, 2014; Perez, Costa, \& Corbi, 2012). 
The academic quality of the curriculum is shaped not just by content but also by attitude and practice. Yet, despite the steadily increasing numbers of culturally, ethnically and linguistically diverse students in our classroom, curriculum content has basically remained Eurocentric. There is a growing need to educate children of different races and abilities that should force educators to find literature and develop curricula that best suits the mix of students in classrooms across America. To do this, curricula must be intentionally developed to provide resources and materials that not only teach literacy, but also instill a sense of pride about students and their history (Pirpfski, 2002; Ryan, 2006)

Much has been written about student curricula, their teachers, and role in the underperformance of African-American males. Ladson-Billings (1994), Gay (2000), Delpit (1995), and Husband (2012) agree that students need a curriculum that includes their history and culture. Leftwich (2002) maintains that in order for all students to increase their capacity to learn, teachers need to become culturally sensitive. They must be taught to think in ways that communicate and connect with not only African-American students but students and families of diverse backgrounds. Diversity is about culture and values. It illustrates how society views family, communities, education, and work. Steinberg and Kincheloe (2009) argue that there is no one paradigm, taxonomy, or way of diversifying and multi-culturalizing citizens and school curricula. Every class is different and unique, making standard texts useful as resource material but not as the core teaching manual. Every student deserves to learn in a class that uses culturally responsive teaching. 
Gay (2000) reveals that culturally responsive teaching is using the cultural knowledge, prior experiences, and performance styles of diverse students to make learning more appropriate and effective for them. It teaches to and through the strengths of these students. Culturally responsible teaching acknowledges the student's culture, and incorporates it into the subjects and skills that students must know and be able to do. Gay (2000) adds that culturally responsible teachers need to incorporate everyday life concepts, such as economics, employment, and the consumer habits of various ethnic groups. Effective classrooms integrate home and school experiences to help students make connections to their learning. Delpit (2006) suggests that teachers understand how different ethnic groups view education and how their views affect motivation, aspiration, and task performance when developing their instructional program. Unfortunately, many teachers of African-American children have their roots in other communities and, therefore, do not have the opportunity to hear the full range of their students' voices. Schools may increase efficacy by becoming more culturally responsible and celebrating the student's culture and language (Delpit, 2006; Kentley, 2012; Dallavis, 2013).

Conversely, there are times when culturally and socially relevant curricula actually contribute to the underperformance of African-American males. For example, elementary school social studies books and secondary U.S. history textbooks that include chapters on various cultural and ethnic groups offer a romanticized view of the Europeans' experience in the United States. Experiences of Asians, Hispanics, or African-Americans are either misrepresented or underrepresented, thereby continuing to marginalize the achievements and significant traditions of the many ethnic minority populations living in the United States (Loewen, 2007). Teachers need to be aware of 
this when developing curricula and understand that the processes of learning include these experiences and impact the students' interpretation(s) or schools and schooling. These interpretations impact student agency.

\section{Agency}

A number of explanations have been offered that detail the reason(s) for student underperformance, each of them containing grains of truths (Walters, 2010; Chen, 2014; Gratz, 2011; Clausing, 2014; Noguera, 2003, 2012; Goodman, 2012; Hooks, 1994; Jackson, 2012; Ladson-Billings, 2007; United Church Press, 2012). Yet, we tend to ignore the role of the students who represent the most crucial link in the education process. Students decide whether they will study or not, complete assigned work, come to school or not, engage in the classroom activities, or not. In fact, students are active decision makers making literally hundreds of decisions every day (Bruce, 2003). These decisions are influenced by identity and implemented by agency.

Agency is a complex and dichotomous issue. It is the capacity of individuals to act independently and to make their own free choices. Agency is the ability to accommodate, resist, or reconfigure the available choices that surround our youth to help them effectively navigate through schools and communities (Stinson, 2004). This capacity is based collectively on identity, socioeconomic status, gender, family, and life experiences of the person.

One of the primary tenets of agency is identity. Murrell (2008), Oldfield (2013), Rahm, Lachaine, and Mathura (2014) assert that identity is a set of characteristics that somebody recognizes as belonging to themselves. It is impacted by the perceptions and 
belief system of those in the participant's family, home, school, and community. We are all products of these systems.

The expectations of teachers or other persons in positions of influence weigh heavily on self-image. Leary, (2006) posits that it is our nature to seek approval from others; to portray ourselves in an acceptable light. An accumulation of negative experiences can result in depression, low self-esteem, and high stress levels. Feelings of low self-esteem become visible when human beings have been exposed to stress early on in their lives and has profound effects on an adolescent's ability to manage and control their emotions that do not improve with age (Leary, 2006).

Ogbu, (1978) maintains that African-Americans developed an oppositional cultural identity after slaves were emancipated and argues that this opposition can be seen in music, clothes, and speech, but is most visible in education. The Oppositional Cultural Theory is a framework that Ogbu used to explain differences in academic performance among African-American male youth. He contends that the achievement gap is a product of the perception that African-Americans educational opportunities are limited, resulting in fewer employment opportunities than Whites. Ogbu (1978), in his seminal work, classifies African-Americans as involuntary minorities because of a slave heritage and subsequent racial discrimination. This discrimination causes them to be disillusioned about promises of success and doubtful about the value of school and schooling. This identity can be seen in oppositional behaviors such as truancy, fighting, suspensions, apathy, and anti-social behaviors, to name a few (Salend \& Sylvestre, 2005; Montague, Enders, Cavendish, \& Castro, 2011; Alkahtani, 2013; Handrickson, 2012). 


\section{Analysis of Research Studies and Scholarly}

\section{Works Related to the Research}

The old cliché 'knowledge is power' still rings true. A quality education

represents hope for success and a way out of poverty. President Obama believes that it is the pathway to a good job and important to the revitalization of the country's economy. The same sentiments can be seen in the Brown ruling, which reveals that education is the most important function of state and local governments and the very foundation of good citizenship. It is pivotal in awakening students to cultural values, preparing them for later professional training, and helping them to adjust normally to their environment. In these days, it is doubtful that any child may reasonably be expected to succeed in life if he is denied the opportunity of an education (Brown v. Board of Education of Topeka, 1954; U.S. Supreme Court ruling on racial segregation in schools).

The Brown ruling was decided over 60 years ago, yet African-American male students still have the worst grades, the lowest test scores, and the highest dropout rates of all students in the country. This is evidenced by the fact that $47 \%$ of African-American male students graduated on time from U.S. high schools in 2008, compared to $78 \%$ of White male students, representing an achievement gap of over 30\% (Jackson, 2012; Schott Foundation for Public Education, 2010). Most educators, researchers and theorists are aware of the lack of educational opportunities available and structural inequality in the educational experiences for children of color (Murrell, 2007). The success rate of African-American students attending public schools, especially those in large urban school districts, is substantially lower than their White counterparts, especially those from White and more affluent backgrounds, according to the National Assessment of 
Educational Progress (NAEP), a congressionally mandated program of the National Center for Education Statistics (NCES). Figure 5 reveals small declines and even smaller gains, interspersed with periods of no change. It implies that disparities in student performance are primarily a result of the shortcomings of minority populations.

However, there is an ongoing debate regarding the reporting of achievement data.

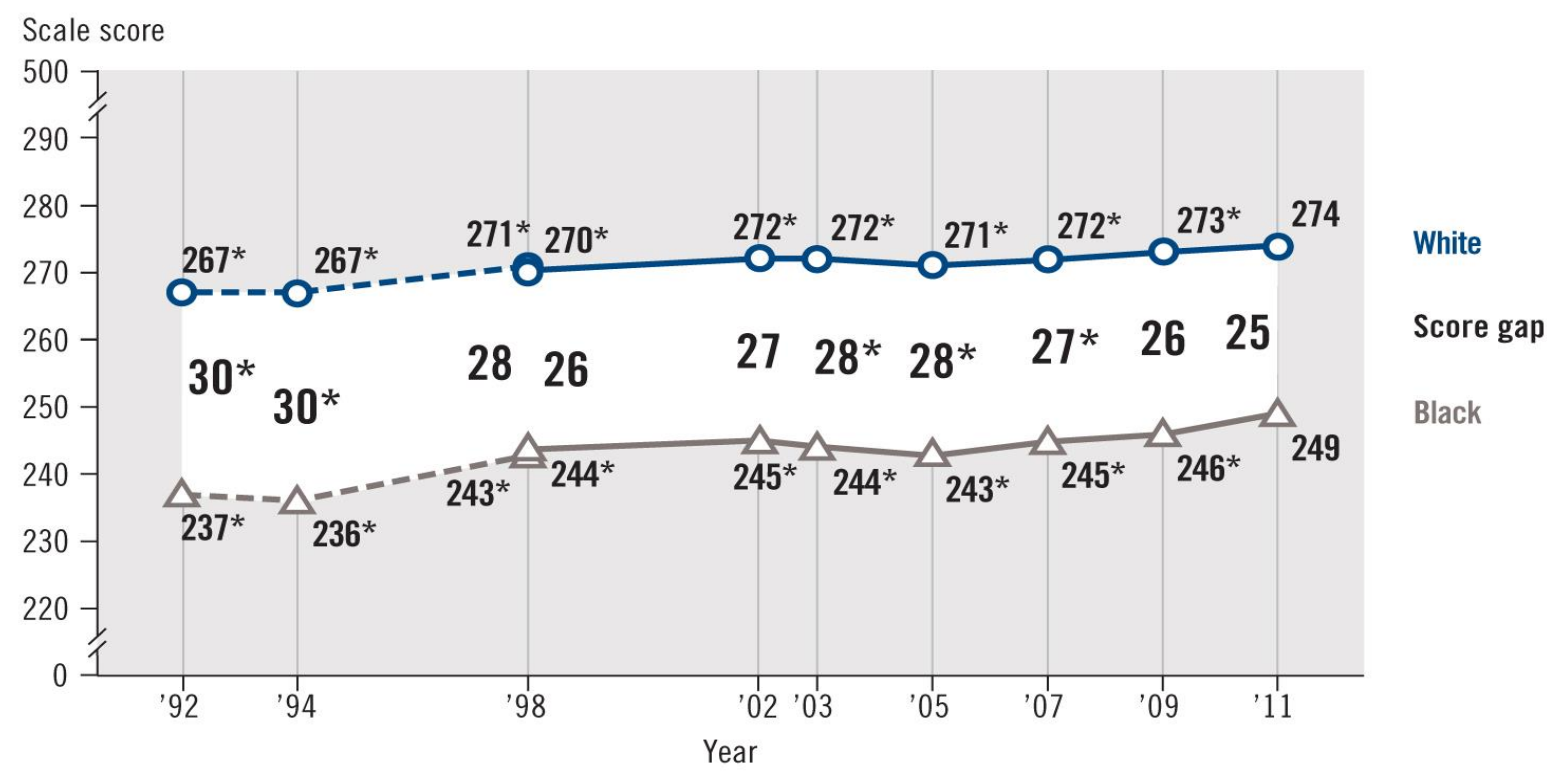

Figure 5. Trend in Eighth-grade NAEP Reading Average Scores and Score Gaps for White and Black Students. Reproduced with permission from NCES (2012).

Gao (2009) disputes this claim and argues that the achievement gap should be reported by factors other than race. She believes that achievement data should reveal socioeconomic status, variations in district funding, the difference in state tests, and percentage of students whose parents attended college, students with books in the home or students who attended public versus private schools. Yet, Maître (2014) argues that the graphic depiction of the achievement gap is accurate and should be used because research indicates that low income, high performing African-American students near the 
top of their classes are continuing to fall behind other high achieving peers by the time they graduate.

Other researchers believe that marginalized students do not benefit from the rewards of academic achievement by simply attending school and believes that increased attention needs to be given to the student's culture and experiences. James Heckman, (2008), economist at the University of Chicago, points to external factors, like parent involvement, as a priori cause of the achievement gap. He posits that the level of parent involvement is far more important than cognitive ability and personality, while noting that one of the real dangers of school success is that the entire burden for lack of achievement gets placed on children's supposed innate abilities and/or motivation. (Murrell, 2007; Delpit, 1995)

Johnny, portrayed in the vignette earlier, has no apparent connection with his teacher, feels inferior, helpless, and powerless. He exhibits low self-esteem and is often ridiculed by his classmates. He is able, however, to regain some semblance of control by acting out. His classroom behavior is an indication that he has disengaged from the learning process and identifies himself as a failure. Despite pleadings from his mother and teachers, he passively resists any attempts at learning, displaying symptoms of "Learned Helplessness", a conditioned response that manifests itself in children who have experienced so much failure in their lives that they simply stop trying. It can also occur when children internalize the fears, low self-esteem, and powerlessness felt by their parents and/or family members. Students like Johnny, who exhibit these behaviors, do not feel that they have any control over their learning, so they either run away from learning or rebel against it. They disengage from learning, become rebellious, and thwart 
any attempts of help or assistance (Gordon \& Gordon, 2006; Seligman, 1993; Lopez, 2011; Pazaki \& Muller, 2012; Rubin, 2012; Segedin, 2012).

Fordham and Ogbu (1986) posit that African-Americans reject certain activities or signs of a perceived proximity to 'Whiteness' and define behaviors not associated with Whites as more legitimate. After the emancipation, African-Americans were expected to assimilate into the dominant culture and adopt the same value system and beliefs as those who previously enslaved them. An oppositional stance to school developed because students believed that education would not lead to social mobility or because successful school engagements require behaviors that were not considered compatible with their race, ethnicity, or class identity. But, Steinberg (2009) argues, by not legitimatizing a marginalized group's way of life, real harm is done to the development of individual identities within a group. NAEP scores remain credible if for no reason other than a reminder of the gulf in academic achievement among African-American and White students.

A number of explanations have been given for the statistically low achievement of African-American males. Many who study literacy problems among African-American children utilize a deficit model focusing on the student, school, classroom, or family. This deficit model makes it appear as if the problem(s) with student achievement lies within the student as opposed to societal issues.

The fact that NCES (2012) data reports that a 25- to 30-point achievement gap between White students and African-American students is the starting point in discussing the issues regarding race, culture, and ethnicity, their impact on education, and other dimensions of social life. African-Americans and Latinos represent a disproportionate 
share of students with low socioeconomic status, so these results are not independent of race (Berliner, 2006).

The student's role in his academic achievement merits examination, and its role is multi-layered. It consists of the student's culture, ethnicity, socioeconomic status, parent's background and education and environment. This role is important because Matsuda (1995) (in Dixson \& Rousseau) believes that we should listen to the concerns of people who have experienced discrimination because they have a special voice or perspective.

Feelings of racial inferiority are developed early in a child's life. Young children may not only be aware of racial differences but in how racialized talk is used in power relationships. An interesting example can be seen in a classroom where a 4-year-old White male told his African-American classmate that he could not take a Whites rabbit home because he was Black. Though the child cried disappointedly, the greater impact was awareness that one's skin color can determine certain rights and privileges (Van Ausdale \& Feagin, 2003).

The use of voice in education research is critical because it helps to convey a person's thoughts, feelings, desires, and experiences. It is the storytelling and counter narratives of critical race theory (CRT) and the interaction between voice and the interpretation of the reader that allows for a critical examination of issues. Listening to the voices of students and comparing common experiences is an essential element in student learning. When student voice is included in decision making, students feel respected, understand that their views are valued, take responsibility for their learning, and generally feel more positive about school. Stories can be used as methodological and 
pedagogical tools to challenge racism, classicism, and sexism as one of the central tenets of CRT is storytelling. This can also be interpreted as the need for personal expression that is best seen through the use of voice. Voice allows for the expression of experiences, a hall-mark of critical race theory. It can be described as the assertion and acknowledgement of the importance of the personal and community experiences of people of color as sources of knowledge (Dei, 2004; Hamilton, 2006; Solórzano \& Yasso, 2002; Dixon \& Rousseau, 2006; McKay, 2010; Strolin-Goltzman, Kollar, \& Trinkle, 2010; Lingis, 2012; Quinn \& Owen, 2014).

CRT scholars Solorzano and Yasso (2002), Delgado and Stefancic (2012), Dixson, and Rousseau (2006), Epstein (2006), Fredrickson (2002), Freire (1974), Gates and West (1997), Gross (2008), Hinchey (2012), Hooks (1994), Jones (2002), Morrison (1992), Murrell (2007), Solorzano (1997), Tuitt (2004), Taylor, Gillborn and LadsonBillings (2009), West (2001), Williams (1991), and Williams (2012) believe and utilize personal narratives as valid forms of evidence in documenting forms of discrimination from a qualitative point of view. Ladson-Billings and Tate (2006) maintain that voice provides an avenue to communicate the realities and experiences of oppressed people, and Delpit (1988) maintains that one of the tragedies of education is in how the voices of people of color have been silenced. Are we responsible for our own learning? If so, to what extent? How important is SES?

\section{Socioeconomic Status (SES)}

Disadvantaged children face a number of challenges to their academic success. Wealthier parents are able to provide more resources and learning opportunities to their children, while children from poorer homes live under more stressful conditions, a 
deterrent to student achievement. There are subtle consequences too: low birth weight that may impair cognitive processing. Wealth, however, is not only monetary; it includes human and social capital. Human capital refers to the skills and knowledge of individuals and is usually based on their education and experience. Parents who have a good deal of human capital pass the knowledge on to their children. Social capital refers to the social and networking connections that individuals possess. Parents with social capital are able to network with people and/or organizations to provide their children with internships, assist them in securing a seat in a more prestigious school, or guarantee that they get a scholarship to the college of their choice (Willingham, 2012).

In a sense, monetary, human, and social capital are related because, if an individual is able to attend college, the chances increase in attaining both human and social capital. For this reason, rather than measuring family wealth, researchers use a composite measure called socioeconomic status (SES). This measure includes income, occupation, and parent's education.

How does this impact education? The American Psychological Association determines that socioeconomic status (SES) is commonly conceptualized as the social standing or class of an individual or group. Families with high SES have the capital to invest in their child's education. Families with low SES deal with more stress, making parenting less effective. Parents with low SES have less time to spend with their children, as in the case of Johnny, which was discussed earlier. Parents with low SES are unable to provide computers, iPads, books or other academic supports like tutors for their children.

Examinations of socioeconomic status often reveal inequities in access to resources, issues related to privilege, power, and control. Wodtke, Harding, and Elwert 
(2011) maintain that children who grow up in poor neighborhoods have a significantly reduced chance of graduating from high school. They also reveal that African-American children who grow up in neighborhoods with high levels of poverty and unemployment have a $76 \%$ chance of graduating from high school, compared to a $96 \%$ chance for African-American students living in more affluent neighborhoods. White children living in low-income neighborhoods have an $87 \%$ chance of graduating high school compared with a 95\% high school graduation rate for Whites children living in affluent neighborhoods. The study by the Annie E. Casey Foundation reports that children who both live in poverty and read below grade level by third grade are three times as likely to not graduate from high school as students who have never been poor (Chang, Park, Singh, \& Sung, 2009; Hernandez, 2011;Knickerbocker, 2011; Raby, 2012; The Hispanic Outlook in Higher Education, 2012).

African-American males, especially those of low socioeconomic status, could be affected by latch-key, at-risk behaviors, sexual activity, media addiction, and a lack motivation in school. Malnutrition and other dietary deficiencies are probably more common in impoverished homes than in working or professional class homes. Dangerous social conditions, especially with the threat of violence, create a condition that requires the male learner to protect himself through gangs and other groups. Other factors that affects student agency are friends with the same parental/economic background. These are issues that are imprinted on a student socially and emotionally and impact his ability to learn (Carter, Hawkins, \& Natesan, 2008; Jones \& Gall, 2009; Rothstein, 2014). 


\section{CHAPTER III}

\section{METHODOLOGY}

Qualitative research provides a framework for understanding how societies work, why people react in certain ways, and/or how organizations operate. It is a lens to examine social issues or other complicated problems by focusing on different aspects of data and providing a framework in which analysis can be conducted. This study employed critical analysis to examine sociocultural and educational factors that impact African-American male student achievement. It examined critical factors and processes that impacted student achievement from the perspectives of adolescent males ages 13-17.

Critical inquiry as the design methodology served to develop a form of cultural criticism that revealed the power dynamics within social and cultural texts. It allowed for the exploration of socially constructed inequities that affected their academic life. It enabled the researcher to highlight social injustices, examine social and political realities, and challenge prevailing conditions as to how issues of power, position, and privilege are often disguised by using student responses to make sense of the data in a way that can be understood. This research was achieved first by interpreting the text, then telling its story in relation to its context. Researchers who use this approach are primarily interested in examining and challenging the status quo and the dominant constructions of reality and power relations that produce inequalities in ways that can lead to marginalization. More specifically, Critical inquiry was important as a methodological approach focusing on an 
examination of public phenomena in American education (Kincheloe \& McLaren, 2011; Coffey \& Atkinson, 1966; Creswell 2009; Kuby 2013). One of the most important aspects of Critical inquiry methodology is couched in the domain of interpretation (Duncan \& Watson, 2004; Kincheloe \& McLaren, 2011) and focuses on the reflective reconstruction of experiences by giving and receiving feedback.

This study investigated the relationship of power as it relates to the role and purpose of schooling through the process of interview. Qualitative research interview is a strategy, purposed to gather descriptions of the life-world of the study participant with respect to interpretation of the meaning of the described incidents. The main task in interviewing is understanding (interpreting) the meaning of what research participants say (Kvale 1983, 1996).

A research design determines how a study will answer [the] research question(s). This study employed Critical inquiry as its research design. Critical inquiry draws from other theoretical orientations, i.e., Feminist Theory, Neo-Marxism, and Post-Colonial theory. Critical Theory, a form of qualitative research, is historically and culturally situated and concerned with issues of power and justice. These issues are often camouflaged by rules, policies, or accepted routines. Critical inquiry, a methodology used in critical theory, allows for an in-depth examination of the issues of student achievement. It is an attempt to expose the inequities that confront the participants in this study (Horn, 2000; Kincheloe, 2001; Grinberg, 2003).

The meanings behind critical thinking, critical inquiry, and problem-solving have long been the subject of debate. Critical thinking and critical inquiry are used almost interchangeably, but do differ. Critical thinking tends to draw on a philosophical tradition 
of logical reasoning. It focuses on problem-solving, reasoning, and higher order thinking skills. Critical inquiry draws on critical and social theory for its rationale. Critical and social theory examines aspects of social life to uncover long-held assumptions about marginalized groups of people. Lathner (2004) asserts that critical inquiry is taking into account how our lives are mediated by systems of inequity, such as classism, racism, sexism, and heterosexism, and adds that education theory is primarily based on issues of power and its distribution. Moreover, Gildersleeve, Kuntz, Pasque, and Carducci (2010) describe Critical inquiry as a methodological approach focusing on an examination of public agenda phenomena in contemporary American education.

Why critical inquiry? There is no panacea for analyzing information transmitted by language and behaviors in daily life. Critical inquiry techniques like interviews, surveys, or observations can be used to 'reach lived parts that other methods cannot reach.' Critical inquiry researchers recognize that reality is a subjective experience. They are more concerned about uncovering knowledge about how people think and feel about the circumstances in which they find themselves than they are in making judgments about whether those thoughts and feelings are valid (Berkwits \& Inui 1998; Thorn 2000). Critical inquiry was crucial to this research because its purpose was to examine the sociocultural and educational factors that impact student achievement. The epistemological view is based on the fact that knowledge is personal, subjective, grounded in culture and experience (Lathner, 2004). This critical inquiry focused on reflection, interpretation and transformation featuring in-depth interviews of six adolescent males through a series of three interviews. 
I collected data from six African-American adolescent males to uncover the story behind their experiences. In each interview, I included opportunities for follow-up and clarifying questions.

Data were analyzed through a process of identifying themes, coding, categorizing, and connections to education. Recognizing that the researcher is also a filter, a fourth interview was added to provide clarification of interpretation, and a fifth and final interview was scheduled with the entire study group to highlight emergent themes for further analysis based on the following research question: What are the perceptions of agency, teaching and learning environments, motivation, engagement and support systems on the academic achievement of six African- American males ages 13-17?

\section{Literature Supporting the Design}

A number of studies have cited the use of Critical inquiry both as an interpretive research methodology and a classroom strategy. As a research methodology, Critical inquiry examines the roles of force and power in social phenomena and in doing so provides for both causal and interpretive explanations (Packer, 2011). Because it examines existing assumptions, knowledge, and the questioning of assumed 'truths', it can be used to focus on elements of reflection by connecting new to existing experiences. As in most examples of post-positivist research studies, this methodology involves interviews and narrative re-telling in the presentation of findings, along with researcher reaction and reflection in the light of the inquiry's lens (Lathner, 2004).

This approach can also be used as a classroom strategy to examine power relations that produce inequalities that can eventually lead to advocacy and community action, (Jennings \& Smith, 2002; Suthers, 1997; Wright, 2004). Preliminary research 
suggests that young children are curious about power, its structures and unfairness (Comber, 2003; Goss, 2009). This research design mimics the traditional scientific method by allowing the teacher, student or researcher to identify a problem, propose solutions, find evidence for or against, and evaluate solutions based on evidence. Critical inquiry has been used as a teaching approach to help children to identify inequities in society by reading books about social issues that spark discussions and in developing questions about their surrounding community. It examines how power, position, and privilege impact the relationship that children have with their peers, teachers, and other adults (Kuby, 2013). The process helps children uncover and examine realities and learn not to simply accept them without thinking of their effect on people and peoples (Comber \& Stinson, 2001; Kincheloe, 2005, in Kuby 2013).

Additional evidence of the usefulness of this design is found in Manfra's (2009) study that described how teacher researchers used Critical inquiry to effect change in their social studies classrooms. It presented four portraits of experienced social studies teachers engaged in critical teacher research. The teachers asked critical questions about schooling and engaged their students in conversations. They used Critical inquiry to analyze classroom data and voiced new understandings. The teachers were reportedly transformed by the research and noted that they developed a heightened awareness of issues of race and ethnicity and worked as advocates for their marginalized students.

Research studies also indicate that Critical inquiry can be a useful tool for teachers of English as a second or foreign language. Language is embedded in social and political issues. Language is considered to be a socially constituted cultural construct that is shaped by, a larger social, political, and historical context of its use. Critical inquiry 
provides opportunities to question people, language, power, lifestyle, morality, and ethics about who are advantaged or disadvantaged according to the mores in society. The work of Elsa Auerbach and Nina Wallerstein with adult immigrants is a well-known example of this type of pedagogy implemented in teaching English as a second language-TESL context (Comber 2001).

There is no single or correct method to use Critical inquiry, as it is an attempt to derive data critically, through in-depth examination. Critical inquiry allows for a design to evolve rather than attempt to fit a generic paradigm. It is difficult to predict the direction of a study beforehand due to the varied perspectives and values systems of the researcher and participants, and the influence on the interpretation of reality and the outcome of the study. For the purpose of this study, Critical inquiry was employed to investigate the meaning of the lived experiences of six adolescent African-American males regarding their academic achievement. It employed the following tenets: Critical Reflexivity, interpretation, and transformation.

\section{Critical Reflexivity}

Critical Reflexivity is a type of self-reflection that involves the development of an awareness of one's own identity and awareness of economic and social structures of oppression. Reflection involves the exploration of values, attitudes, and personal history. Examining personal biases and prejudicial attitudes, particularly when one is learning about and working with different identity groups, necessitates a process of change. In Critical inquiry, reflexivity demands that the researcher evaluate how his/her belief system, behavior, speech and methods of interacting with others might contribute to biases or discrimination against people from marginalized groups. The goal is to 
recognize, identify, and correct behaviors and attitudes that may impact data collection, analysis, and results (Kondrat, 1999, in Self Awareness, Critical Awareness and Reflexivity, 2008).

Critical Reflexivity is characterized by looking at both the data collected and the impact of the researcher (RECOUP, 2008). Central to conducting research is to view the researcher as a research instrument (Denzin \& Lincoln, 2000; Marshall \& Rossman, 1995, in Chenail, 2011). Critical reflexivity examines the subjective experiences and perceptions of individuals from their own perspectives. However, it is through the researcher's facilitative interaction that a context is created where participants share personal data regarding their school and life experiences. The researcher facilitates the flow of communication, identifies cues, and sets respondents at ease (Poggenpoel \& Myburgh, 2003, in Chenail, 2011)

\section{Interpretation}

Interpretation involves the ability of a researcher to interpret elements of interview data by integrating human interest into a study. Accordingly, interpretive researchers assume that access to reality (given or socially constructed) is only through social constructions, such as language, consciousness, shared meanings, and instruments (Myers, 2008). Researchers interpret the meaning of objects and actions from the data, and then analyze them according to the research questions. Interpretation draws meaning from data. It allows the researcher to identify similarities across multiple instances of data. It gives the researcher a broader scope to address issues impacting marginalized groups. It allows one to ask questions as to why and how (Denzin, 1998; Bernardo, 2012). 


\section{Transformation}

Transformation is a two-way process of change in character, form, appearance, or substance. It is based on the ideology of human rights and the belief that personal power can be obtained through collective problem solving and action. Educational transformation is pivotal to any process of change within an existing group or organization. However, transformation cannot begin until it is understood that change is a process that directly involves the participant.

A part of this process includes a challenge to established definitions of power, the introduction of the language for change, and the role of the participants. Together, each of these aspects of the process of education for change must be addressed for transformation to occur. Reynard and Freire (1970) and Duncan and Watson (2004) talked of the importance of engaging the experiential reality of the individual learner in the process to achieve a transformative learning experience for the individual and society as a whole. Transformation is precipitated by critical inquiry, promoted by praxis, motivated by the desire to grow on a personal level and the acceptance of certain assumptions.

\section{Assumptions of Critical Inquiry}

For the purpose of this study, the researcher adopts these assumptions borrowed from Rossman and Rallis (2003) who believe that critical inquiry relies on the following assumptions believed to be relevant to the study of student achievement.

1. Research fundamentally involves issues of power. Critical research theorists concerned with societal injustices and inequalities primarily directed on oppressed peoples contend that unequal power relationships exist that result in the marginalization 
of non-Whites. It includes relationships between teaching and learning in a continuous process of "unlearning", "learning", and "relearning", "reflection", "evaluation", and their impact on students, particularly those that have been historically marginalized and continue to be disenfranchised by what may be deemed "traditional schooling". This is evident especially in institutions like schools, where only Eurocentric knowledge is legitimatized, thereby perpetuating the status quo (Giroux, 2011; Apple, 2012; Hooks 1994; Freire, 2000; McLaren \& Kincheloe, 2007).

2. Research reports are authored by a gendered, classed, and politically-oriented individual(s). A good deal of culturally produced, socially supported research shapes and guides social mores and actions. They perpetuate beliefs and attitudes that foster social order based on the needs of the dominant population to the exclusion of existing races, cultures and ethnicities as seen in the inequities of school funding.

Researchers in this field posit that the design of state funding fails to provide the necessary supports or resources to areas of greater need. Designs such as allocations for student attendance are impacted by average daily attendance, rather than number of students enrolled result in decreased funding because schools in high poverty areas tend to have lower attendance rates. These same districts also have lower property values, which reduces budget allocations and local property taxes.

\section{Race, class, and gender are crucial for understanding education and social}

experiences. Traditional education involves people teaching people. Consequently, every aspect of the teacher and student's experiences and mental make-up become important factors in this process. Therefore, issues of race and class are critical variables in how education is transmitted and received (UK Essays). Additionally, acknowledging that 
males and females learn and develop differently is essential to effective teaching and plays a powerful role in the schooling process. Since classrooms are microcosms of society, socialization patterns are reflected in the classrooms (Marshall, 1997, in Chapman, 2014).

While education should ideally be untouched by race, class, or gender, it is an unreal expectation. Our world is defined by these elements and so our educational processes should factor these in when developing policies and practices. The time has come to critically examine our concept of schools and schooling. Critical inquiry enables one to examine inequality and justice; areas within our schools that can be subtle and covert. To not acknowledge the role of race, gender, and social class in our schools and society can only be summed up in this old adage: If we keep doing what we've done; we'll keep getting what we've gotten.

\section{Historically, traditional research has silenced members of oppressed and/or} marginalized groups. Traditional research has always pertained to gathering knowledge. The primary role that traditional research assumes emphasizes the voice of the researcher, not the voice of the person. This research breaks from the traditional research on student achievement, by including the perspectives of adolescent African-American males into the discussion (Gildersleeves, Kuntz, Pasque, \& Carlucci, 2010; Rossman \& Rallis, 2003; Tortoriello, 2009).

This study examined the academic experiences of African-American males using Critical inquiry as the research design. It investigated the relationship of power as it relates to the role and purpose of schooling and history. Freire (1970) believes that we must be aware of the conditions of their worlds and how they are shaped by them. He 
maintains that beliefs are shaped by discussion and critical reflection. Without this, we would have no access to the way they think and can only guess at what they perceive as truth. Learning is not simply about the transmission of knowledge, but about the meanings constructed through the activities of learners as they engage/interact with their environment (Wright, Macdonald, \& Burrows, 2004). Critical inquiry is a way to interpret and explain human action and thought.

Critical inquiry research can be performed using case study, interviews, questionnaires, surveys, participant and direct observation (Trochim, 2006). Because this study focused on student achievement and education, the interview was most appropriate strategy to address the research question. There have been a plethora of studies on schooling, yet, very little of it involves the perspectives of the students, their values, or perceptions (Seidman, 2013).

\section{Research Design Procedures}

This research design examined subjective data using standardized, open-ended interviews. Interview was most appropriate strategy to address the research because it was structured to focus on student achievement and education. Critical inquiry is an effective tool because within the teaching and learning relationship, the question of power and authority is paramount. This design compelled the researcher to ask questions and, upon coming up with an answer, question those answers in an effort to get more clarity (Trochim 2006; Hooks, 2003; Lathner, 2004; Seidman, 2013).

\section{Methods of Data Collection and/or Field Procedures}

This research utilized Critical Case Sampling to identify six student participants. Critical Case Sampling is an effective process to use when data are to be collected from a 
small population. It allowed the researcher to:

- identify problems that can be logically generalized,

- collect in-depth information, and

- build broad themes or patterns to formulate categories or instances that impact student achievement.

The adolescent males participate in a mentor program in Chicago. There are between 30 and 40 young men registered in the program, but only 6 were needed for the study. The 6 study participants were identified through random sampling to assure that each individual had an equal probability of being selected. The sampling number was determined by the final number of interested students, which allowed for a representative sample of the population (Creswell, 2009; Sparrow \& Sparrow, 2012) African-American males were selected because the research was gender and race specific.

The protocol for the interview was designed so that each participant was asked the same question regardless of follow-up. The protocol included an ice-breaker to help the participant relax, followed by the interview questions, subsequent follow-up and thank you statement (Creswell, 2009).

The researcher used a directive style of interviewing that allowed for the freedom to control pacing and subject matter and recorded the information from the interview by using an audio recording and observed participant reactions using hand-written notes.

\section{Interviews}

There were three interviews for each participant, most lasting approximately 30 minutes. The first interview focused on the participant's life history. The second interview added follow-up questions from the first interview then focused on their 
experiences attending an urban school. The third interview focused on how the experiences reported from the second interview impacted their academic achievement.

The study used standardized, open ended, face-to-face interviews. Standardized open-ended interviews are the most popular form of interviewing utilized in research studies because the nature of the open-ended questions allows participants to fully express their viewpoints and experiences. These face-to-face interviews allowed the researcher to get the story behind the participant's experiences and pursue in-depth information around the topic. Participants were asked identical open-ended questions (Gall, Gall, \& Borg, 2003). This technique allowed the participants to contribute as much detailed information as they wanted and provided opportunities to ask follow-up and/or probing questions as a means of clarity.

This model was applicable to this study because it sought answers regarding the role that the participant played in his own agency, its interpretation, and the impact of school curricula critical in an examination of student achievement. The face-to-face interview strategy used in this study gave the researcher an opportunity to go beyond simple questions to explore the experience of the participants.

Kvale (1996) reminds us that interviews help to understand experiences from the subject's point of view and uncover their meaning. They also allowed participants an opportunity to describe everyday experiences from their own perspective, in their own words through conversations with structure and purpose, defined and controlled by the researcher. Van Manen (1990) in Seidman (2013) maintains that we can only get to a participant's experiences through reconstruction. Although the research interview may not lead to objective information, it captured many of the subject's views on his school 
experiences. Interview was also vital to this study because it represents a social situation between two persons, the interviewer and participant. This method is a good technique for getting information that can be emotionally layered, as it allows for:

- direct conversation to take place in a safe setting.

- is adaptable to the person or situation

- allows for immediate follow-up or clarification

- required only an audio recorder. (Data collection posted in research methodology)

The following processes and procedures were utilized: participants, setting, interview, data collection, data analysis, and follow-up.

\section{Participants}

This study utilized adolescent African-American males ages 13-17. This age was important because:

- Adolescent teens make more of their own choices about school and how to perceive the world around them.

- Adolescent teens have a stronger sense of right and wrong and are better able to express feelings by talking.

- Adolescent teens are able to express their concerns and discuss issues that affect them.

- Adolescent teens 13-17 represent a category with the highest number of underachievers 


\section{Setting}

Research was conducted at the participant's mentee meeting location or local public library when the mentee location was not available. Due to the nature of the study, the familiarity of the meeting location increased the comfort level and allowed the student to respond to questions without fear of any embarrassment, possible retaliation or embarrassment from parents or peers. At the mentee location, interviews were conducted in separate rooms; at the public library, the researcher requested the use of one of their meeting rooms to preserve privacy. An audio recorder was the only equipment used.

\section{Follow-up}

The review of audio recordings was used to develop secondary or tertiary followup questions for use during the student interviews. These follow-ups provided insight and direction regarding interview questions used during data collection. They also provided an opportunity to explore the participant's thinking process regarding how they solved problems and how they decided on the appropriate solution.

\section{Member Checks}

Member checking is a technique used to establish the validity of qualitative data e.g., interviews. These checks are used when data, interpretations, and conclusions are tested with members of the groups from whom the data were originally obtained (Cohen, Crabtree; 2006). All six study participants were given an opportunity to review interview transcripts before the next interview began. Although they appeared intrigued at the interview transcript, they offered no changes to its interpretation. 


\section{Data Analysis}

Creswell (2013) posits that data analysis involves making sense out of text. This involves preparing data for analysis, moving deeper into the analysis, and making an interpretation based on the results of the data by collecting open-ended data as a result of the interview responses.

Analysis utilized the following steps:

1. Organize and prepare data for analysis. This step involved transcribing interviews, integrating research notes, and looking for common themes.

2. Read through all of the data. This allowed the researcher to get a general sense of the data, tone, and overall impression as it relates to the research questions.

3. Begin detailed analysis with the coding process. Coding is the process of organizing the material into common themes to interpret its meaning (Creswell 2013).

\section{Coding}

Coding is a process of organizing material into segments to interpret meanings. It is the critical link between data collection and data analysis (Charmaz, 2001). Detailed information obtained as a result of participant interviews were arranged into categories according to agency, critical pedagogy, and culturally and socially relevant curricula. Coding is necessary when interpreting qualitative information, such as interview data, whose effectiveness is dependent on the filter (lens) that is used. Categories were organized into patterns according to their relevance to the research questions.

Critical inquiry requires that interview data are examined from a variety of analytic lens. Data were coded utilizing the following coding filters: descriptive/ In 
Vivo, values, axial, and causation.

Descriptive coding is the foundation for qualitative inquiry. It helps the reader to see the action being described as it was told during the interview. Descriptive coding is often referred to as topic coding. It forms a summary description of the interview transcript and is appropriate for literally all qualitative studies, particularly the interview process. Descriptive coding is also useful in documenting field notes and or other artifacts as a detailed inventory (Saldana, 2013). In Vivo coding uses a student's own words for the summary.

Values coding assesses the participant's values, attitudes, and belief systems. Beliefs are embedded in the values that are attached to them. A value is the importance that we attribute to a person, someone else or a thing. Value coding is important to this study because it allows a researcher to examine cultural values, identity experiences and actions of study participants (Saldana, 2013).

Causation coding is designed to uncover what people believe about events and their causes. A cause is an explanation for an attitude or behavior (Bachman, 2006). The goal of this technique is to locate, extract, and infer causal beliefs from qualitative data; in this case, interviews. Causation coding is not about how, but why a person's beliefs came about, its attribution (Saldana, 2013). An attribution is an expression of the way a person thinks about an outcome and can consist of an event, characteristic, or action (Munton et al., in Saldana, 2013).

Axial coding makes connections between categories by determining which codes are dominant and which are not. It relates categories to subcategories by referring to components such as context, conditions or consequences, or actions that assist the 
researcher in understanding when, what and how something happened. It reorganizes the data set by omitting redundant codes and synonyms leaving the researcher with the best selection of representative codes (Boeije, 2010; Charmaz, 2006; Glaser \& Strauss, 1967; Strauss \& Corbin, 1988, in Saldana, 2013).

It is important that the researcher considers their influence on the participant and the analysis, to present an accurate and realistic account of the participant's position. It is virtually impossible for a researcher to examine and interpret interview data without an understanding of the participant's culture, experiences, and values. McCracken (1988) describes the researcher as an instrument and, in this sense, secondary to the participant because it is the researcher's responsibility to categorize and code interview data. Research bias, also called experimenter bias, is a process where the investigator, performing the research, unknowingly influences the results in order to portray a perceived outcome.

\section{Researcher Bias}

Researcher bias is a major challenge for qualitative researchers who use interviewing as the primary data collection method in their studies. In qualitative data the researcher can be considered a filter and may impact interview data consciously or unconsciously by influencing the participant, by body language, types of questioning, interview schedule, existing relationship with the participant, or pre-existing ideas about the findings. In Critical Reflexivity, the researcher must practice self-reflection (RECOUP, 2008). This is important because, in an investigation of student achievement, it helps to anticipate problems or unseen difficulties that may appear. 
To uncover materials and generative themes based on their emerging knowledge of students and their sociocultural backgrounds, the researcher must understand the ways students perceive themselves, their interrelationships with other people, and their social reality. This information is essential to the interviewer because it helps to understand how participants make sense of schooling and their lived world. It is with these understandings in mind, that the researcher understands what and how students make meaning. This information enables the researcher to construct interviews that engage students to discuss their experiences (Freire \& Faundez, 1989; Kincheloe \& Steinberg, 1998). It is important that any researcher considers their influence on the participant and the analysis, and that they present an account of their position so readers are able to follow the thought process and subsequent analyses. As a result, a fourth meeting (member check) was scheduled with each participant to review the interview data and intended interpretation. 


\section{CHAPTER IV}

\section{ANALYSIS OF DATA}

This study examined some of the factors related to the academic achievement of African-American males ages 13-17. The purpose of this research was to examine educational and socioeconomic factors that contributed to the academic performance of urban African-American (AA) males using the theoretical framework of critical race theory.

The research question for this study asked: What are the perceptions of agency, teaching and learning environments, motivation, engagement and support systems on the academic achievement of six African- American males ages 13-17?

Critical inquiry employed as a research methodology reveals the power dynamics within social and cultural texts. It allows for the exploration of socially constructed inequities that affect a student's academic life. Critical inquiry enables the researcher to highlight social injustices, examine social and political realities, and challenge prevailing conditions as to how issues of power, position, and privilege are often disguised by, in this case, using student responses to make sense of the data in a way that can be more easily understood.

\section{Statement of the Problem}

As referenced in Chapter II, data indicates that males consistently receive lower grades than females, averaging a range of $1 \frac{1}{2}$ years behind in reading and writing. But 
the academic achievement gap between African-American students and their White counterparts continues to be one of the most troubling educational issues in our country.

This research focused specifically on the impact of gender, race, social justice, and equity on the academic achievement of African-American males between the ages of 13 through 17 by interviewing adolescent African-American males in regard to their school experiences, analyzing their responses, and looking at similar themes. This age range was targeted because, within this context, individuals develop values that are personal and significant according to how they make sense of life experiences. These perceptions, gathered through the student's own voices, allowed us to get a realistic view of the issues that they identified concerning their views of school and schooling.

Data were primarily collected at Metro Station (a pseudonym) in Chicago, Illinois, because students were familiar with the location and met there monthly for mentor meetings. Metro Station is a not-for-profit organization with a dedicated focus on public service targeting the African-American community. Since its founding, Metro Station has been at the forefront in creating programs to improve the political, educational, social, and economic conditions of African-Americans. Participants were selected from one of the organization's varied programs where students attend a variety of schools in the Chicago area and participate in monthly activities, recreational outings, and book talks with an assigned mentor.

Metro's president was asked for permission to distribute a letter to program mentees about participating in a study that would examine the academic achievement of adolescent African-American male students. After receiving the president's consent, letters were distributed. Twelve students responded to the invitation, but only six were 
needed for the study. The six study participants were identified through random sampling (Creswell, 2014) to assure that each individual had an equal probability of being selected.

Table 1

Characteristics of the Program Participants

\begin{tabular}{|c|c|c|c|c|c|c|}
\hline Participant & Age & Grade & $\begin{array}{c}\text { \# of } \\
\text { Parents in } \\
\text { the home }\end{array}$ & School Type & $\begin{array}{l}\text { Single Gender } \\
\text { or Co-ed School }\end{array}$ & Future Plans \\
\hline Hawk & 14 & 8 th & 2 & Public & Co-ed & $\begin{array}{l}\text { To attend } \\
\text { college or-play } \\
\text { in the NFL or } \\
\text { NBA or } \\
\text { become a chef }\end{array}$ \\
\hline Kane & 13 & 8 th & 2 & Charter & Single Gender & $\begin{array}{l}\text { Go to college } \\
\text { major in } \\
\text { computer } \\
\text { science or } \\
\text { engineering }\end{array}$ \\
\hline Kent & 16 & 10th & 2 & Charter & Single Gender & $\begin{array}{l}\text { Go to college- } \\
\text { become a } \\
\text { better person }\end{array}$ \\
\hline Josh & 17 & 11 th & 1 & Charter & Single Gender & $\begin{array}{l}\text { Go to college if } \\
\text { awarded a } \\
\text { scholarship; if } \\
\text { not, go to a } \\
\text { junior college }\end{array}$ \\
\hline Xyan & 16 & 10th & 1 & Public & Co-ed & $\begin{array}{l}\text { Go to college if } \\
\text { awarded a } \\
\text { scholarship; if } \\
\text { not, become a } \\
\text { boxer or } \\
\text { policeman }\end{array}$ \\
\hline Noah & 16 & 12 th & 2 & Public & Co-ed & $\begin{array}{l}\text { Go to college } \\
\text { become a } \\
\text { software } \\
\text { specialist }\end{array}$ \\
\hline
\end{tabular}


Study participants ranged from 13 to 17 years of age and attended charter as well as public schools in and around the city of Chicago. All grade levels represent their current grade status at the time of the initial interview. Most participants came from twoparent homes, all parents/guardians were gainfully employed, and most had other siblings in the home. The original intent was to interview each student three times followed by a transcript review. The fourth filter, a member check, allowed the participant to review his interview responses for accuracy. The fifth and final interview was to be a group discussion of the study questions to add or delete any information that did not appear relevant or to focus on areas that they felt was important. As a result of their school and social schedules, this group interview did not take place.

\section{Data}

The steps in the analysis of data were:

- Collect data

- Transcribe and interview data

- Review by research question

- Review by study questions

- Review for descriptive/In Vivo coding

- Review for values coding

- Review for causation coding

- Review for axial coding

- Review for emerging themes 

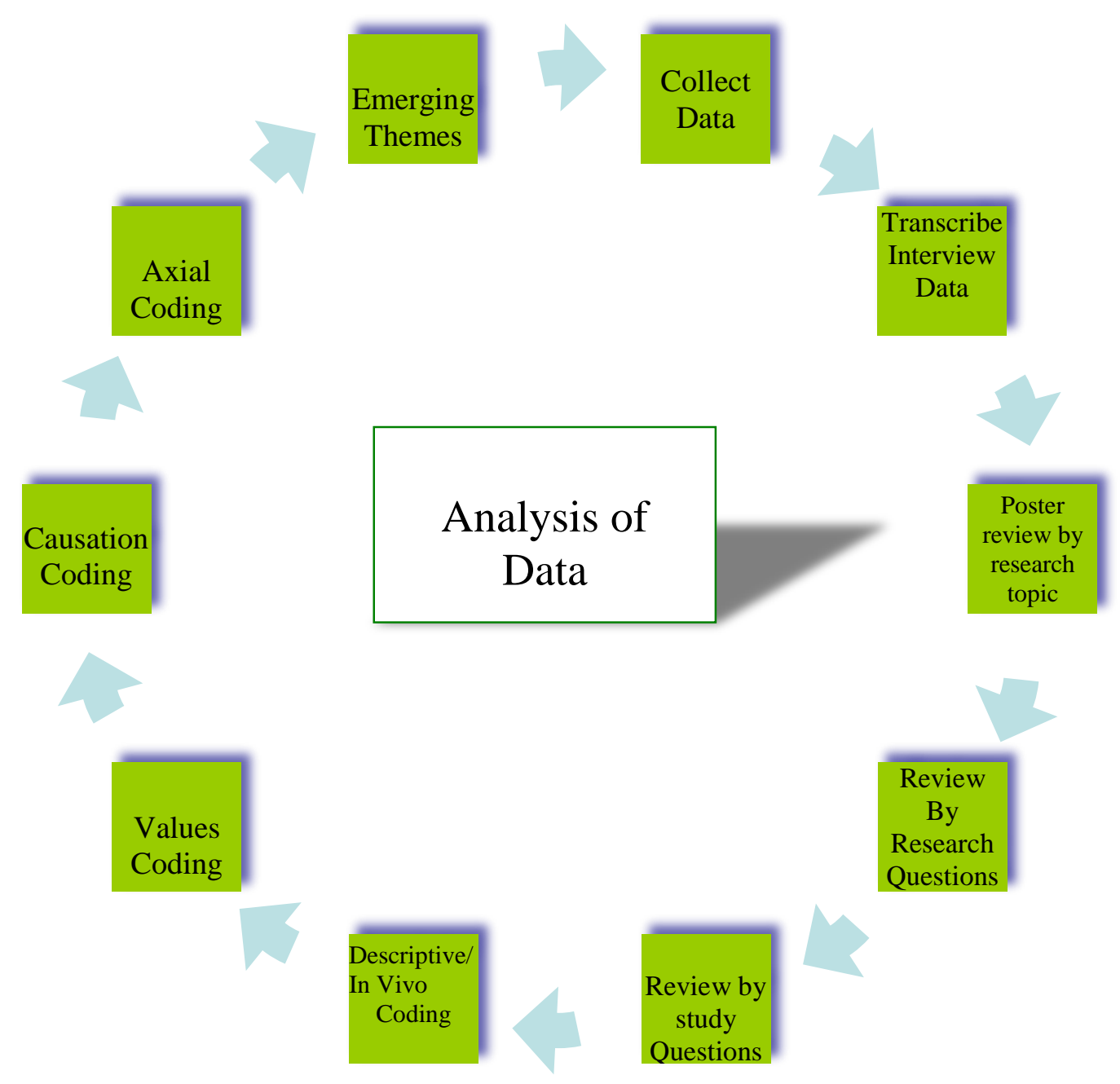

Figure 6. The Process Used to Identify the Study's Emerging Themes

This analysis began with the collection of interview data that was transcribed and reviewed by each study participant. Transcribed data was color coded by research question topics, then transferred to poster paper. The data underwent a series of filters that began with a review by research question components, study questions as they relate to the research question components. Coding began with a descriptive summary of the participant's interview using an In Vivo coding process (student's own words), followed 
by values, causation, and axial codings that produced five broad areas of concern.

Data collection began in June of 2014 at Metro Station. When access to Metro Station was not possible, interviews were held at several public library locations in or near the students' neighborhoods for flexibility in student scheduling. Interviews were constructed using Seidman's three interview series (Seidman, 2013).

The interviewer's task is to put the participant at ease to help him relate as much information as possible about his academic life and experiences. As a result, during the first interview the researcher included information about sports or other things that interested the student as a way of getting to know the participant.

The second interview concentrated on more concrete details of the participant's school life. It probed for values, beliefs, and his interpretation of his role as a student. Follow-up questions from the first interview were added before the second interview questions were asked. The third interview focused on how the experiences reported from the second interview impacted academic achievement. It probed for goals and future plans in regard to education and career. Member checks were scheduled after each interview.

Data collection was carried out over a sustained 5-month period from June to November 2014. Audio tapes were transcribed and corrected to begin analysis. Data was divided into three segments for analysis: data condensation, data display, drawing and verifying conclusions (Miles, Huberman, \& Saldana, 2014). Data condensation, the first step in the analysis, refers to the process of simplifying field notes from interview transcripts, which aids the researcher in determining which 'chunks' help to tell the story. Data display, the second step in the process, allows the researcher to organize 
information in an organized manner. Participant interviews were grouped in a compact chart to help the researcher get an understanding of how the students interpreted their views and the areas that appeared most important (see Table 2). Drawing and verifying conclusions, the third step in the process, interprets what things mean. This interpretation was carried out using a series of four coding filters: descriptive/In Vivo, values, causation, and axial.

Table 2

Data Analysis by Research Questions

\begin{tabular}{|c|c|c|c|c|}
\hline $\begin{array}{l}\text { Research question: What are the } \\
\text { effects of agency, teaching and } \\
\text { learning environments, motivation } \\
\text { and engagement and support } \\
\text { systems on student achievement? }\end{array}$ & Agency & $\begin{array}{l}\text { Teaching } \\
\text { and learning } \\
\text { environments }\end{array}$ & $\begin{array}{l}\text { Motivation } \\
\text { and } \\
\text { engagement }\end{array}$ & $\begin{array}{l}\text { Support } \\
\text { systems }\end{array}$ \\
\hline Interview 1 & 7 & 2 & 1 & 0 \\
\hline Interview 2 & 1 & 7 & 0 & 2 \\
\hline Interview 3 & 4 & 7 & 1 & 3 \\
\hline Totals & 12 & 16 & 2 & 5 \\
\hline
\end{tabular}

Codes are labels that are attached to 'chunks' of data; words or phrases that symbolically assign some type of attribute to language based data (Saldana, 2013). The data consists of using interview transcripts to assign meaning to the text for later analysis. Interviews were transcribed after each session to allow for follow-up or clarification. Data were first analyzed by research questions that had been color coded. Question one asked about the effect of agency on student achievement and was coded yellow. Question two, coded green, inquired if teaching and learning environments impact academic achievement. Question three, coded turquoise, asked about the effect of 
motivation and engagement on student achievement. Question four, coded fuchsia, asked if support systems affected student achievement.

Once data had been summarily coded by research question, study questions were reviewed to see how they related to the research question by interview (see Table 2). The intent of this analysis was to begin to delineate some of the themes that would emerge according to the filters. This review indicated a plethora questions regarding the impact of teaching and learning environments and the effect of agency comprised the bulk of my queries. This is probably indicative of researcher bias focusing on my years as a teacher and administrator.

The next process was to code using descriptive and In Vivo processes. To begin the analysis, a descriptive/In Vivo summary was assigned to the interview transcript that described the basic topic of the passage. A descriptive code is summarized data by words or short phrases. In Vivo coding uses the participant's own words in a summary. In Vivo coding is usually reserved for grounded theory, but was used here because it honored the participant's voice (Miles, Huberman, \& Saldana, 2014).

The next step in the process was to determine what the participant valued. Values coding assesses the participant's values, attitudes and belief systems. Beliefs are embedded in the values that are attached to them. A value is the importance that we attribute to a person, someone else, or a thing. Value coding was important to this study because it allowed the researcher to examine cultural values, identity experiences, and actions of the study participants (Saldana, 2013).

Once we assess one's belief system, we may begin to question why these beliefs came to be. Causation coding (Bachman, 2006) is designed to uncover what people 
believe about events and their causes. A cause is an explanation for an attitude or behavior. The goal of this technique was to locate, exact and infer beliefs from qualitative data, in this case, interviews. Causation coding is not about how; but why a person's beliefs came about - its attribution. An attribution is an expression of the way that a person thinks about an outcome and can consist of an event, characteristic, or action (Saldana. 2013). It is not only important to know one's action, but to know how that action came to be; this is the only way that we can interpret its meaning. As a result, causation coding was used as the sixth filter.

The seventh and final filter involved examining the previous codes for similarities. This process, known as axial coding, served to compare, reorganize and focus codes into similar groups to formulate categories for further analysis. Data was reviewed, coded, and categorized, which led to the development of 10 general categories that interpreted the views of the participants. The following general themes were extracted from interview data: (a) perspective of schooling and success; (2) motivation/ rewards; (c) motivated by interest/gatekeeper; (d) stereotypical treatments; (e) cultural/ social capital; (f) prejudice, being bullied/ridiculed at school; (g) are schools fair? (h) importance of grades and GPA; (i) curriculum effectiveness/appropriateness; and (j) external supports.

These categories were reviewed again for frequency of occurrence. Categories and sub-categories were collapsed into similar areas that yielded the five topics seen in Table 3. 
Table 3

Themes Extracted from Interview Data

\begin{tabular}{llc}
\hline Emerging Themes & Categories & \# of Responses \\
\hline $\begin{array}{l}\text { Perception of schooling } \\
\text { and success }\end{array}$ & Perceptions of schooling & 19 \\
& Grades/ curriculum & 12 \\
& Teacher disposition/perception & 13 \\
& Provides opportunities for learning & 13 \\
Disposition & Student disposition & 26 \\
Motivation & Discipline/Boredom & 9 \\
Support & Rewards & 42 \\
& Interests & 14 \\
& Parent/family- mindset and attitude as a & 12 \\
factor into consideration & 11 \\
Social capital & Teachers /Administrators & 13 \\
& Other (peers, coaches, mentors) & 16 \\
& Stereotypes-ridiculed/bullied & 10 \\
\hline & Prejudice & \\
& Identity & \\
\hline
\end{tabular}

\section{Overall Summary of Interview One Responses}

Interview one asked the participants to connect what they are learning with 'real world' experiences. For example, when asked about a challenging situation, one student felt that the challenge came about not due to his lack of understanding, but to the teacher's limited knowledge of the subject matter in a chemistry class. Some of the overriding themes that appeared to be paramount were the importance of education, money, grades, and GPA. Most were excited about attending school because it was a place to socialize and have fun, but the excitement of school began to wane about mid-year and 
participants admitted that, for the remainder of the year, they simply 'went through the motions'. There was a strong consensus that parents were their strongest motivators, but they also attributed their success to teachers, coaches, other area instructors and friends. It was interesting to note that most participants experienced some form of challenge or failure that occurred during their elementary school years.

\section{Overall Summary of Interview Two Responses}

It appeared that education was important to each participant but for different reasons and with varied outcomes. For one, it was self-enlightening, for another; it would allow him to take his place in society. For two of them it became a gatekeeper to the world of sports and for one it represented a way out.

Even though only two of the six participants admitted to being bullied, I suspect that the percentage is a bit higher. Being bullied also carries a stigma that may be difficult to overcome. It may take the form of verbal, physical, psychological attacks, or onlookers who appear to be a part of the action. Two of the participants reported that they saw it but were not a part of it.

Less than $2 \%$ of teachers in the United States are African-American men; that's less than 1 in 50 teachers (Huntspon \& Howell, 2012), and most male teachers can be found in high school. The response from one participant ("We had a lot of Black teachers in our school") took place in his elementary school, not his high school. There is also evidence that participants appear to confuse race with skin color.

Most of the participants reported having had some form of instruction in AfricanAmerican history. It appears that most parents and educators believe that is should be taught; and a month has been devoted to it, but relegating Black History to a month, 
project, class field trip or assembly is inauthentic and minimizing.

Only one of the participants admitted to failing a class, while only one admitted to failing a test. When asked who participants felt was their hero, one participant credits his karate instructor because he is inspired by her accomplishments even as she approaches middle age; while the other one credits his dad as his hero because he has taught him a lot of things and believes in him.

A good deal of discussion surrounded the issue of stereotypes, and participants were bothered by the fact that they were being stereotyped simply because of the color of their skin. What was interesting is that they used the criticism as motivation.

One participant cited that he was bothered by a teacher who discussed a classmate's behavior with him. He felt that the teacher should have been able to handle the situation himself and not make him a part of it. In this instance he did not appear to be concerned with what the teacher thought of him. Other participants, however, wanted their teachers to hold them in high regard and see them as possible role models. It appears that being African-American in an African-American school with an African-American principal as administrator brings with it a higher expectation than if the reverse were true.

\section{Overall Summary of Interview Three Responses}

Participants understood the important role that school plays in their lives. It was evident from some of the participant responses that they mimicked advice that had been given to them by those around them—-parent, coach, or teacher. Although they all declared that college was in their futures, it was evident that they would need a scholarship, be recruited by another college or university, or prepare to incur a good deal of debt. As a result, they made allowances in their statements by saying that if attending 
college did not work out, they would consider careers in law enforcement, firefighting, or train to become a professional chef.

As students reflected on how they might change their school life, responses included eliminating uniforms so that their personalities could be reflected in their clothes. This appeared to have merit as one of the goals that educators try to prepare students to do is to think independently; yet uniforms (which many school systems perceive as leveling the playing field) may serve to stifle their creativity and feelings of independence by requiring that they all look alike.

When asked what they regretted about their schools, some responses called for a stricter school system that would require that students take their education more seriously. In contrast, another participant suggested that students be given more independence to help them navigate their role in society. Some participants noted that they had no regrets but were in one accord about taking the transition from elementary school to high school more seriously. However, they all acknowledged taking responsibility for their learning.

Lastly, opinions are judgments based on circumstance, yet one does not have to live the experience to form an opinion. When asked about prejudice, one participant stated that he had been raised in an accepting environment. Therefore, opinions regarding prejudice are valid for each participant according to his environment. When I probed the theory of prejudice between light- and dark-skinned Blacks, Kane explained that lightskinned Blacks have a greater mixture of Whites than dark-skinned Blacks. This mixture makes them not only physically better, but smarter. One young man offered an interesting take; he claimed that he sees prejudice as a "war between light-skinned and dark-skinned 
Blacks'. If you are light skinned, you hate dark-skinned Blacks and vice versa.

\section{Analysis}

The primary themes listed above emerged from summaries of five qualitative filters using Miles, Huberman, and Saldana's (2014) three-step approach to data analysis. This analysis afforded me an opportunity to engage with the data from the perspective of the student. As I re-read the interview data, I was able to reflect on the participant, his mannerisms, his passion(s), and yes, his fears. It is through these reflections that I begin this analysis.

\section{Perception of Schooling and Success}

Perception is a belief or opinion; how things seem; what one believes to be true based on his/ her experiences. Study participants' view perceptions of schooling and success as graduating from eighth grade or secondary school, increasing their GPA and gaining academic recognition. Generally speaking, students saw school as a stepping stone to a good job and career. With respect to school promotions, Xyan has plans to go to college; however, those plans are dependent on his ability to secure a scholarship. His perception of success revolves around getting a football scholarship. In the event that his plans go unfulfilled, his alternatives are to go into boxing, the military, or law enforcement. In contrast, Josh viewed schooling with a good deal of trepidation. He has plans to go to college but is apprehensive about money. He worries that he will be saddled with an insurmountable debt that would take years to repay.

Graduating from eighth grade and grade point averages (GPA) also caused

dismay for Xyan and Kent. Xyan, realizing the importance of a high grade point average, set a personal goal of 3.0-4.0. Instead, his GPA hovered closer to a 2.5, which he 
considered a personal failure. Kent also entered ninth grade with feelings of inadequacy, but for different reasons. He applied to a selective enrollment high school and was not accepted. Similarly, Josh noted that he had to work especially hard on his own to increase his GPA (grade point average) because he had no help at home. Unlike the previous participants, Kent and Kane sought success through academic recognition. Kent found recognition by applying to as many schools and privately funded resources available. He participated in a program at Michigan State University, was selected to go to Washington, DC, for a presidential convention, was recognized as a Rhodes Scholar, and initiated into the National Honor Society. In addition, he had offers to go overseas to China, as well as Yale, Northeastern, and Boston, Massachusetts. Kent talked passionately about these recognitions. I believe that in some way, he wanted to make up for the failure to be selected to attend a selective enrollment school earlier. Similarly, Kane regrets that discipline issues caused him to lose a nomination to the National Young Leaders Program in Washington, DC, and initiation into the Junior Beta Club. Both of these activities required referrals or nominations from his teachers.

Perception of schooling. Schooling refers to students' experiences, their perceptions, and feelings about school. This includes feeling that they are a part of the school, that the adults at school care about them, that their learning matters, that they are close to people at school, have supportive relationships with adults, and that teachers and administrators treat them with respect. Study participants believe that education will provide direction to life and careers are echoed in responses like: people say the more you learn the more you earn; just in case football don't [doesn't] work out, I can have something to fall back on; education will get you ready for the rest of your life; necessary 
for jobs and to help you achieve the things that you want to accomplish; it gonna [it's going to] like, help me get along and give me tools so that I can get the class situation; to help me learn about computer science-with computer science and it can help me learn better in the future. These views are in keeping with research by Milner (Harper \& Davis, 2012) who maintains that Black students can and do succeed in schools across the world.

All participants appear to value education, view it as a means to an end and, as a result, are willing to expend as much effort as required. They believe that getting an education would make life easier but are also aware that some of their peers see schools and schooling simply as an entry into certain programs, i.e., sports, and once that becomes difficult its usefulness is no longer viable and attendance is no longer warranted.

Grades/curriculum. People can learn a lot and acquire a really good education without making A's. Moreover some students who consistently get A's might concentrate so much on getting A's that they miss the lesson. Still, society uses school grades as a yardstick to determine whether you have the aptitude to accomplish your career choices.

It appears that all study participants experienced some form of failure in elementary school or entering high school as a result of school activities, events, grades, or behaviors. Participants cited a number of causal factors that included: lack of preparedness, peer pressure, mindset, and low reading comprehension. Xyan wanted to graduate from eighth grade with a 4.0, but ended up with a 2.5. Though not an 'F', he indicated that it was "just like having an ' $F$ '. Josh recalls that, during his freshman year, 
he never did any homework, got two 'D's' and had to go to summer school. Although he got out with a 'B', he regrets not taking classes more seriously. One participant failed algebra but acknowledged that he did not complete assignments.

Teacher disposition/perception. An ongoing issue in schools concerns teacher disposition and perception. When we think about disposition, we are referring to a teacher's mood, temperament, mindset or inclination, while perception is a belief or an opinion; an attitude or value. Research tells us that teacher quality is one of the main influences to student achievement. There is also evidence that African-Americans males are viewed more negatively by teachers than their female counterparts As a result, disposition and perception are paramount to a quality education. However, when these African-American male participants were asked if their teachers had given them enough attention, they responded with a resounding yes. The one exception to this can be found in the response from Xyan. He indicated that his teacher accused him of talking in class because of an earlier incident. He believes that “there's always a teacher [who's] going to go with their first thought." I understand this to mean that her disposition and perception of African-American males is clouded by stereotype. Xyan recalled that he has one like that every year, Black, female and only looking at him.

Provides opportunities for learning. Since the introduction of (NCLB), the No Child Left Behind Act of 2001), schools have been under pressure to demonstrate gains in academic achievement measurable through test scores. As a result, there is growing interest in giving students broader opportunities and experiences before and after the school day to give them a better chance at success. Some participants express a good deal of skepticism when asked about opportunities for learning. They cite that 31 students 
in a class diminish many of the opportunities that are provided. Although some participants appreciate the increased attention that they receive, Kent cites that only $75 \%$ of teachers fit that category. Still, other study participants readily recount travel opportunities to attend a presidential convention, participation in the National Honor Society or the Young National Leaders Program. Kent adds that students need to be given opportunities to be more independent. He feels that allowing students an opportunity to make more of their own decisions will better prepare them for college and adulthood.

\section{Disposition}

An earlier treatise indicated that mood, temperament, mindset, and inclination were important variables to understanding dispositions.

Student disposition. The participants all agree that what their teachers think of them is important. Josh realizes that teachers are powerful in that they are the ones who judge students and may be called upon to determine who graduates (walks across the stage). Kane believes that you need to make a lasting impression on the teacher; one that may help them remember you if you need their assistance in the future.

Discipline/boredom. This section brings together two primary areas of interest related to academic achievement: discipline and boredom. Research cited in Chapter II speaks of children who internalize the fears, low self-esteem and powerlessness felt by their parents and/or family members. Xyan believes that teachers sometimes go overboard with discipline. He states that people [students] get discouraged with the overuse of disciplinary measures and that they [students] simply stop caring. They get bored sitting in class doing the same routine every day. Josh recalled that when rules are changed abruptly, students may become disruptive because they feel that the rule was 
changed to target them. These are often the perspectives that shape the mindset of young African-American males.

\section{Motivation}

Motivation is the process that initiates, guides, and maintains goal-oriented behaviors. Motivation is what causes us to act, whether it is getting a glass of water if you're thirsty or reading a book to learn about something. It involves emotional, cognitive, and social forces that activate behaviors. Motivation refers to why a person does something. An example of this can be seen in the response by Hawk, who believes that an education gets you ready for life-or Josh, who recounted that the reason he takes education so seriously is because of the struggles he has been through. He fears that if he doesn't go to college, his future will dim. He is motivated by the need to survive, but motivations can intrinsic as well as extrinsic. Xyan believes that 'education is huge', but his main goal in completing his high school education and going to college revolves around sports. He is motivated by the desire to play college and, hopefully, professional football.

Rewards. All the participants expressed plans to attend colleges. Josh views college as a way out of the violence of his environment. Xyan is of the same opinion; he cites "I need education, you know, pursuing a football life and just in case football doesn't work out, I can have something to fall back on.” While Kent is intent to do well because he feels that it will benefit him monetarily in the future. He has set a personal goal to receive a salary of $\$ 200,000$ by the age of 30 .

Interests. Although all participants expressed a desire to go to college, their motivations for doing so varied. Some of them, like Noah, believe that completing high 
school and going on to college helps you figure out your life's direction. Hawk wants to be able to take care of the people in his family and community. He adds that if you don't go to school you are sure to get into trouble. Still, Xyan, always the athlete, says playing sports helps you make it through the day.

\section{Support}

Support is needed at some time in everyone's life. It may come in the form of a phone call, a card, a loan, a gift, a yell, or simply an ear. It may come from a family relative, friends, coach, or stranger on the street. This next section examines support.

Parent/family. One of the most consistent predictors of student success is the support of parents and family. There is an old adage that says 'nobody rises to low expectations'. Where there is an expectation of student achievement, data exists that indicates a higher rate of success for these students. This is consistent with interview data from Hawk who says that his most important influences are his mom and dad. His dad because he cheers him on, tells him to never quit, never give up, and to work harder. The influences of the father on the participant's success can also be seen in the response from Noah. He has internalized a mantra that says: "It's not who you know but how you know them." This melody, along with his understanding and acceptance of his father's work ethic, is what Noah uses to make college and career decisions. Yet, not all participants view their father in the same manner. Kane acknowledges that, although his father screams and yells at him, he understands that it is teaching him to get it right - the first time. He believes that his father does it out of love and concern for his future. Xyan credits his mom and his mom's friend for support, while Kane acknowledges that he gets support from his mom, grandma, auntie, and other family members. On a slightly 
different note, Josh reveals that, although he respects his father, he is not the type of man that he wants to emulate. He acknowledges that his dad has helped him 'down the line' but is going through some tough times.

Teachers/administrators. Having lived the roles of teacher and school principal, I unequivocally understand their role in student success. The principal is the foundation by which the school operates and, as such, has a great influence on student learning. Kent reflects on his principal who, during an assembly, had a heart-to-heart talk about his journey as an African-American male trying to navigate through the educational system. By letting them know that he understood some of their issues, he was able to dispel some of the negative behaviors that characterize many inner city African-American males in public schools. Kane also holds his principal in high regard. He reveals that even if she is Black and female, she expects a lot from each student and adds that, if you need help, she can personally come to help you with your situation or problem.

What about the role of the teacher? No, what about the role(s) of the teacher. Teachers are loco parentis; they are counselors, nurses, mentors, coaches, confidants, cheerleaders, disciplinarians, instructors, and sometimes friends. How do teachers fare according to research participants? Noah says his teachers didn't minimize the work that he had to do, instead they just worked with you until you understood it.

Contrary to research that suggests that males are not being given sufficient attention in class, Xyan, Kent, Kane, and Hawk all agree that when they are in class, they get more than enough attention from the teacher and have no problem asking for help. Yet, in response to a question of teacher disposition, Kent was distraught over a chemistry teacher whose teaching methods were heavily reliant on the computer. When 
he asked for help after school, the teacher declined, citing that she was too busy.

Others (coaches, mentors, peers). When we think of coaches, we picture a football, basketball, or hockey coach. I've often wondered what a coach says to his team during halftime to change the outcome of the game. Why is this person so effective? What is it about coaching that commands and gets complete attention and dedication? John Wooden, Hall of Fame coach for UCLA, says that a coach is someone who can give correction without resentment. That seems to fit Josh. He believes his strongest motivator is his coach. He admits that he has a tendency to turn on and off at times, but it appears that the coach knows just what to do to get him to re-focus. He recalls that she's always going to be there for him and that he can always count on her.

A mentor is someone that you would like to emulate, oftentimes unbeknownst to that person. This happened in the case of Kent who looks up to Derrick Rose, point guard for the Chicago Bulls basketball team. Kent admires him because he has a similar background, both coming from Chicago. Rose had a great deal of adversity in his life and Kent believes that it shaped him into the person that he is today. He also admires him because, despite several injuries, he does not quit. Similarly, he admires singer and actress Beyoncé Knowles, because he says that she knows what she wants and works hard to get it.

Peers hold a special place in a student's life. They are often in the same grade, have the same race, religion and/or culture, have the same likes and dislikes, and often live in the same neighborhood or within close proximity. For these reasons and more, peers remain valuable assets to school and schooling. Noah says that all of his friends keep up with their classes, while Josh reveals that he likes to surround himself with 
positive influences. He makes it a point to remind his peer friends about the importance of keeping up in class, sits with them while they log in to the student portal to check on any grades of ' $C$ ' or lower, then encourages them to talk to the teacher about doing another assignment to make up for a poor showing, because he doesn't want his friends to fail.

\section{Social Capital}

Social capital looks at shared values and understandings that help individuals work together in society. Shared values reflect a person's sense of right and wrong or what right should be (Palmer \& Gasman, 2008). They include those things that we take for granted in everyday life; for example, the importance of an education, equal rights, and the right to believe in a higher power. Several study participants related a violation of their social capital. Hawk has been dealing with a bully at his school. He says that Maurice [a pseudonym], who is in all of his classes, picks on him and says 'stuff' to him completely unprovoked. When asked how he planned to handle the situation, his response was, 'I'll deal with it'. Kent says that he gets ridiculed at his school for being smart. He thinks that the ridicule is 'lame', feels that his classmates are jealous of him and that their ridicule is based on them trying to fit in. Fortunately, Kent, who is very focused, says that he uses their ridicule as motivation. Josh revealed that he's been ridiculed in many of the schools that he has attended beginning at around fourth grade. Unlike Kent, Josh became very aggressive and felt that they [his classmates] were jealous of him because he was 'above' them in his school work. He rationalized that their ridicule of him was simply a ploy to make themselves feel better and admits that he has since 'calmed down'. 
Prejudice. Public schools represent the pluralism of our society. Due to the prejudicial attitudes played out in society and the media, African-American children often view their schools with apprehension. Josh believes that prejudice is created by stereotypes. He believes that the stereotype of an African-American male being unemployed, a thug, gang banger, thief, or killer often seen in the media causes Whites to accept these behaviors as truth. Interestingly enough, many African-Americans believe the same stereotypes. They, too, secure their bags and tighten the grip on a child's hand when an African-American man walks toward them. Noah stated that he has always been raised in an accepting environment and, as such, has not experienced prejudice. He does, however, admit that he has seen a lot of prejudice on TV with the Michael Brown killing, and believes that when "people are singled out, it usually involves a dark-skinned African-American male who poses a threat." This idea of light-skinned versus darkskinned Blacks is prevalent in the African-American community. Lighter skinned African-Americans are purportedly closer genetically to Caucasians and, as a result, more intelligent.

Stereotypes. Stereotypes are generalizations used to describe what some believe to be characteristics of a particular race or culture. Everyone stereotypes. A boy with horn-rimmed glasses could be labeled as smart, nerdy, or unpopular. A very tall male is expected to play basketball. A smart African-American male could be accused of 'acting White' [see Ogbu, p. 45], an African-American male with a hoodie could be perceived as a threat. Kane believes that some students fall prey to these stereotypes and fail because they believe that school fits their need to be social, may not see the value of work, or they may succumb to outside influences of gangs, drugs, and other addictions. Josh is aware of 
the same stereotypes, but the one that catches his attention states that all AfricanAmericans are inferior to Whites. Kent is disturbed by the stereotypes because he acknowledges that "there are some African-Americans that don't do that." He regrets being 'put into a box' and prefers to be known for his actions as an individual rather than by a stereotype.

Everybody stereotypes. Kane believes that Black girls are crazy and dramatic. He recounts that during school recess there were always girls outside and the girls only wanted to talk to the lighter-skinned males. The dark-skinned males complained and fights ensued. When I asked what having light skin meant to a dark-skinned person, he responded: “They think that you're mixed, between Whites and Black. They think that you're physically better than them because you have some Whiteness in you, and they think you're smarter than them." This statement is probably indicative of his age and maturation and speaks to how easily we drift into stereotypic portrayals.

Identity. There is a poem that is centered on the concept that children learn what they live and, I would add, they are what they learn. They learn from their parents, family members and peers. They learn from media portrayals, newspapers, magazines, and radio personalities. Schools have an enormous influence on shaping a student's identity. History books often devote a chapter to African-American history; February has been designated Black History month, and most schools have students put on assembly programs touting the achievements of Dr. Martin Luther King, Rosa Parks, Colin Powell, Michael Jackson, and Jean Baptiste Pointe DuSable, to name a few. Josh is currently taking African-American History and is working on an assignment titled "Who Am I"? It is meant to have students examine their identities based on their race. It sought to make 
students aware of the terms Black, African-American, or just American. Hawk remembers his Black history assembly because they ended the program with a dance by a Michael Jackson impersonator. Kent remembers that, when he was 10 years old, his father gave him a book about African-Americans. He admits that he wasn't very interested in learning about Black history, but knows that he was only trying to help. Although these programs and exercises do not appear to speak to the breadth and depth of the African-American's contribution to this country, it reminds us that we still have a lot of work to do to be comfortable in our identity. We must continue to find ways to celebrate the uniqueness of every race and culture living in this country.

\section{Summary}

Participant data yielded a strong consensus that their perception of school and success is highly influenced by the world around them. For some, continuing on from eighth grade to high school was a natural progression. Others approached the ability to graduate with trepidation because, in his world, it was not a given, there was no natural progression, only hope. For some, going to college was also a natural progression, but for others, there was the hope of a football or basketball scholarship. Without a scholarship, the idea of a college education fades away and students are left to answerwhat next: boxing, law enforcement, firefighter, chef, soldier?

Parents were recognized as their strongest motivators, but they but also attributed their success to teachers, coaches, other area instructors and friends. Participants respected their teachers and administrators and felt that they were getting the attention and education that they were entitled to. 
The study group understood the important role that school plays in their lives. It was evident from some of the their responses that they took to heart some of the advice that had been given to them by their supporters, acknowledged taking responsibility for their own learning, and surround themselves with friends and others who share the same beliefs. In some cases, the students monitor their own grades using the student portal.

Students recounted the significance of elementary school. They all experienced some form of challenge or failure that occurred during their elementary school years. Most claimed that they underestimated the challenges and rigor of high school and wish that they had 'done better'. Still, all participants want to attend college and believe that a college degree will lead to a good job and/or career.

Most of the participants are very aware of the Black male stereotypes and bothered by the fact that they are being judged simply because of the color of their skin. They did not, however, blame their teachers or administrators for harboring any racist views and felt that their schools were fair.

\section{Conclusion}

This analysis revealed patterns of how students perceived school and schooling, the importance of a strong support system and how stereotypes impact their thinking. The implications for these differences are discussed in Chapter V. 


\section{CHAPTER V \\ SUMMARY, CONCLUSIONS, AND RECOMMENDATIONS}

\section{Summary of the Study}

The most recent graduation statistics reveal that eighty-one $81 \%$ of this country's youth is continuing to make progress on high school graduation rates, which is an indication that more young people will have the chance for a promising future (Hall, 2015). While research reports that overall graduation rates are on the rise (Brounstein \& Yettrick, 2015), African-American, low income, special education, Native American, and Hispanic students continue to graduate at rates that are well below the average.

One-third of students from low-income families did not graduate. AfricanAmerican students posted a $69 \%$ graduation rate, while African-American males graduated at a rate of 59\% (Schott Report, 2015), up from 51\% in 2010-2011. Despite promising reforms (school turnaround grants, college pathways programs), there is no coordinated national response for what amounts to a national crisis. Changing this trajectory has again become the topic of debate, dialogue, and research (NEA 2011).

The purpose of this study was to examine the impact of gender, race, social justice, and educational equity on the academic achievement of African-American males between the ages of 13 through 17 . This is the age range in which individuals develop values that are personal and significant, according to how they make sense of life experiences. 
This study employed critical analysis to examine sociocultural and educational factors that impact African-American male student achievement. It examined factors and processes that impacted student achievement, from the perspectives of adolescent males, to get a realistic view of the issues that they identify concerning their views of school and schooling. Using a series of interviews, data was collected from six young men over a 5-month period from June to November 2014. Following the completion of each interview, the researcher used member checking to allow the participant to review the typed transcript to clarify, correct, or re-state any information that they felt may have been misinterpreted or impacted by researcher bias.

\section{Findings in Relationship to the Research Question}

The research question provided the framework for this summary of findings. The researcher used caution in noting these findings because: (a) they represent results from a small study population, and (b) participants' maturity and maturation levels vary according to their lived experiences.

\section{Research Question}

What are the perceptions of agency, teaching and learning environments, motivation, engagement and support systems on the academic achievement of six African-American males ages 13-17?

Agency. Jackson (2003) believes that students are central to the educational process, although researchers are not apt to say it lest they be blamed for blaming the students for the quagmire that we seem to be in today. Instead he suggests that many researchers blame the school, teachers, parents, poverty, lack of neighborhood or community resources, socioeconomic status, racism, or the cumulative effects of 
prejudice- and they are not wrong. Our education quagmire contains all of these factors and more. The quagmire also includes agency. Education requires that students think, question, become independent learners, take agency, and ownership of their learning (Briceno, 2013).

Agency is not something that can be purchased in a food or department store; it must come from within. It is formed by parents, family, friends, schools and other supporters (Schnee \& Bose, 2010). Its frame is made from a ready-made supply of encouragement, confidence, and the knowledge that mistakes are critical to the learning process (Lindgren \& McDaniel, 2012). All six participants in this study have an appreciation and respect for education. In many cases, education is seen as a means to an end. They believe that, without an education, the likelihood of getting a good job will be lessened, and they are willing to devote this time in their lives to enhance their future. A necessary component of student agency is goal setting (NetFamily News, 2014). All of the participants also have goals, and the motivation for the goal varies by age, maturity, and exposure to life and living. Although their parents play a major role in their education, these participants accept and acknowledge their roles in school and what it will take for them to be successful. For example, one participant stated that he doesn't get any support from home and his other siblings are all in lower grades. He understands that his success is based on his willingness and determination to succeed. He understands that he does not have the luxury of waiting his turn, as it may never appear. Another participant described how his father yells at him, but he acknowledges that he does it because he doesn't want him to make unnecessary mistakes and understands that this level of concern is pivotal to his success. 
Yet, at the same time, if we acknowledge the importance of agency, we must also acknowledge the social forces that lead students to disengage from school (Atweh, Bland, Carrington, \& Cavanaugh, 2008). These issues include identifying with cultures other than your own, belonging to or not measuring up in the school environment, difficulty with the rigors of the curriculum, and little academic support or difficulty in seeing the validity of school work and how it will help them achieve their goals (Jackson, 2003).

Teaching and learning environments. Although all students currently attend either all African-American or predominately African-American schools, two of them had an opportunity to attend schools with diverse populations. One student, Josh, immediately noticed that a school that he attended in Rewards (a pseudonym) was special because of the variety of resources that were available for students. He looked forward to school because it offered many curricular as well as extracurricular activities that were not available in his neighborhood or community. After he returned from the school in Rewards, he was enrolled in a school in Chicago. When asked about his school in Chicago, he recounted that it too was the best he had ever attended. This suggests that his level of maturity did not allow him to perceive the difference in the schools and how this difference would impact his life. Yet, the ages 13-17 signal a time when students are able to make their own decisions about things that concern them (Cohen, Michener, Holmes, Merseth, \& Ralph, 2007).

This statement lends credence to the fact that students who hold their schools in high esteem enhance the teaching and learning environments of their schools, but what of the other schools? When asked if schools were fair, participants agreed but acknowledged that they knew of other schools that were lacking the same types or levels of resources. 
It is by no stretch of the imagination that some young men look to sports as their primary resource. One participant admits that while the opening semesters of school are fun and fulfilling, the curriculum and class work becomes routine and boring, especially towards mid-term. However, as long as he has opportunities to play sports, he is willing to work harder at maintaining an acceptable GPA.

Motivation and engagement. Most people are motivated toward some goal. Some are motivated toward academics, some towards sports, some towards playing an instrument or singing a song. Whatever the goal, motivation is as much about what one is motivated to do as they are about the reason for it (Nakkula, 2013). As discussed in Chapter II, motivation is an internal drive that compels one to find a means to an end. Students may work longer, harder, and more efficiently if motivated to do so. In the learning process, this means that if students are compelled to go to school, complete their education and graduate, they must be motivated to do so by parents, family, and teachers, and this motivation must begin at an early age (Small, 2012).

Some of the study participants struggled just to make grades. Most of them recount their transition from eighth grade as a pivotal time in their lives. As a result, grades and grading permeated our discussion of their importance. What stood out was the level of motivation and engagement that students need to be successful. If the teachers, parents, or friends push the students toward improvement, it encourages them to do better and to be better. The encouragement motivates them to work harder, not just for themselves, but for those who care about them (Harper, 2012).

Also worth mentioning is the impact of motivation and engagement by their peers. Successful students appear to surround themselves with successful friends and 
classmates. An example of this can be seen in one participant working with his friends to access the student grade portal to help them to manage their overall grades. While another acknowledges that there are times when he himself has to assist some of his friends with their work (Johnson, 2000; Long, Monoi, Harper, Knoblauch \& Murphy 2007; Harper, 2012)

Support systems. Toldson (2009) states that home-based involvement with children, including parent or sibling help with homework or monitoring the amount of time spent with friends, TV, or computer activities, has the strongest potential for academic success. He also believes that parents who let their children know when they have done a good job and that they are proud of them are likely to be successful. As referenced in Chapter II, it helps students feel respected, valued, and responsible for their own learning.

The six participants in this study are fortunate to have strong support systems. They all recount the support of their parents and believe that their parents hold high expectations for them. For many, their parents also serve as their role models. For example, one participant stated that, even though his father works a lot, he finds time to interact with his family. Another recalls stories that his father told him about his childhood; stories that encourage and motivate him to never give up. Support is, however, not limited to parents. Students also recounted multiple instances of teachers, coaches, and mentors who encourage them to work hard and get good grades.

Finally, participants acknowledge that they have a lot of friends whom they support and who look to them for support. They surround themselves with others who have the same values as they do, because "birds of a feather stick together." 


\section{Interpretation of Findings}

This study reports interview findings that explored African-American male student achievement through the context of critical analysis. With respect to the research question, findings were consistent with the research. In regard to agency, the data compliments research from (Jackson, 2003) who maintains that students are in charge of how they spend their time, how they wish to be seen, and who they wish to be. Agency can be detected in a student's determination and commitment to further their education by attending college. This is a deliberate and conscious decision, as some participants describe graduating from eighth grade to be a major accomplishment in their lives (Schwartz, 2011). This data suggests that completing high school and attending college has to be a personal goal. Although the participant's motivation differed by reason, the goal remained the same. When this study was designed, I expected that a discussion of schools and schooling would be met with a good deal of negativity. My assumptions were formed as a result of years of interacting with elementary and high school students, their teachers, staff, and parents. However, my assumptions were not found. What I did find was six male participants ranging in age from 13 to 17 years old, from freshmen to seniors, all attending different schools, both public and charter, and all determined to go to college. When asked why they had chosen to go to college, some stated that a college education would pave the way to their future career, some stated that it would open the door to a sports career, one stated that it would keep him off the streets, and some stated that it would position them to be an asset to the community. These findings bear a striking similarity to Ogbu's research highlighted in Chapter II, which stated that the motivation for getting an education was based on the premise that the more education one 
has, the better the job opportunities, the higher the wages, social status, and self-esteem. In addition, Ogbu indicated that when students become aware of the role of race and class in society, this motivation and determination will recede. Interview data, in part due to the supporting factors noted by participants, did not support this premise.

The participants in this study have fully developed goals. Not only have they decided that they are going to college, but they have decided which college they plan to attend and the jobs that they seek after graduation. This point suggests that their level of maturity does not allow them to perceive their place in society or how race and class might impact their ability to go to college, complete college or get a job after graduation.

This observation is not meant to suggest that race and class issues do not apply in this situation; rather, that the students have been sheltered, exposed only to 'accepting' environments, or their maturation and maturity levels simply did not recognize inequalities; the result of a society where schools, communities, employment or other situations are impacted by race. An example of this can be seen in the experiences surrounding light and dark skinned Blacks.

Teaching and learning environments are important in that they affect our thoughts, feelings, moods, ability to learn and behaviors in a profound manner. A positive environment creates a stable foundation for learning. Learning environments become a part of our life's focus because, from preschool to eighth grade to high school and on through college, our relationships, expectations, and how we plan future goals are heavily dependent on how we interpret our environment and its impact on the importance of education. The environment provides signals that tell us how to respond and how to act. Participant data suggests that students were highly motivated to learn and viewed 
their classes positively. Research data also reveals that an education will provide the tools that these students will need in securing a job. This suggests that whatever the rationale for completing high school, whether it is due to intrinsic or extrinsic motivations, will lead to a college degree.

Despite increased interest in student achievement, perceptions of school and schooling are influenced by their interpretation(s) of the world around them. Students enter schools with their own perceptions of what to expect from school, some positive and some not. However, when embraced by a positive, supportive teaching and learning environment where students feel safe and respected regardless of preconceived notions, students can and many do achieve. This environment includes their teachers' perceptions of them because they understand that the classroom teachers' influence extends beyond daily instruction to include promotions, recommendations for college entrance and nominations for inclusion in special programs and projects.

To be successful, students must be motivated and engaged in the learning process. This study indicated that participants were highly motivated and engaged in their own schooling. For some, this motivation and engagement extends into their churches, as these organizations often provide tutors, after school or mentoring activities for their members. This finding is in keeping with research that reveals that when students can see the relevancy of something in their lives, they are more apt to invest the mental energy to make it happen (Blumenfeld, Kempler, \& Krajcik, 2006). Unfortunately, the opposite, a lack of interest and relevancy, causes students to dis-engage, but this was not evident from the interview data. What participants did recount were instances of boredom, particularly during mid-year, when the excitement of the new school year had passed, 
reconnections with old friends had faded, and the demands of classroom assignments were more stringent.

Participants all acknowledged having a strong support system comprised of their parents, other family members, coaches, mentors, teachers, and friends. This data concurs with a study by Field and Diego (2002) who found that adolescents with high parent and peer relationships had more friends, more cohesive family relationships, lower incidences of depression, and a higher grade point average than students who lacked family and peer support. The students who acknowledged their teachers most frequently were the students entering the ninth grade. This suggests that the idea of teacher as friend and supporter that was established in elementary school extends into secondary school. The idea of a strong support network cannot be overstated. Not only did data participants attribute their success to parents and family, but their teachers as well. Participants also felt that the perceptions of their parents, teachers, and administrators were important. This, however, was not unusual in that most children seek the respect and acceptance of the people who are important in their lives.

Although participants reported that they as well as their peers are keeping up with their classes, some admitted to being bored with the routine nature of their instruction. They indicated that joining clubs and sports teams help abet the boredom. They also indicated that most of their failures and successes occurred in elementary school. This was an interesting development, because there are varied differences between elementary schools and secondary schools. We know that the typical elementary schools paradigm is one teacher per grade. The only exceptions are library and physical education and sometimes language, art, and music, while in secondary school, a student can have as 
many as 8 to 10 different teachers. Another comparison can be made in the affective domain, as elementary school teachers are more nurturing than secondary school teachers.

Making the move from eighth grade to high school can be critical to student success for a number of reasons. Most high schools are larger, students are more independent, have a greater responsible for their learning, lose their connection to their old school, have more anxiety, and the environment is less nurturing. Participants revealed that one of the most significant things to happen in their schooling was how they underestimated the transition from eighth grade to high school, and 50\% of them described it as their biggest failure. Both anecdotal and empirical evidence suggest that students begin thinking about dropping out of school during this critical period of time. Although study participants seemed to falter in their freshman year, they were able to improve their grades and were now on track for an on-time graduation.

All of the students possessed a strong sense of agency regarding their academic pursuits. They have been taught to believe that in order to make a living, get a job and become independent, it is imperative that they get an education. I did not get a sense, however, that, if left to their own devices, the same could be said. Only two participants admitted that education would serve them as well as their communities; most were looking for the reward of a job, career, or an opportunity to play professional sports.

When participants were asked for their opinions regarding student failures, they recounted several reasons that included laziness, apathy, lack of parental or other supports, failure to set goals, and a lack of role models as causal factors. The idea of positive role models appeared frequently. Students surmise that if you are surrounded by 
failure, failure is what you become. They recounted experiences in their own neighborhoods and communities about the constant reminders of what failure looks like — seeing people on the streets, high on drugs, panhandling, or selling drugs. These images, constant reminders of wasted lives and potential, as well as parents' constant pleading, serve to inspire students to stay in school, because that is what the alternative looks like. This supports the notion that student success is highly dependent on staying engaged both inside and outside of school (Fryer and Levitt, 2004).

Schools were not mentioned directly but have and continue to play a role in student academic failure. Wasserberg (2009) suggests that research is necessary to examine the relationship between stereotype threat and school climate at the elementary and secondary levels. Stereotype threat (Steele \& Aronson, 1995) asserts that the stereotype of being African-American and male can seriously alter academic achievement and motivation for these students due to the risk of confirming the stereotype. They also found that African-American students who value academic success are the most susceptible to this threat. This may set up a hegemonic system where minority students fail because schools reinforce and reproduce social inequalities and stereotypes.

This is especially important in that CRT research examines the impact of race and racism along the entire educational experience that includes both elementary and secondary schools and on to college.

The idea of curriculum did not appear to be as much as an issue to them as it was to the researcher. Students for the most part did not question the curriculum design or what they were expected to know and/or be able to do. This suggests a high level of trust in the schools, teachers, and administrators. There were isolated incidents that merit 
mentioning here. One participant recounted that he did not fully understand some of the instruction in his chemistry class and asked the teacher for help. The teacher declined, stating that she would not be able to meet after school for any additional assistance. He suggested that the teacher may not possess enough content knowledge, because she was providing instruction via a computer program. As a result, he asked some of his fellow classmates, and they suggested that he pull up a program from 'Khan Academy' to get answers to his questions. He did this and was able to pass the class. Previous research in Chapter II suggests that students in public, low performing schools have a higher than average ratio of teachers who are not certified in the areas that they teach. This challenges the concept of teacher support and lends even more credence to the idea of agency. Has this become so prevalent in our schools that students accept it and view it as a norm? When students include teachers as primary members of their support groups is it with limited expectations?

CRT explains how people of color experience life and how it impacts their thinking and learning experiences. It investigates ways of thinking about and examining social systems and groups. It maintains that racism is institutionalized and an ingrained feature of racialized social systems. With this understanding, everyone within racialized social systems contribute to the reproduction of these systems through social practices that include racial identities. Additionally, privileges, practices, and assignments of power are also socially constructed based on a group's self-interest (Delgado \& Stefancic, 2009). This is a CRT moment; one that can be used to understand the rationale behind the light skin/ dark skin phenomenon. A CRT moment is when the salience of race is highlighted during the course of normal events (Dixson \& Rousseau, 2006). 
The friction between dark-skinned Blacks and light-skinned Blacks has been in existence for over 400 years. Historians have named this phenomenon, Colorism. This ingroup discrimination began when lighter-skinned slaves were given preferential treatment over darker-skinned slaves. Preferential treatment included working in the main house rather than the fields, being a nanny to the slave owners' children, or being assigned as a maid, servant or butler in the main house. In the aftermath of legalized slavery, this phenomenon continued to divide Blacks. Clubs and other organizations were created whose unspoken tenet served to maintain the color barrier. They used techniques like the blue vein test (Blacks being light enough to see the blue vein in their arm) or the brown bag test (Blacks being lighter than a brown paper bag) to recruit and maintain their members. As was expected, a lot of animosity grew from these relationships, and darkerskinned Blacks began to resent lighter-skinned friends and even family.

Evidence of these relationships continues to exist and is seen through the participant's view of prejudice that mimics society's portrayal of African-Americans and Whites. What surprised this researcher is how casually the students accept this prejudicial view; a view that still divides friends and family and further segregates light- and darkskinned African-Americans. Certain members of the Black community have to contend not only with prejudicial attitudes from the White community, but from the Black community as well, constituting another CRT moment. This is in keeping with the first tenet of critical race theory, which states that racism, discrimination and prejudices are so imbued in our society that it has become an acceptable norm. In a sort of reverse discrimination, at least half of the students interviewed included incidents of discrimination between light-skinned Blacks and dark-skinned Blacks as an issue at 
school. They believe that most of the trouble that is caused in school is due to darkskinned Blacks and that lighter-skinned Blacks have more intelligence.

\section{Implications of Findings}

Many African-American students living and going to school in urban cities live in a society that is very different from the one in which this researcher or their parents lived. These young men have grown or are growing up in a society where both AfricanAmerican and females have become mayors, congressmen, judges, other public officials and, yes, even the President of the United States. They have not been subjected to attend legally segregated schools, earn 'Black' wages, or live in areas specifically designated for non-Whites.

The framework for this study sought to investigate the impact of critical pedagogy, socially and culturally relevant instruction and their impact on agency. CRT was selected to conduct this research because (a) it maintains that racial power is maintained and supported by the law, and (b) explains how people of color experience life and how it impacts their thinking and experiences.

Participant data was used to examine if students perceived any barriers to their education that focused on values, perceptions, or covert acts of racism. An analysis of data suggests that students' value systems were constructed by the parent's value system. They are determined, self-reliant, strive for financial independence, and motivated to attend college. Whether or not they are successful will also depend on their parents' ability to help them realize their goals.

Student's perceptions of their teachers are mixed. Their devotion to their teachers is based on power, the flip side of agency. Students realize that the classroom teacher has 
the power to promote or retain, refer a student for suspension or expulsion, or recommend them for inclusion in school projects or activities. In some cases the teacher is cast in the role of parent and, as a result, students seek their approval on a daily basis. The principal's perception is different. The student does not see the school principal as much a threat as the teacher. Ergo, the power lies with the teacher, not the administrator.

Most of the students attend either all African-American schools or schools with a majority African-American school population. In the absence of a significant number of White students, any perceived covert acts of racism involve Colorism. Colorism is a process that privileges light-skinned people of color over dark-skinned people of color. It is the apparent discrimination between light- and dark-skinned African-Americans and the social values connected to it. Study participants have been so impacted by Colorism that they believe (a) dark-skinned students do not have the same intellect as light-skinned students, and (b) most of the discipline/ behavioral infractions in school are committed by darker-skinned African-Americans. This suggests that, regarding income, education, housing, and the marriage market, light-skinned people have clear advantages over darker-skinned people of color in these areas (Hunter, 2007).

How does this study help to advance research methodology? This study was never intended to solve the issues of African-American male student achievement. There are already countless bodies of research and a bevy of researchers who purport to know why this phenomenon exists. This study, however, was intended to open a dialogue and ignite critical consciousness regarding the academic achievement of the AfricanAmerican male by giving them a voice in the issue. 


\section{Limitations of Study}

It is important to bear in mind certain limitations when reviewing these findings. First, this study has a small sample size. Regarding the sample size, data was obtained from six participants ranging from eighth grade to high school senior. As interviews began in June at the school year, students already considered themselves as having been promoted to the next level. However, some of the responses suggested that the participant had not 'lived' certain experiences and, as such, their responses were 'shallow'. Although a small sample size limits the generalizability of the study, it did enable the researcher to get more depth, review, and follow-up data from the previous sessions. A different pattern of findings may have emerged if the sample size were larger, more interview data collected over a longer period of time, and students were more mature.

The students' understanding of prejudice varied according to their age, grade in school, and maturation level. These differences in understanding may have contributed to the varied responses regarding race and prejudice. However, it is important to make sure that any replication of this study uses a student population of different ages attending a variety of schools across the city.

Having a focus group session after data has been collected and students have had an opportunity to review their transcripts would facilitate more clarity. The researcher's original intent was to convene a meeting of the study participants to discuss their concerns or responses to the queries. Unfortunately, one student left for college, two were booked with football games and practice, and two were booked in study sessions both during weekdays and Saturdays. The researcher should be cautious, however, to make 
sure that the students' responses do not take a different direction when participating in a group session with upperclassmen.

I would be remiss to end this section without acknowledging the potential role of bias in my interpretation of this data. I use the word potential because I am what is technically known as a 'baby boomer', a class of post-war children born between 1946 and 1964. As an African-American female, my 'lived' experiences include the rise of civil rights, Brown v Board of Education, and the era of bussing students in an attempt to desegregate schools. As I cannot know the degree to which these factors impacted my ability to interpret student data, it is my hope that the number of filters used served to minimize this researcher's known and unknown biases.

\section{Future Directions for Research}

It is noteworthy that study participants indicated satisfaction with the type of support they received from their teachers and administrators. This particular finding suggests that some students, especially African-American boys, may not realize that they are at risk for academic failure because of the type of academic support they receive at school, as they have nothing to compare it to. These findings need further exploration. Additional research is needed to clarify inconsistencies in students' perceptions of the type of support they obtain at school.

It is also important to obtain information regarding how students from various cultural backgrounds view the impact of race and gender on their behavior. In addition, the effects of socioeconomic status and its impact on African-Americans needs further investigation. Recent analyses of achievement patterns among African-American students emphasize the need for a cultural framework (Ogbu, 1990). Such a framework 
should begin in elementary school and not only include cultural perspectives and values; but what is being taught, how it is being taught and focus on concerns related to how teachers relate to students.

We are encouraged to examine elementary and high school curriculum. Participants revealed that one of the most significant things to happen in their schooling was how they underestimated the transition from eighth grade to high school, and $50 \%$ of them describe it as their biggest failure. In fact, most of their failures and successes occurred in elementary school. With data that reveals that this is the age group with the highest number of underachievers, it is imperative that schools offer a curriculum that prepares students for success.

Lastly, this study reminded us of the power of student voice. Their experiences tell us that, regardless of media reports, biased achievement reports, or stereotypical depictions, these African-American males believe that education is the gatekeeper to a bright future. 


\section{REFERENCES}

Abdulkadiroğlu, A., H. Weiwei Hu, P. A. Parag. (2013). Small high schools and student achievement: Lottery-based evidence from New York City. NBER Working paper No. 19576. National bureau of economic research- (NBER) program.

McArdle, C. G. and Young, N. F. (1970), Classroom discussion of racial identity or How can we make it without "acting White"? American Journal of Orthopsychiatry, 40: 135-141. doi: 10.1111/j.1939-0025.1970.tb00687

Achilles, C. M., et al. (2012). Class-size policy: The star experiment and related classsize studies. NCPEA Policy Brief. Retrieved from www.ncpeapublications.org/attachments/article/525/policyBrief2 pdf

Advancement Project. (2005). Education on lockdown. Retrieved from www.advancementproject.org/education-on-lockdown.

Alexander, M. (2012). The New Jim Crow. Mass incarceration in the age of colorblindness. New York, NY: The New Press.

Alkahtani, K. D. F. (2013). Using concept mapping to improve parent implementation of positive behavioral interventions for children with challenging behaviors. International education studies, 6(11). Retrieved from Questia.com.

Allen, S. (2008). Eradicating the achievement gap: History, education, and reformation. Black History Bulletin, 71(1). Retrieved from Questia.com.

Apple, M. (2012). Can education change society? New York, NY: Routledge Publishing Company.

Arai, S., \& Kivel, D. B. (2009). Critical race theory and social justice perspectives on Whiteness, difference(s), and (anti)racism: A fourth wave of race research in leisure studies. Journal of Leisure Research, 41(4). Retrieved from Questia.com

ASCD. (2006). Closing the gap: An overview. Retrieved from www.ascd.org/publications/newsletters/policy-prioritie

Atweh, B, Bland B C, Carrington, S B \& Cavanagh, R. (2008). School disengagement: its constructions, investigation and management. In Peter, J (ed.), AARE International Education Research Conference, 25-29 November 2007, 
Fremantle, WA. Retrieved from

http://files.eric.ed.gov/fulltext/EJ1048870.pdf

Austen-Smith, D, \& Fryer, R. G., Jr. (2006). Acting White or just acting naturally. The Quarterly Journal of Economics. Retrieved September 2014 from

http://insight.kellogg.northwestern.edu/article/acting_Whites_or_just_acting_ratio nally

Bachman. (2006). Causation and research design. Thousand Oaks, CA: Sage

Publications. Retrieved from www.sagepub.com/upm-

data/14289_BachmanChapter5.pdf

Balfanz, R. (2007). Preventing student disengagement and keeping students on the graduation path in urban middle-grades schools: Early identification and effective interventions. Johns Hopkins University

Bell, D. (1980). Race, Racism and American Law. Boston: Little Brown

Beeman, A., Glasberg, D. S., \& Casey, C. (2010). Whiteness as property: Predatory lending and the reproduction of racialized inequality. Critical Sociology, 37(1) 27-45. Retrieved from http://www.tsjugephd.com/uploads

Berkwits, M., \& Inui, T. (1998). Making use of qualitative research techniques. General internal medicine. Retrieved from: 13(3): 195-199. doi: 10.1046/j.15251497.1998.00054.xPMCID: PMC1496926

Berliner, D. (2006). Our impoverished view of educational reform. Retrieved from Teachers College Record, 108(6), 949-995.

Bernardo, J. T. (2012). Description, analysis, and interpretation in qualitative research. Retrieved from http://www.personal.psu.edu/jtb17

Black Males in Urban Schools. Council of the Great Schools. Retrieved from www.cges.org

Bloomfield, A., Foster, J., Hodes, C, Konopniki, \& P. Pritz, S (2013). Credentials: One tool for retaining students. Techniques, 88(2). Retrieved from Questia.com

Blumenfeld, P.C., Kempler, T.M., Krajcik, J.S. \& Blumenfeld, P. (2006). Motivation and Cognitive Engagement in Learning Environments. In Sawyer, R. K. (ed.). The Cambridge handbook of the learning sciences. New York: Cambridge.

Boeije, H. (2010). In Saldana, J. (2013). The coding manual for qualitative researchers ( $2^{\text {nd }}$ ed). Thousand Oaks, CA: Sage Publications, Inc. 
Boyd-Zaharias, J., \& Helen, P. B. (2008). Class matters-in and out of school: Closing gaps requires attention to race and poverty. Phi Delta Kappan, 90(1) Retrieved from Questia.com

Bruce, J.D. (2003). A special section on the achievement gap: Education reform as if student agency mattered: Academic microcultures and student identity. Phi Delta Kappan. Retrieved www.Questia com

Caraballo, L. (2012). Identities in a figured world of achievement: Toward curriculum and pedagogies of hope. JCT (Online), 28(2).. Retrieved from Questia.com

Carter, N. P., Hawkins, T. N., \& Natesan, P. (2008). The relationship between verve and the academic achievement of African-American students in reading and mathematics in an urban middle school. Educational Foundations, 22(1-2). Retrieved from Questia.com.

Chang, M., Park, B., Singh, K., \& Sung, Y.Y. (2009). Parental involvement, parenting behaviors, and children's cognitive development in low income and minority families. Journal of Research in Childhood Education, 23(3). Retrieved from Questia.com.

Chapman, A. (2014). Gender bias in education. Edchange project. Retrieved http://www.edchange.org/multicultural/papers/genderbias.html

Charmaz, K. (2001). Grounded theory. In N. K. Denzin \& Y. S. Lincoln (Eds.), The American tradition in qualitative research (pp. 244-85). London: SAGE.

Charmaz, K. (2006). In Saldana, J. (2013). The coding manual for qualitative researchers $\left(2^{\text {nd }}\right.$ ed). Thousand Oaks, CA: Sage Publications, Inc.

Chen, G. (2014). 10 Major challenges facing public schools. Public School Review. Retrieved from http://www.publicschoolreview.com/articles

Chenail, R. J. (2010). How to read and review a book like a qualitative researcher. The Qualitative Report, 15(6), 1635-1642. Retrieved from http://www.nova.edu/ssss/QR/QR15-6/readreview.pdf

Chizhik, E., \& and Chizhik, A. (2009). Resistance theory. Education.com. Retrieved from http://www.education.com/reference/article/resistance-theory

Chudowsky, N., \& Chudowsky, V. (2010). State test score trends through 2007-08, Part 5: Are there differences in achievement between boys and girls? The Center on Education Policy. Retrieved from http://www.cepdc.org/displayDocument.cfm?DocumentID=322 
Clausing, J. (2014). Gates says fixing education toughest challenge. Huff impact. Retrieved from http://www.huffingtonpost.com/2014/07/01/bill-gates-educationchallenge

Coffey, A., \& Atkinson, P. (1996). Making sense of qualitative data: Complementary research strategies. Thousand Oaks, CA: Sage Publications.

Cohen, C.J.; Michener, J.C; Holmes, J.; Merseth, J.L.; Ralph, L. (2007). The attitudes and behavior of young Black Americans: Research summary University of Chicago Center for the Study of Race, Politics, and Culture. Retrieved from www.blackyouthproject.com

Cohen D, Crabtree B. 2006). Qualitative Research Guidelines Project. Retrieved http://www.qualres.org/HomeCres-3682.html

Comber \& Stinson. (2001); Kincheloe (2005) in Kuby, C. R (2013). Critical inquiry in early childhood education: A teacher's exploration. Voices of practitioner's No. 1. Retrieved from www.naeyc.org/files/naeyc/file/Voices

Comber, B., \& Simpson, A (Eds.) (2001). Negotiating critical literacies in the classroom; TESL- EJ- Teaching English as a second of foreign language. Mahwah, NJ: Lawrence Erlbaum Associates. Retrieved from http://tesl-ej.org/ej22/r10.html

Comber, B. (2003). Critical literacy: What does it look like in the early years? In N. Hall, J. Larson, \& J. Marsh (Eds.), Handbook of early childhood literacy (pp. 355368). London: Sage.

Common Core State Standards Initiative. Retrieved from http://www.corestandards.org/about-the-standards/

Corbin, \& Strauss. (2008) Saldana, J. (2013). The coding manual for qualitative researchers $\left(2^{\text {nd }}\right.$ ed.). Thousand Oaks, CA: Sage Publications, Inc.

Coy, P. (2012). The plight of young, Black men is worse than you think. Business Week. Retrieved from http://www.businessweek.com/articles

Crenshaw, Gotanda, Peller, \& Thomas. (2002). The first decade: Critical reflections, or 'a foot in the closing door'. In Crossroads, directions, and a new critical race theory. Philadelphia, PA: Temple University Press.

Cvencek, D, Meltzoff, A.N, and Greenwald, A.G. (2011). Math-Gender stereotypes in elementary school children. University of Washington Child Development, pages $1-14$.

Creswell, J. (2009). Research design: Qualitative, quantitative, and mixed methods approaches. Los Angeles, CA: Sage Publications. 
Creswell, J.W. (2013). Research Design: Qualitative, Quantitative, and Mixed Methods Approaches, 4th Edition. SAGE Publications, Inc.

Cvencek, D, Meltzoff, A.N, and Greenwald, A.G. (2011) Math-Gender Stereotypes in School Children. University of Washington Child Development, pages 1-14.

Dallavis, C. (2013). Culturally responsive caring and expectations for academic achievement in a Catholic school. Catholic Education, 17(2). Retrieved from Questia.com.

deHaan, A. K. E., Elbers, E., \& Leseman, P. M. (2014). Teacher and child managed academic activities in preschool and kindergarten and their influence on children's gains in emergent academic skills. Journal of Research in Childhood Education, 28(1). Retrieved from Questia.com

Dei, G. J. S., Karumanchery, L. L., \& Luik-Karumanchery (2004). Playing the race card: Exposing Whites power and privilege. New York, NY: Lang Publishing.

Delgado, R. (1995). Critical race theory: The cutting edge. Philadelphia, PA: Temple University Press.

Delgado, R., \& Stefancic, J. (2012). Critical race theory: An introduction. New York, NY: New York University Press.

Delpit, L. (1988). The silenced dialogue: Power and pedagogy in educating other people's children. Harvard Educational Review, 58(3). Retrieved from http://faculty.washington.edu/silenced dialogue.

Delpit, L. (1995). Other people's children: Cultural conflicts in the classroom. New York, NY: New Press.

Demir, S., Kilinc, M., \& Dogan, A. (2012). The effect of curriculum for developing efficient studying skills on academic achievements and studying skills of learners. International Electronic Journal of Elementary Education, 4(3). Retrieved from Questia.com

Denzin, N. K. (1998). Collecting and interpreting qualitative materials. Thousand Oaks, CA: Sage Publications.

Dixon, I. (2008). Reflections of society in children's literature. Retrieved from http://www.essayforum.com/writingresearch-paper-argument

Dixson, A. D., \& Rousseau, C. K. (Eds.). (2006). Critical race theory in education: All god's children got a song. New York, NY: Taylor \& Francis Group. 
Dockett, S., Whitton, D., \& Perry, B. (2010). What will my teacher be like? Australasian Journal of Early Childhood, 35(3). Retrieved from

http://www.earlychildhoodaustralia.org.au/australian_journal_of_early_childhood /ajec_index_abstracts.htm

Dove, S. (2009). The campaign for Black male achievement. The Journal of Negro Education, 78(3). Retrieved from Questia.com

Duncan, A. (2009). Call to Teaching: Secretary Arne Duncan's Remarks at The Rotunda at the University of Virginia. Retrieved www2.ed.gov/news/speeches/2009/10/10092009.html

Duncan, M., \& Watson, R. (2004). Transformation through occupation: towards a prototype. In R. Watson \& L. Swartz (Eds.), Transformation through occupation. London \& Philadelphia: Whurr Publishers

Earp, B. (2012). Early academic self-concepts and the racial achievement gap. Journal of Social and Psychological Sciences, 5(1). 1. Retrieved from Questia.com

Education Trust. (2007). African-American achievement in America. Retrieved from http://www.thefreelibrary.com

Elliott, D. (2014). Decades later, desegregation still on the docket in Little Rock. Code Switch. Frontiers of race, culture and ethnicity. Retrieved http://www.npr.org

Emirbayer, M, \& Mische, A. (1998). What is agency? The American Journal of Sociology, 103(4), 962-1023. Retrieved from http://www.jstor.org/stable/2782934 Accessed: 28/05/2010.

Epstein, K. K. (2006). A different view of urban schools: Civil rights, critical race theory, and unexplored realities. New York, NY: Peter Lang.

Farrington, C.A., Roderick, M., Allensworth, E., Nagaoka, J., Keyes, T.S., Johnson, D.W., \& Beechum, N.O. (2012). Teaching adolescents to become learners. The role of noncognitive factors in shaping school performance: A critical literature review. Chicago: University of Chicago Consortium on Chicago School Research. Retrieved Questia.com

Ferguson, R. F. (2001). Analysis of Black-Whites gap disparities in Shaker Heights, OH. New York, NY: Brookings Institute, Papers on Educational Policy.

Field, T., Diego, M. \& Sanders, C. (2002). Adolescents' parent and peer relationships. Adolescence, 37, 121-130. Retrieved from www.Questia.com 
Fincham, F. (2009). Learned helplessness. Education.com. Retrieved from http://www.education.com/reference/article/learned-helplessness

Firchow, N. (2004). Child development 13 - 16 years old. Schwab Foundation Retrieved Insighpsychological.com/library/child development

Fisher, E. J. (2005). Black student achievement and the oppositional culture model. The Journal of Negro Education, 74(3). Retrieved from Questia.com

Flynn, L., Liang, Y., Dickson, G. L., Xie, M. and Suh, D.-C. (2012), Nurses' Practice Environments, Error Interception Practices, and Inpatient Medication Errors. Journal of Nursing Scholarship, 44: 180-186. doi: 10.1111/j.15475069.2012.01443.x Retrieved from http://onlinelibrary.wiley.com

Fordham, S., \& Ogbu, J. (1986). Black students' school success: Coping with the "burden of 'acting Whites'. The Urban Review, 18(3), 176-206. Retrieved from http://www.nyesma.org/documents/BlackStudents Acting White. PDF

Fordham, S. (1996). Blacked out: Dilemmas of race, identity, and success at capital high. Chicago, IL: University of Chicago Press. Retrieved from Questia.com.

Freire, A.M.A. (2000). Foreword. In P. McLaren, Che Guevara, Paulo Freire, and the pedagogy of revolution. Boulder, CO: Rowman and Littlefield.

Freire, P. (1970). Pedagogy of the oppressed. New York: Seabury Press

Freire, P \& Faundez, A. (1989). Learning to question: A pedagogy of liberation. Published by Continuum Intl Pub Group (Sd)

Freire, P. (2004). Pedagogy of hope. New York, NYZ: Continuum International Publishing Group.

Fremon, C., \& Hamilton, S. R. (1997). Are schools failing Black boys? Parent's Magazine. Retrieved from http://people.terry.uga.edu/dawndba/4500FailingBlkBoys.html

Fryer, R. G., and Levitt, S. D. (2004). Understanding the Black-White test score gap in the first two years of school." The Review of Economics and Statistics 86, no. 2 : 447-64.

Fuller, L. (2011). Breaking barriers to Black student achievement. NEA Today. National Education Assoc. Retrieved from http://neatoday.org/2011/06/02/breakingbarriers-to-Black-student-achievement 
Gall, M. D., Gall, J. P., \& Borg, W. R. (2003). Educational Research: An Introduction (7th ed.). Boston: Allyn \& Bacon

Gao, G. (2009). Too focused on the achievement gap. Retrieved from http://lawandeducation.wordpress.com/tag/the-achievement-gap/

Gates, H. L. Jr., \& West, C. (1997). The future of race. New York: Random House.

Gay, G. (2000). Culturally responsive teaching. New York, NY: Teachers College Press.

Getz, L. M., \& Roy, M. M. (2013). Student leadership perceptions in South Africa and the United States. International Journal of Psychological Studies. Retrieved from Questia.com

Gildersleeve, R. E., Kuntz, A. M., Pasque, P. A., \& Carducci, R. (2010). The role of critical inquiry in $(\mathrm{Re})$ constructing the public agenda for higher education: Confronting the conservative modernization of the academy. The Review of Higher Education, 34(1), 85-121.

Giroux, H. (2011). On critical pedagogy. Continuum international publishing group. New York, NY.

Field, T., Diego, M. \& Sanders, C. (2002). Adolescents' parent and peer relationships. Adolescence, 37, 121-130. Retrieved from www.Questia.com

Goetz, J. P., \& LeCompte, M. D. (1984). Ethnography and qualitative design in educational research. San Diego, CA: Harcourt Brace Jovanovich.

Gomez, N. (2003). Perceptions of stereotypes in Hispanic children's literature. A dissertation submitted to the graduate faculty of Louisiana State University and Agricultural and Mechanical College. Retrieved from etd.lsu.edu/.../unrestricted/Gomez_dis.pdf

Goodman, J. (2012). Gold standards? State standards reform and student achievement. John F. Kennedy School of Government, Harvard University. Retrieved from www.hks.harvard.edu/pepg/PDF/Papers/PEPG12-05_Goodman.

Gordon, D.M, Iwamoto D, Ward N, Potts R, Boyd E. (2009). Mentoring urban Black middle-school male students: Implications for academic achievement, Journal of Negro Education. Retrieved www.Questia.com

Gordon, R., \& Gordon, M. (2006). The turned-off child. Learned helplessness and school failure. Salt Lake City, UT: Millennial Mind Publishing. 
Goss, E. (2009). "If I were president: Teaching social justice in the primary classroom." Voices of Practitioners, 4(2), 1-14. Online: http://www.naeyc.org/files/naeyc/file/vop/Voices.

Gratz, D.B. (2001) Student achievement: What is the problem? Education Week. Retrieved from: http://www.edweek.org/ew/articles/2001/09/05/01 gratz.h21.html

Grinberg, J. (2003). Only the facts? In D. Weil \& J. L. Kincheloe (Eds.), Critical thinking and learning: An encyclopedia for parents and teachers. Westport, CT: Greenwood.

Gross, A. J. (2008). What blood won't tell: A history of race on trial in America. Cambridge, MA: Harvard University Press.

Gurian, M. (2005). The minds of boys. Saving our son from falling behind in school and life. San Francisco, CA: Jossey-Bass.

Hamilton, M. (2006). Listening to student voice. Curriculum matters.

Handrickson, K. A. (2012). Student resistance to schooling: disconnections with education in rural Appalachia. High School Journal, 95(4). Retrieved from Questia.com.

Harper, S. R. (2012). Black male student success in higher education: A report from the national Black male college achievement study. Philadelphia, PA: University of Pennsylvania, Center for the study of race and equity in education.

Harper, S. R., \& Davis, C. H. F., III. (2012). They don't care about education: A counter narrative on Black male students' responses to inequitable schooling. Educational Foundations, 26(1-2). Retrieved from Questia.com

Hassinger, M., Plourde, L. A. (2005). Beating the Odds: How Bi-Lingual Hispanic YouthWork through Adversity to Become High Achieving Students. Education, 126(2), 316-327.

Harris, C. (1993). Whiteness as property. Harvard Law Review, 106(8), 1707. UCLA School of law research paper No. 06- 35.

Harris, M. (2012). Department of education data show urgent need to address racial disparities in school discipline. Retrieved from http://www.dignityinschools.org

Harris, S. (2008). Are boys losing out? Dr Leonard Sax (right) believes boys flourish more in single sex schools and wants more state schools to provide such classes. London Daily Mail. Retrieved from Questia.com 
Hawkins, M. (2008). Minority status, oppositional culture and schooling. Negro Educational Review, 59(1/2). Retrieved from Questia.com

Hernandez, D. J. (2011). How third-grade reading skills and poverty influence high school graduation. Annie E. Casey Foundation.

Horvat, E. M., \& Lewis, K. S. (2003). Reassessing the "burden of acting white": The importance of peer groups in managing academic success. Sociology of Education, 76(4), 265-280.

Hilliard, A. (2003). No mystery: Closing the achievement gap between Africans and excellence. In T. Perry, A. Hilliard, \& C. Steele (Eds.), Young, gifted, and black: Promoting high achievement among African-American students (pp. 131-166). Boston: Beacon.

Hilliard, P. L. (2011). Educating African-American students: Foundations, curriculum, and experiences. The Journal of Negro Education, 80(3). Retrieved from Questia.com.

Hinchey, P. H. (2010). Finding freedom in the classroom. Practical introduction to critical theory. New York, NY: Peter Lang Publishing Co.

Hiraldo, P. (2010). The role of critical race theory in higher education. The Vermont Connection, 31. Retrieved from http://www.uvm.edu/ vtconn/v31/Hiraldo.pdf

Holzman, M., (2006) Public education and Black male Students: The 2006 state report card. Schott Educational Inequity Index. Cambridge, MA: The Schott foundation for Public Education. Retrieved from www.schottfoundation.org

Hooks, B. (1994). Teaching to transgress. Education as the practice of freedom. New York, NY: Routlege Publishing Company.

Hooks, B. (2003). Teaching community: A pedagogy of hope. New York: Routledge Publishing Company.

Hooks, B. (2004). We real cool: Black men and masculinity. New York, NY: Routledge Publishing Co. Retrieved from Questia.com

Horn, R. (2000). Teacher talk: A post-formal inquiry into educational change. New York, NY: Peter Lang.

How race, gender and class may affect learning. UK Essays, Retrieved http://www.ukessays.com/essays/php

Hunsader, P. D. (2002). Why boys fail and what we can do about It. Retrieved from Principal-dealing with diversity, 82(2), 52-55. 
Hunter, M. (2007). The persistent problem of Colorism: Skin tone, status, and equality. Social Compass. Retrieved http://www.mills.edu

Huntspon, A., \& Howell, G. (2012). Black male teachers becoming extinct. Retrieved CNN.

Husband, T. (2012). Why can't Jamal read? There's no simple answer why Black males struggle with reading, but part of the problem stems from correctable factors that tend to lead to an early disconnect. Phi Delta Kappan. Retrieved from www.questia.com

Jackson, B. D. (2003). Educational reform as if student agency mattered: Academic microcultures and student identity. Phi Delta Kappan. Retrieved from Questia.com

Jackson, P. (2012). America has lost a generation of Black Boys. Retrieved from http://www.Blackstarproject.org

Jacobson, L. (2014). Why boys don't read. Great schools. Retrieved from http://www.greatschools.org/students/academic-skills/6832

James, M. (2010). Never quit: The complexities of promoting social and academic excellence at a single-gender school for urban American males. Journal of African American Males in Education .Vol. 1 Issue 3

Jennings \& Smith, (2002). In Clinical reasoning and critical inquiry. Boise State University School of Nursing. Retrieved from http://hs.boisestate.edu/nursing/mission-vision/clinical-reasoning/

Jensen, B. (2010). Investing in our Teachers, investing in our economy. Melbourne: Grattan Institute in David Zyngier (2014)

Johnson, C., \& Gooliaff, S. (2013). Teaching to strength: Engaging young boys in learning. Reclaiming Children and Youth, 21(4). Retrieved from Questia.com.

Johnson, K. (2000). The peer effect on academic achievement among public elementary school students. Center for Data Analysis Report \#00-06 on Education. Retrieved http://www.heritage.org/research/reports/2000/05/peer-effect-on-achievementamong-elementary-school-students

Jones, B. D. (2002) Critical race theory: New strategies for civil rights in the new millennium. Harvard Black Letter Law Journal, 18. Retrieved from http://www3.law.harvard.edu/journals/hjrej-articles/archive/vol18/jones.pdf 
Jones, C. P. (2002). Confronting institutionalized racism. Phylon 50. Retrieved October 2013 from http://www.unnaturalcauses.org/assets/uploads/file/Jones-ConfrontingInstitutionalized-Racism.pdf

Jones, E. F., Gall, S., N-L (2009). Black children's judgment of in-group and out-group students' academic achievement, motivation, and behavior. Negro Educational Review, 60(1-4). Retrieved from Questia.com.

Kanes, D. (2013). Classroom practice- Do you need to get down with the kids?: Pedagogy. Times Educational Supplement. Retrieved from Questia.com

Keck-Staley, T. L. (2010). The role of human resource capital of Black and Latino middle schoolers' mathematics identities. Negro Educational Review, 61(1-4). Retrieved Questia.com

Keilman, J. (2013). Why won't Johnny read? Declining reading habits in men may stem from disconnect as boys. Retrieved from http://articles.chicagotribune.com/201310-16/news/

Kentley, C. (2012). Intentions and beliefs: Why they matter and a conceptual framework for understanding them in culturally responsive teachers. Curriculum and Teaching Dialogue, 14(1-2). Retrieved from Questia.co

Killion, J., \& Hirsch, S. (2011). The elements of effective teaching. Journal of Staff Development. Retrieved from Questia.com

Kincheloe, J. L., and McLaren, P. L. (1994). Rethinking critical theory and qualitative research. In N. K. Denzin \& Y. S. Lincoln (Eds.), Handbook of qualitative research (pp. 138-157). Thousand Oaks, CA: Sage

Kincheloe, J. L. (2001). Getting beyond the facts: Teaching social studies/social sciences in the twenty-first century ( $2^{\text {nd }}$ ed.). New York: Peter Lang.

Kincheloe, J.L. and McLaren, P.L. (2007).Critical pedagogy: Where are we now 2007, Published by Peter Lang and Associates.

Kincheloe, J.L. and McLaren, P.L (2011). Bold visions in educational research. Rethinking critical theory and qualitative research. Volume 32,pp 285-326. Retrieved www.Questia.com

Kincheloe (2005) in Kuby (2013). Critical inquiry in early childhood education: A teacher's exploration. Voices of practitioner's No. 1. Retrieved from www.naeyc.org/files 
Kincheloe, J. L., Steinberg, S. R., Rodriguez, N. M., \& Chennault, R. E. (Eds.). (1998). White reign: Deploying whiteness in America. New York: St. Martin's.

Kondrat (1999). Self-awareness, critical awareness and reflexivity (2008).

Kozol, J. (1991). Savage inequalities. New York, NY: Three Rivers Press.

Kozol, J. (2006). The shame of the nation. The restoration of apartheid schooling in America. New York, NY: Three Rivers Press.

Knickerbocker, B. (2011). Child poverty rate hits 20 percent in US as families struggle. The Christian Science Monitor. Retrieved from Questia.com.

Kuby, C. (2013). Critical inquiry in early childhood education. A teacher's exploration. National Association for the Education of Young People. Retrieved from naeyc.org.

Kunjufu, J. (1985). Countering the conspiracy to destroy Black boys. African-American Images. Chicago, IL.

Kvale, S. (1983). The qualitative research interview: A phenomenological and a hermeneutical mode of understanding. Journal of Phenomenological Psychology, 14, 171-196.

Kvale, S. (1996). Interviews: An introduction to qualitative research interviewing. Thousand Oaks, CA: Sage Publications.

Lacy, M. G., \& Ono, K. A. (2011). Critical rhetoric of race. New York, NY: New York University Press

Ladson-Billings, G. (1994). The dream keepers. Successful teachers of African-American children. San Francisco, CA: Jossey-Bass.

Ladson-Billings, G. (1999). The role of critical race theory in higher education.

Ladson-Billings, G. (2006). "Yes, but how do we do it?" Practicing culturally relevant pedagogy. In J. Landsman \& C. Lewis (Eds.), White teachers/diverse classrooms: A guide to building inclusive schools, promoting high expectations, and eliminating racism (pp. 29-42). Sterling, VA: Stylus

Ladson-Billings, G. (2007). From the achievement gap to the education debt: Understanding achievement in U.S. schools. Speech delivered at the urban sites network conference. Washington, DC.

Lai, A. (2013). Culturally responsive: Art education in a global era. Art Education, 64(5). Retrieved from Questia.com 
Lather, P. (2004). Critical inquiry in qualitative research: Feminist and poststructuralist perspectives: Science "after truth." Retrieved from http://www.contaduria.uady.mx/seccip/articulos/libros_online/educacion

Leary, J. D. (2005). Post traumatic slave syndrome. America's legacy of enduring injury and healing. Milwaukee, OR: Uptown Press.

Lee, J. O. (2011). Reach teachers now to ensure common core success: Top down implementation of common standards ignores the realities of instruction and the conservative culture of schools. Phi Delta Kappan, 92(6). Retrieved from Questia.com

Lewis, S, Simon, C., Uzzell, R., Horwitz, A., \& Casserly, M. (2010). A call for change: The social and educational factors contributing to the outcomes.

Lingis, A. (2012). One's own voice. Mosaic (Winnipeg), 45(4). Retrieved from Questia.com.

Lindgren, R., \& McDaniel, R. (2012). Transforming online learning through narrative and student agency. Educational Technology \& Society. Retrieved Questia.com

Loewen, J. W. (2007). Lies my teacher told me: Everything your American history textbook got wrong. New York, NY: Simon \& Schuster.

Long, J. F., Monoi, S., Harper, B., Knoblauch, D., \& Murphy, K. P.( 2007). Academic motivation and achievement among urban adolescents. Urban Education, 42(3). Retrieved from http://uex.sagepub.com

Lopez, S. (2010). The highs and lows of student engagement. Phi Delta Kappan, 93(2). Retrieved September 2014 from Questia.com.

Lyons, J. (2001). Paulo Freire's educational theory. New Foundations. Retrieved from www.newfoundations.com/GALLERY/Freire.html

Lyons, N. (2013). Pupils with difficulties 'disengage'. Daily Mail (London). Retrieved from Questia.com

Lynch, M. (2014). Black boys in crisis: Why aren't they reading? Education Week. Retrieved from http:www.edweek.org/edweek/education

Maitre, M. (2014). Achievement gap persists, even among high-performing students, report says. Retrieved from http://edsource.org/2014/achievement-gap-persistseven-among-high-performing-students-report-says/63498 
Manfra, M. M. (2009) Critical inquiry in the social studies classroom: Portraits of critical teacher research. Theory and Research in Social Education, 37(2), 156-191

Margolis, H. and McCabe, P.P. (2006) Improving Self-Efficacy and Motivation: What to Do, What to Say. Intervention in School and Clinic, v41 n4 p218-227. Retrieved from http://eric.ed.gov/?id=EJ757868

Marshall, C.S. \& Reihartz, J. (1997) Gender issues in the classroom in Chapman 2014 Gender Bias in Education. Retrieved from http://www.edchange.org/multicultural/papers/genderbias.html

Masuda, M. (1995). Critical race theory in education: All god's children got a song. In A. D. Dixson \& C. K. Rousseau (Eds.). (2006). New York, NY: Taylor \& Francis Group.

McCracken, D. Grants (1988). The Long Interview (Qualitative Research Methods, Vol. 13). Sage Publications. Thousand Oaks, CA

McDougal, S. III. (2013). Framing the Black experience: A discourse analysis of President Barack Obama's Speeches. Journal of Pan African Studies, 6(4). Retrieved from Questia.com

McEwen, M. K. (2003). Nature and use of theory. In S. R. Komives \& Associates (Eds.), Student services: A handbook for the profession ( $4^{\text {th }}$ ed.) San Francisco, CA: Jossey-Bass.

McGee, K. (2008). How cultural differences may affect student performance. Great Schools. Retrieved fromgreatschools.org.

McGlynn, A. P. (2012). Key Findings of Latest Report on Student Engagement a Mixed Bag. The Hispanic Outlook in Higher Education. Retrieved www.Questia.com

McKay, C. L. (2010). Community education and critical race praxis: The power of voice. Educational Foundations, 244(1-2). Retrieved from Questia.com.

McLaren, P. (1995). Critical pedagogy and predatory culture: Oppositional politics in a postmodern era. New York, NY: Taylor \& Francis e-Library ed. Web. 28 Dec. 2012- Retrieved from questia.com

McLauren, P., \& Kincheloe, J. (Eds.). (2007). Critical pedagogy. Where are we now? New York, NY: Peter Lang Publishing Inc.

Meadows, K. (2011). The desegregation of public schools: Ruby Bridges, Millicent E. Brown, and Josephine Boyd Kentley-Black educators by any means necessary. Vitae Scholasticae, 28(2). Retrieved from Questia.com 
Miles, M. B., Huberman, A. M., \& Saldana, J. (2014). Qualitative data analysis. A methods sourcebook. Thousand Oaks, CA: Sage Publications

Milner, H. R., IV. (2008) Critical race theory and interest convergence as analytic tools in teacher education policies and practices. Journal of Teacher Education, 59(4). Retrieved from Questia.com

Mitra, D. L. (2003). Student voice in school reform: Reframing student-teacher relationships. McGill Journal of Education. ProQuest Education Journals

Monk, T. Y. (1998). Variables associated with academic achievement of AfricanAmerican males in four year undergraduate educational institutions: A synthesis of studies. Virginia Polytechnic and State University.

Montague, M., Enders, C., Cavendish, W., \& Castro, M. (2011). Academic and behavioral trajectories for at risk-adolescents in urban schools. Behavioral Disorders, 36(2). Retrieved from Questia.com.

Moore, F. M. (2008). Agency, identity, and social justice education: Preservice teachers' thoughts on becoming agents of change in urban elementary science classrooms. Retrieved from http://adsabs.harvard.edu/abs

Morrell, E. (2009). Critical research and the future of literacy education. Journal of adolescent and adult literacy. International Reading Association pgs. 96-104. Retrieved from www.academia.edu

Morrison, T. (1992). Playing in the dark: Whiteness and the literary imagination. Cambridge, MA: Harvard University Press.

Mortenson, T. (2011). Economic change effects on men and Implications for the education of boys. Meeting on boys' initiatives, Washington, DC. Education Week. Retrieved from http:// edweek.org

Mosteller, F. (1995). The Tennessee study of class size in the early school grades. The future of children; Critical issues for children and youths. No. 2 retrieved from http://www.princeton.edu/futureofchildren/publications/docs

Moyer, J. E. (2010). Teens today don't read books anymore": A study of differences in interest and comprehension based on reading modalities: Part 1, introduction and methodology. The Journal of Research on Libraries and Young Adults. Retrieved from http://www.yalsa.ala.org/jrlya

Murrell, P. C., Jr. (2007). Race, culture, and schooling. Identities of achievement in multicultural urban schools. New York, NY: Routledge Publishing Company. 
Myers, M. D. (2008). Qualitative research in business \& management. Retrieved from SAGE Publications.

Naiditch, F. (2013). Cross the street to a new world: Learning about and respecting each student's family, history, and literacy skills will improve educator's opportunity to reach those students. Phi Delta Kappan, 94(6). Retrieved from Questia.com

Nakkula, M. (2013). A crooked path to success: Becoming a successful student, particularly for those who have fallen behind, requires motivation, engagement with school, and authentic ownership of one's own education. Phi Delta Kappan, 94(6). Retrieved from Questia.com

National Assessment of Education Progress. (2011). Retrieved from http://nces.ed.gov.

National Assessment of Education Progress (2009) Achievement Gaps: How Black and White Students in Public Schools Perform in Mathematics and Reading on the National Assessment of Educational Progress. Retrieved from http://nces.ed.gov

National Center for Education Statistics. (2013). The nation's report card: Trends in academic progress 2012 (NCES 2013-456). National Center for Education Statistics, Institute of Education Sciences. Washington, DC: U.S. Department of Education.

National Center for Education Statistics_-Statistics Brief. (1993). Parent and student perceptions of learning environment at school. Retrieved from http://nces.ed.gov/pubs93/93281.pdf

National Center for Fair and Open Testing (NCFOT) (2007). Retrieved from http://fairtest.org/2007-average-act-scores

National Education Association (NEA). Identifying factors that contribute to achievement gaps. Retrieved from http://www.nea.org/home/17413.htm

Neumann, S. (2012). Violence in schools: How big a problem is it? NPR. Retrieved from http://www.npr.org/2012/03/16/148758783/violence-in-schools-how-big-aproblem-is-it

Nieto, S., \& Bode, P. (2007). Affirming diversity. The sociopolitical context of multicultural education ( $5^{\text {th }}$ ed.). Boston, MA: Allyn \& Bacon, Publishers

Noguera, P. (2003). The trouble with Black boys: The role and influence of environmental and cultural factors on the academic performance of AfricanAmerican males. Urban Education, 38, 431 Retrieved from http://uex.sagepub.com 
Noguera, P. (2003). City schools and the American dream: Reclaiming the promise of public education. New York, NY: Teachers College Press.

Noguera, P. (2012). The achievement gap and the schools we need. Creating the conditions where race and class no longer predict student achievement. Motion Magazine. Retrieved from http://www.inmotionmagazine.com/er12/pn_achvgap.html

Noguera, P. (2012). Saving Black and Latino boys: What schools can do to make a difference. Phi Delta Kappan, 93(5). Retrieved from Questia.com

Ntiri, D. W. (2009). Framing the literacy issue: Correcting educational misrepresentations in U.S. society. The Western Journal of Black Studies, 33(4). Retrieved from Questia.com.

Obama, B. (2014). Remarks by the president on 'My brother's keeper initiative. Retrieved from http://www. Whiteshouse.gov/my-brothers-keeper

Office of Head Start. U.S. Department of Health and Human Services. Retrieved from http://www.acf.hhs.gov/programs/ohs

Oforlea \& Mullen, P. B. (2012). Introduction: Critical race theory and African-American folklore. The Western Journal of Black Studies, 36(4). Retrieved from Questia.com

Ogbu, J. U. (1978). Minority education and caste: The American system in cross-cultural perspective. Academic Press.

Ogbu, J. U. (1991). Cultural diversity and school experience. In C. E. Walsh (Ed.), Literacy as praxis: Culture, language, and pedagogy (pp. 25-50). Norwood, NJ:

Ogbu, J. (1992). Adaptation to minority status and impact on school success. Literacy and the African-American learner. Ohio State University College of Education.

Ogbu, J., \& Simmons, H. (1998). Voluntary and involuntary minorities: A culturalecological theory of school performance with some implications for education. Anthropology \& Education Quarterly, 29(2), 155-188. American Anthropological Association. Retrieved from http://faculty.washington.edu

Ogbu, J. (2003). Black American students in an affluent suburb. A study of academic disengagement. Mahwah, NJ: Lawrence Erlbaum associates, Inc.

Ogbu, J. (2008). Minority Status, Oppositional Culture and Schooling. New York, NY: Routledge.

Oldfield, E. F. (2013). Agency, voice, and sense of self re-writing “African' women's identity. Cross/cultures. No. 161. Retrieved from Questia.com. 
Oran, G. (2009). Culturally relevant pedagogy. Retrieved from http://www.education.com/reference/article/culturally-relevant-pedagogy

Packer, M. J. (2011). The Science of Qualitative Research. Cambridge University Press

Patterson, G. A. (2012). Separating the boys from the girls: Can separate ever be equal? Single sex schools draw fire from rights groups who say separate is never equal; proponents say closing the achievement gap requires innovation. Phi Delta Kappan, 93(5). Retrieved from Questia.com

Payne, R. (2005). A framework for understanding poverty ( $4^{\text {th }}$ ed.). .aha! Highlands, TX: Process, Inc.

Pazaki, S., Hooshang, Muller, R. (2012). Addressing student disengagement in a socially and culturally diverse society: Developing 'sociological Inquiry' as a new course. Making Connections, 13(12). Retrieved from Questia.com.

Perez, P. M., Costa, J-L.C., \& Corbi, R.G. (2012). An explanatory model of academic achievement based on aptitudes, goal orientations, self-concept and learning strategies. The Spanish Journal of Psychology, 15(1). Retrieved from Questia.com

Pirofski, K. I. (2012) Race, gender, and disability in today's children's literature. EdChange.org. Retrieved from http://www.edchange.org/multicultural/papers/literature2.html

Poggenpoel, M., \& Myburgh, S. (2003). The researcher as research instrument in educational research: A possible threat to trustworthiness? Retrieved from Education, 124(2), 418-21, 320.

Pople, C. (2012). Schooling poor minority children: New segregation in the post-Brown era. The Journal of Negro Education, 81(1). Retrieved from Questia.com

, A. (2007). How sputnik changed U.S. education. Fifty years later, panelists consider a new science education 'surge'. The Harvard Gazette. Retrieved from http://news.harvard.edu/gazette/story/2007/10/how-sputnik-changed-u-seducation

Quinn, S., \& Owen, S. (2014). Freedom to grow. Children's perspectives of student voice. Childhood Education, 90(3). Retrieved from Questia.com.

Raby, J. (2012). Number of state kids raised by other relatives up 27\%. The Charleston Gazette. Retrieved from Questia.com.

Race against time: Educating Black boys. (2011). National Education Association. Focus on Blacks. Retrieved from http://www.nea.org 
Rahm, J., LaChaine, A., \& Mathura, A. (2014). Youth voice and positive identitybuilding practices, the case of science girls. Canadian Journal of Education, 37(1). Retrieved from Questia.com.

Ralabate, P., \& Foley, B. (2003). IDEA AND NCLB: Intersection of access and outcomes. National education association. Retrieved from http://www.nea.org/home/18617.htm

Rankin, L. (2013). Colorblindness is the new racism. Policymic. Retrieved http://www.policymic.com/articles/55867/colorblindness-is-the-new-racism

Read This Not That: Why Boys Don't Read (2012). C2Education. Retrieved http://www.c2educate.com/read-this-not-that/read-this-not-that-why-boys-dontread

Reichert, M., \& Hawley. (2013) Relationships play primary role in boy's learning: Positive relationships should come first in efforts to improve boy's learning and engagement with school. Teachers can make the difference. Phi Delta Kappan.

Research consortium on educational outcomes and poverty (RECOUP), (2008). Reflexitivity handout. Retrieved from http://manual.recoup.educ.cam.ac.uk/wiki/index.php/Qualitativehandout

Reynard, R. Critical approaches-Education for change and transformation within the church. Trevecca Nazarene University. Retrieved from http://didache.nazarene.org/pdfs/6-1_Reynard.

Rocque, M., \& Patemoster, R. (2011). Understanding the antecedents of the 'school-tojail' link; the relationship between race and school discipline. Journal of Criminal Law and Criminology, 101(2). Retrieved from Questia.com

Rosler, B. (2010). Can I read some more?” Getting engaged in science class. Ohio Reading Teacher, 40(1). Retrieved from Questia.com.

Ross, T., \& Kena, G. (2012). Special needs children--higher education: Gaps in access and persistence study. Statistical analysis report. Retrieved from http://nces.ed.gov

Rossman, G. B., \& Rallis, S. F. (2003). Learning in the field: An introduction to qualitative research (2nd ed.). Sage Publications. Thousand Oaks, CA.

Rothstein, R. (2014). The urban poor shall inherit poverty: Sociologist Patrick Sharkey proves a mother's insecure upbringing harms her child as surely as a neighbor's broken window. The American Prospect, 25(1). Retrieved from Questia.com. 
Rubin, R. (2012). Independence, disengagement, and discipline. Reclaiming Children and Youth, 21(1). Retrieved from Questia.com.

Ruffins, P. (2013). Challenging stereotypes. Diverse issues in higher education. Vol. 29. No. 26. Retrieved from Questia.com

Ryan, A. M. (2006). The role of social foundations in preparing teachers for culturally relevant practice. Multicultural

Saldana, J. (2013). The coding manual for qualitative researchers. Sage Publications, Thousand Oaks, CA

Salend, S. J., \& Sylvestre, S. (2005). Understanding and addressing oppositional and defiant classroom behaviors. Teaching Exceptional Children, 37(6). Retrieved from Questia.com.

Sanders, K. (2013). PolitiFact Florida: Kathleen Ford says private prisons use third-grade data to plan for prison beds. Retrieved from www.tampabay.com/news/politics/stateroundup/politifact

Savrock, J. (2008). Student voice is an integral component of school reform Penn state college of education. Retrieved from http://www.ed.psu.edu/educ/news/newsitems-folder/mitra-student-voice

Sax, L. (2009). Boys adrift: The five factors driving the growing epidemic of unmotivated boys and underachieving young men. New York, NY: Basic Books.

Schlein, C. (2010). Effects of cross-cultural teaching. Curriculum and teaching dialogue, 12(1-2). Retrieved from Questia.com

Schott Foundation for Public Education. (2004). Black boys: A litmus test for public school education. Retrieved from http://www.schottfoundation.org/publications/Defining Future Dreams. PDF

Schanzenbach, D. W. (2014). Does Class Size Matter? National Education Policy Center Policy Brief. Retrieved July 2014 from www.questia.com

Schnee, E; Bose, E. (2010). Parents don't do nothing: Reconceptualizing parental null actions as agency. School Community Journal. Retrieved Questia.com

Schwartz, R. (2011). Middle School 'Graduation' Is No Time for Excessive Celebration. Huffington Post. Retrieved www.huffingtonpost.com 
Schweiger, B. B. (2012). Schooling citizens: The struggle for African-American education in antebellum America. American Studies, 52(1). Retrieved from Questia.com

Segedin, L. (2012). Listening to the student voice: understanding the school related factors that limit student success. McGill Journal of Education (online), 47(1). Retrieved from Questia.com.

Seidman, I. (2013). Interviewing as qualitative research ( $4^{\text {th }}$ ed.). New York, NY: Teacher's College, Columbia University.

Self-awareness, critical reflectivity, and identity. (2008). Critical multiculturalism for social workers. Retrieved from http://lyceumbooks.com/pdf/CriticalMulticulturalSW_Chapter_02.pdf

Seligman, M., Peterson, C., \& Maier, S. (1993). Learned helplessness. New York, NY: Oxford University Press.

Sewell, T. (1998). Black masculinities and schooling: How Black boys survive modern schooling, Stoke-on-Trent Shelton: Trentham Books.

Shaull, R. (1970). Introduction to pedagogy of the oppressed. New York, NY: Seabury Press.

Shor, I. (2006). War, lies, and pedagogy: Teaching in fearful times. Radical Teacher. Retrieved from Questia.com

Small, C. L. (2012) Student engagement and achievement of middle school Black males in single-gender and co-educational reading classes. Electronic Theses, Treatises and Dissertations. Retrieved from http://diginole.lib.fsu.edu/etd/5188

Smith, R. (2004). Exploring the usefulness of a conceptual framework as a research tool: A researcher's reflections. Issues in Educational Research, 14. Retrieved May 2014 from http://www.iier.org.au/iier14/smyth.html

Smyth, R. (2004). Exploring the usefulness of a conceptual framework as a research tool: A researcher's reflections. Issues in Educational Research, 14. University of New England. Retrieved from http://www.iier.org.au/iier14/smyth.html

Solórzano, D. G. (1997). Images and words that wound: Critical race theory, racial stereotyping, and teacher education. Retrieved from http://www.teqjournal.org 
Solorzano, D. G., \& Delgado Bernal, D. (2001). Examining transformational resistance through a critical race and LatCrit theory framework: Chicana and Chicano students in an urban context. Urban Education, 36(3), 308-342.

Solorzano, D., \& Yosso, T. (2002). A critical race counter story of affirmative action in higher education. Equity and Excellence in Education, 35, 155-168. Retrieved from https://www.academia.edu

Sparks, S. D. (2011). Report points to widening gap in boys' educational attainment. Education Week. Retrieved from:http://blogs.edweek.org/edweek/inside-schoolresearch/2011/05/report_boys_college_readiness.html

Sparrow, T., \& Sparrow, A. (2012). The voices of young Black males. Phi Delta Kappan. Retrieved from www.edweek.org

Spaulding, E. K., Cari, Klecka, C. L., Lin, E., Wang, J., \& Odell, S. J. (2011). Learning to teach: It's complicated but it's not magic. Journal of Teacher Education, 62(1). Retrieved from Questia.com

Spencer, M.B., Cross, W.E., Harpalani, V., \& Goss, T.N. (2003). Historical and developmental perspectives on Black academic achievement: Debunking the "acting White" myth and posing new directions for research. In C. C. Yeakey \& R. D. Henderson (Eds.), Surmounting all odds: Education, opportunity, and society in the new millennium. Greenwich, CT: Information Age Publishers. Retrieved http://www.urbanedjournal.org/archive/volume-2-issue-2-fall2003/contributions-controversies-and-criticisms-memory-john-u-ogbu-193

Stallings, P. M. (2011). A qualitative study on African-American males' perceptions of reading. ETD Collection for Wayne State University. Paper AAI3454827. http://digitalcommons.wayne.edu/dissertations

Steele, C. M., \& Aronson, J. (1995). Stereotype threat and the intellectual test performance of African-Americans. Journal of Personality and Social Psychology, $69,797-811$.

Steinberg, S. (Ed.). (2009). Diversity and multiculturalism. A reader. New York, NY: Peter Lang Publishing.

Steinberg, S., Kincheloe, J. (2009) Smoke and mirrors. More than one way to be diverse and multicultural. Diversity and multiculturalism. A reader. Peter Lang Publishing, Inc.

Stinson, D. (2004). African-American male students and achievement in school mathematics: A critical postmodern analysis of agency. Georgia State University. Retrieved from www.Academia.edu 
Strolin-Goltzman, J., Kollar, S., \& Trinkle, J. (2010). Listening to the voices of children in foster care: Youths speak out about child welfare workforce turnover and selection. Social Work, 55(1). Retrieved from Questia.com.

Suthers, (1997). Clinical reasoning and critical inquiry. Boise State University School of Nursing. Retrieved from http://hs.boisestate.edu/nursing/mission-vision/clinicalreasoning

Tatum, B. D. (1997). Why are all the Black kids sitting together in the cafeteria? New York, NY: Basic Books.

Taylor, E. (2009). The foundations of critical race theory in education: An introduction. In E. Taylor, D. Gillborn, \& D. Ladson-Billings (Eds.), Critical race theory in education. New York, NY: Routledge Publishing Company.

Teachers College Record, 106(4), 651-688. (2004). Retrieved from http://www.tcrecord.org/Home.asp ID Number: 11531.

The Achievement Gap. (2011). Education week. Retrieved www.educationweek.org

The ACT: Biased, Inaccurate, and Misused. (2007). National Center for Fair and Open Testing (NCFOT) retrieved from fairtest.com

The benefits of agency, choice, and student-centered learning. (2014). NetFamily Retrieved www.NetFamilynews.org

Thompson, L. R., \& Lewis, B. F. (2005). Shooting for the stars: A case study of the mathematics achievement and career attainment of an African-American male high school student. Retrieved from High School Journal, 88(4).

Thorne, S. (2000). Evidence based nursing. Data analysis in qualitative research. Retrieved from http://bmj-ebn.highwire.org/content

Tobia, E. F., \& Hord, S. (2012). I am a professional. Journal of Staff Development, 33(3). Retrieved from Questia.com.

Toch, T. (2003). High schools on a human scale: How small schools can transform American education, Beacon Press in Abdulkadiroğlu, A., H. Weiwei Hu, P.A. Parag (2013). Small high schools and student achievement: Lottery-based evidence from New York City. NBER Working Paper No. 19576. National Bureau of Economic Research- (NBER) Program

Toldson, I. A. (2013). Fixing the miseducation of Black children. Show me the numbers: Black students need parent-school partnerships. Here's how to build those 
bridges. The Journal of Negro Education's monthly series with the root. Retrieved from http://www.theroot.com/articles/culture/2013/07

Toldson, I. A., \& Owens, D. (2010). What Black kids think about being smart and other school related experiences. The Journal of Negro Education, 79(2). Retrieved from Questia.com

Toldson, I. A. (2010). The happy bell curve: how misguided research on race and achievement is duping Black progressives and liberal Americans into accepting Black inferiority. The Journal of Negro Education, 79(4). Retrieved from Questia.com.

Torgensen, J., Houston, D., Rissman, L., \& Kosanovich, M. (2007). Teaching all students to read in elementary school: A guide for principals. Florida Center for Reading Research. Retrieved September 2013 from: Questia.com

Tortoriello, N. (2009) Education Trust. Examining the causes of school funding inequity. Retrieved from http://www.edtrust.org/dc/press-room/news/examining-thecauses-of-school-funding-inequity

Trochim, W. M. (2006). The research methods knowledge base ( $2^{\text {nd }}$ ed.). Retrieved from http://www.socialresearchmethods.net/kb/

Tuitt, P. (2004). Race, law, resistance. London: Glasshouse Press.

Tyre, P. (2008). The trouble with boys. New York, NY: Three Rivers Press.

United Church Press. (2002). A reflection on academic achievement gaps in public schools. Retrieved from http://www.ucc.org/justice/action/w061202.htm

United States Department of Education (USDOE). (2009). The condition of education. National Center for Education Statistics. Retrieved from http://nces.ed.gov/pubs2009/2009081.pdf

United States Department of Education (USDOE). (2012). The condition of education. National Center for Education Statistics. Retrieved from http://nces.ed.gov/pubs2009/2009081.pdf

United States Department of Education (USDOE). (2013). The condition of education. National Center for Education Statistics. Retrieved from http://nces.ed.gov/pubs2009/2009081.pdf

Urgency of Now. The 50 state report on public education and Black males. (2012). The Schott Foundation for Public Education. Retrieved from http://www.schottfoundation.org/publications/schott-2010-Black-male-report.pdf 
Van Barneveld, C. (2008). Using data to improve student achievement. What works, research into practice. Lakehead University. Retrieved from http://www.edu.gov.on.ca/eng/literacynumeracy/inspire/research/Using_Data.pdf

Van Ausdale, D., \& Feagin, J. R. (2003). How children learn racism. Teachers College Record, 105(1). Lanham: Rowman \& Littlefield.

Van Manen. (1990), Quoted in Seidman (2013). Interviewing as qualitative research $\left(4^{\text {th }}\right.$ ed.). New York, NY: Teacher's College. Columbia University.

Vasquez, E., Forbush, D. E, Mason, L. L. Lockwood, A. R., \& Gleed, L. (2011). Delivery and evaluation of synchronous online reading tutoring to students at-risk of reading failure. Rural Special Education Quarterly, 30(3). Retrieved from Questia.com

Walters, G. (2010). The real challenge for higher education. Inside higher education. Retrieved from https://www.insidehighered.com/views/2010/07/15/walters

Walton Jr., S. (2010). Educational bias and the pipeline to prison. Systematic prejudice in academia and its effect on Black males. Philosophy Professor J. D. Carmine's essay, Liberal Racism in American Education. Retrieved from seanwaltonjr.com/wp-content/uploads

Wasserberg, M. J. (2009). Stereotype threat and the standardized testing experiences of African-American children at an urban elementary school. FIU Electronic Theses and Dissertations. Paper 116.Retrieved http://digitalcommons.fiu.edu/etd/116

West, C. (2001). Race matters. Boston: Beacon Press

What is critical pedagogy? $21^{\text {st }}$ century schools. Retrieved http://www.21stcenturyschools.com/What_is_Critical_Pedagogy.htm

White, H. (2009). Increasing the achievement of African-American males. Department of Research, Evaluation and Assessment. Retrieved from http://www. vbschools.com/accountability/research_briefs/aamalebrieffinalamarch.pdf

Whitmire, R., \& Bailey, S. M. (2010). Gender gap: Are boys being shortchanges in K-12 schooling? Education Next, 10(2). Retrieved from Questia.com.

Widdersheim, M. M. (2013). Critical communicative pedagogy: Framing critical pedagogy with the theory of communicative action. Making Connections, 14(2). Retrieved from www.questia.com 
Willingham, D. T. (2012) Why does family wealth affect learning. American Educator. Retrieved from http://www.aft.org/pdfs/americaneducator/spring2012/Willingham.pdf

Williams, E. J. (Eds.). (2012). Critical issues in literacy pedagogy. Notes from the trenches. San Diego, CA: Cognella Publishing Co.

Williams, P. J. (1991). The alchemy of race and rights. Cambridge, MA: Harvard University Press.

Williams, R. D. (2009). The easy way versus the hard way: Middle-class Black male students' perceptions of education as it relates to success and career aspirations. Dissertation, Georgia State University. Retrieved from http://scholarworks.gsu.edu/eps_diss/38

Wright, B. L. (2009). Racial ethnic identity, academic achievement, and AfricanAmerican males: A review of literature. Journal of Negro Education, 78(2). Retrieved from Questia.com

Wright, J., Macdonald, D., \& Burrows, L. (Eds.). (2004). Critical inquiry and problemsolving in physical education. London: Routledge https://www.academia.edu.

Yazdani, D. (2011). Why closing the achievement gap is more important than ever. The global consciousness. Retrieved from http://theglobalconsciousness.wordpress.com

Yes we can. The 50 state report on public education and Black males. (2010). The Schott foundation for public education. Retrieved from http://www.schottfoundation.org/ pdf

Zyngier, D. (2014). Class size and academic results, with a focus on children from culturally, linguistically and economically disenfranchised communities. Evidence Base, issue 1, 2014, journal.anzsog.edu.au>, ISSN 1838-9422 (C) The Australia and New Zealand School of Government. 


\section{APPENDIX A \\ SERIES 1 INTERVIEW QUESTIONS}

The first interview focused on the participant's life history. It asked the following questions:

1. Can you tell me about your feelings regarding your education?

2. Do you remember an occasion when you were most excited about school?

3. What have been your biggest successes in terms of your education? Why was it a success? What did you do to make it a success?

4. Who is your strongest motivator? Why?

5. What have been your biggest failures in terms of your education? Why was it a failure? What did you do to cause it to be a failure?

6. Have you ever felt that you were treated unfairly in your school? If yes, how so and by whom?

7. Do you take any responsibility for your learning? If so, what have you done? If not, what should have been done differently?

8. Would you describe in as much detail as possible a situation in which learning was difficult for you?

9. What do you want to do after high school? Why?

10. Do you consider yourself smart? Why or why not. 


\section{APPENDIX B \\ SERIES 2 INTERVIEW QUESTIONS}

The second interview focused on the participant's experience as an African-American male attending an urban school. It asked the following questions:

1. Do you feel that education is a priority among African-American males? Why or Why not?

2. Have you ever been ridiculed (made fun of) for doing well in school?

3. Have you had male teachers? Were they White or African-American?

4. Have you had lessons about African-Americans? If so, what do you remember about it?

5. Who do you respect? Why?

6. Have you ever failed a grade or subject? If so which one. If not, what do you think would have happened?

7. Who is your hero? Why?

8. What kinds of negative stereotypes are you aware of?

9. Do you ever wonder what your teachers think about you? If so, why?

10. Do you believe that being African-American has anything to do with your teacher or administrator's perception of you? 


\section{APPENDIX C \\ SERIES 3 INTERVIEW QUESTIONS}

The third interview focused on the meaning that the schooling experience holds for them. It included the following questions:

1. Given what you said about your school life, what is your plan? Why?

2. If given the opportunity, what would you change in your school life? Why?

3. What advice would you give a student (in your grade) Why?

4. What do you regret? Why?

5. Do you take any responsibility for your learning? If so, what have you done? If not, what should have been done differently?

6. Do you feel as though you are or have been given enough attention from your teachers? If yes, did it help you to understand the concept or activity? If not, why not?

7. Are equal learning opportunities provided for all students in schools? If so, how? If not, why not?

8. Are you keeping up with your classes? If yes, did you have help? From whom? If not, why not?

9. Are your friends keeping up in their classes? If so, what factors contribute to their success? If not, what gets in the way?

10. Are there students of other races in your school?

11. Is race a factor in your school?

12. Are schools fair? If so, why? If not why not?

13. What are the factors that cause students to fail?

14. Have you experienced prejudice?

15. What creates prejudice? Can prejudice be overcome? 


\section{APPENDIX D}

\section{IRB APPROVAL LETTER}

February 26, 2014

Eurvine Williams

5330 Teaching and Learning

Thank you for submitting the IRB protocol titled "Listen. I have something to say! A critical inquiry into the educational and sociocultural context of African-American male academic achievement in the urban setting" for review by the Illinois State University Institutional Review Board (IRB). The IRB has Protocol is Undergoing Initial Review this research protocol following an Expedited Review procedure. You may begin this research.

This protocol has been given the IRB number 2014-0051. This number should be used in all correspondence with the IRB. You may proceed with this study from $\mathbf{2 / 2 6 / 2 0 1 4}$ to 2/22/2015. You must submit a continuation request and receive approval prior to continuing your research beyond this expiration date.

Please also note that research protocols may be approved for continuation for a maximum of three years from the original date of approval in periods not to exceed one year. Research protocols having had three years of approval must be resubmitted and reviewed as a new proposal.

This approval is valid only for the research activities, timeline, and subjects described in the above named protocol. IRB policy requires that any changes to this protocol be reported to, and approved by, the IRB before being implemented. You are also required to inform the IRB immediately of any problems encountered that could adversely affect the health or welfare of the subjects in this study. Please contact Kathy Spence, Director of Research Ethics \& Compliance at 438-2520 or myself in the event of an emergency. All other correspondence and questions should be addressed to:

Institutional Review Board

Campus Box 3330

Hovey Hall, Room 307

Telephone: 438-2529

E-mail: rec@IllinoisState.edu 